INEEL/EXT-01-00015

January 2001

\title{
Hazardous Waste Code Determination for First/Second-Stage Sludge Waste Stream (IDCs 001, 002, 800)
}

R. E. Arbon 


\title{
Hazardous Waste Code Determination for First/Second-Stage Sludge Waste Stream (IDCs 001, 002, 800)
}

\author{
R. E. Arbon
}

Published January 2001

Idaho National Engineering and Environmental Laboratory Idaho Falls, Idaho 83415

\author{
Prepared for the \\ U.S. Department of Energy \\ Assistant Secretary for Environmental Management \\ Under DOE Idaho Operations Office \\ Contract DE-AC07-99ID13727
}




\begin{abstract}
This document, Hazardous Waste Code Determination for the First/Second-Stage Sludge Waste Stream, summarizes the efforts performed at the Idaho National Engineering and Environmental Laboratory (INEEL) to make a hazardous waste code determination on Item Description Codes (IDCs) 001, 002, and 800 drums. This characterization effort included a thorough review of acceptable knowledge (AK), physical characterization, waste form sampling, chemical analyses, and headspace gas data. This effort included an assessment of pre-Waste Analysis Plan (WAP) solidified sampling and analysis data (referred to as preliminary data). Seventy-five First/Second-Stage Sludge Drums, provided in Table 1-1, have been subjected to core sampling and analysis using the requirements defined in the Quality Assurance Program Plan (QAPP). Based on WAP defined statistical reduction, of preliminary data, a sample size of five was calculated. That is, five additional drums should be core sampled and analyzed. A total of seven drums were sampled, analyzed, and validated in compliance with the WAP criteria. The pre-WAP data (taken under the QAPP) correlated very well with the WAP compliant drum data. As a result, no additional sampling is required. Based upon the information summarized in this document, an accurate hazardous waste determination has been made for the First/Second-Stage Sludge Waste Stream.
\end{abstract}




\section{SUMMARY}

This document, Hazardous Waste Code Determination for the First/Second-Stage Sludge Waste Stream, summarizes the efforts performed at the INEEL to make a hazardous waste determination on IDCs 001,002 , and 800 drums. This characterization effort included a thorough review of AK, physical characterization, waste form sampling, chemical analyses, and headspace gas sampling data. Based upon the information and data summarized in this document an accurate hazardous waste determination has been made for the First/Second-Stage Sludge Waste Stream. 


\section{CONTENTS}

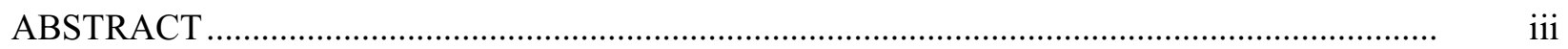

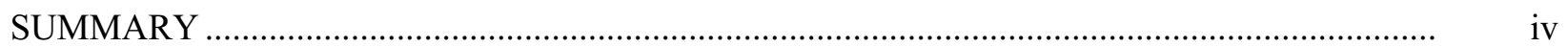

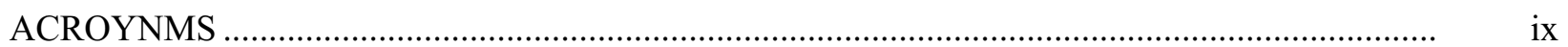

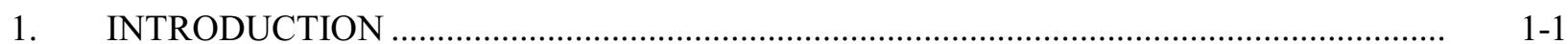

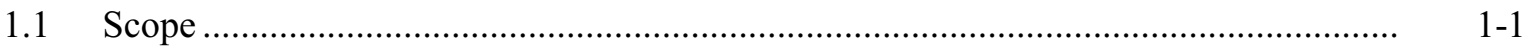

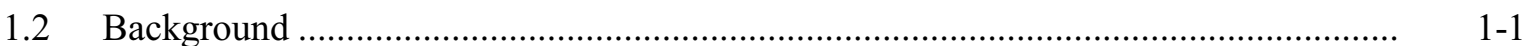

1.3 Existing Data (pre-WAP) Usage ….............................................................................

1.4 WAP Compliant Sampling and Analysis Data...............................................................

2. WASTE DESCRIPTION AND ACCEPTABLE KNOWLEDGE ..................................... $2-1$

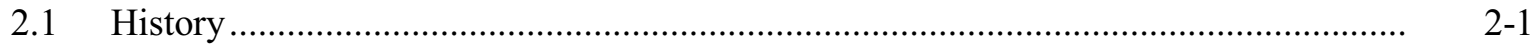

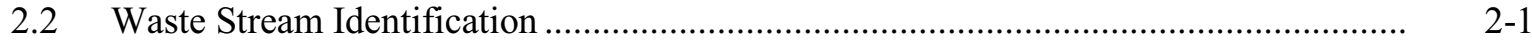

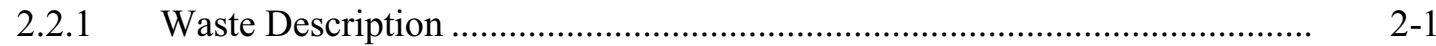

2.2.2 Waste Generation Process ........................................................................... 2-2

3. ACCEPTABLE KNOWLEDGE HAZARDOUS WASTE CODE DETERMINATION ........ 3-1

3.1 Characteristic Determination.............................................................................

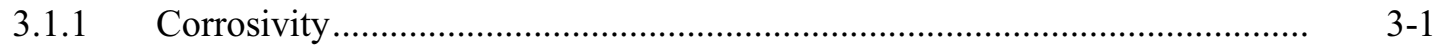

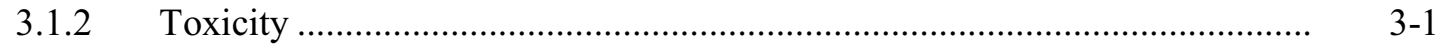

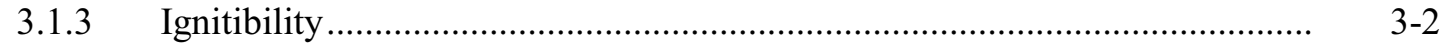

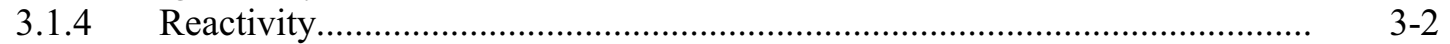

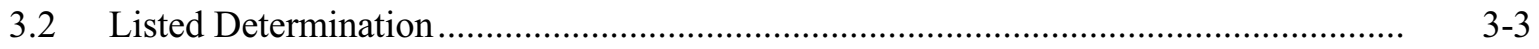

3.3 Additional WAP/Waste Acceptance Criteria (WAC) Characterization Data .............. 3-4

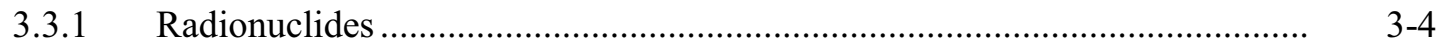

3.3.2 Radiography/Visual Examination (VE) ..................................................... $3-4$ 
4. CONFIRMATION OF HAZARDOUS WASTE CODE ASSIGNMENTS

BASED ON HEADSPACE GAS SAMPLING AND HOMOGENOUS

SOLIDS ANALYSIS

4.1 Headspace Gas Sampling and Analysis Results......................................................

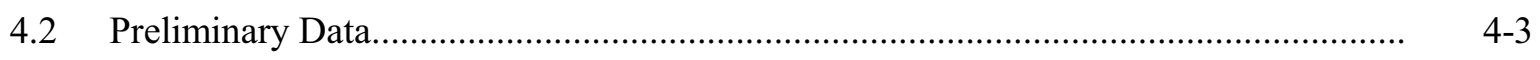

4.2.1 Preliminary Metals Data Assessment Summary ...........................................

4.2.2 Preliminary SVOC Assessment Summary ..................................................

4.2.3 Preliminary Purgeable VOC Assessment Summary .....................................

4.2.4 Preliminary NH VOC Data Assessment......................................................

4.2.5 Preliminary Data TIC Assessment .............................................................. 4 4-4

4.2.6 Preliminary Data Results and Sample Size Determination ........................... 4-5

4.2.7 Non-Toxic Characteristic Analytes .............................................................

4.3 WAP Compliant Drum Analysis/Confirmation of Hazardous Waste Codes Assigned 4-8

4.3.1 Metals Data Assessment............................................................................

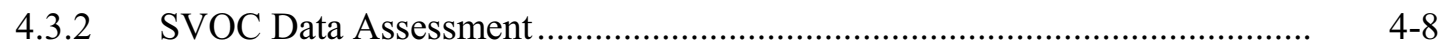

4.3.3 Purgeable VOC Assessment................................................................

4.3.4 NH VOC Assessment .........................................................................

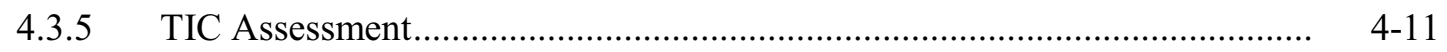

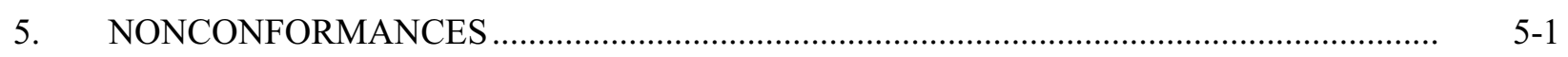

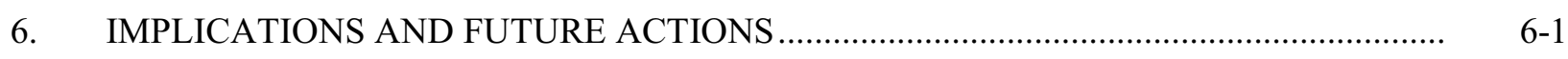

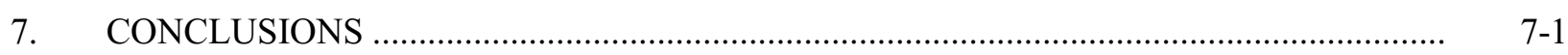

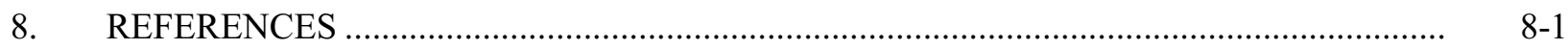

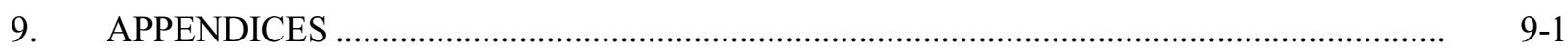

FIGURES

2-1. Aqueous Treatment Process....................................................................................... $2-3$

M-1. Average Percent Recovery and RPD MSs and MSDs Metals Analyses .............................. A-3

M-2. Average Percent Recovery LCSs Metals Analyses...................................................... A-3

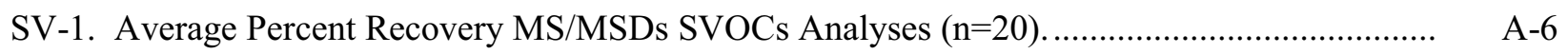

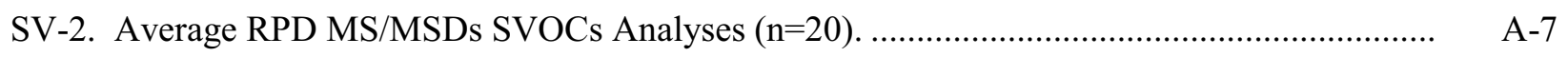

SV-3. Average Percent Recovery LCSs SVOCs Analyses.................................................... A-7

SV-4. Average Percent Recovery of SVOCs Analyses Surrogate Nitrobenzene-d5 (NBZ)............ A-9

SV-5. Average Percent Recovery of SVOCs Analyses Surrogate 2-Fluorobiphenyl (FBP)........... A-9 
SV-6. Average Percent Recovery of SVOCs Analyses Surrogate 2-Fluorophenol (2FP).

SV-7. Average Percent Recovery of SVOCs Analyses Surrogate 2,4,6-Tribromophenol (TBP)....

V-1. Average percent recovery MS/MSDs VOC analyses ( $\mathrm{n}=24$ batches)

V-2. Relative percent difference MS/MSDs VOCs analyses ( $\mathrm{n}=24$ batches).

V-3. Average percent recovery LCSs VOCs analyses ( $\mathrm{n}=24$ batches).

V-4. Average Percent Recovery of Surrogate Dibromofluoromethane (BFM) VOCs Analyses......

V-5. Average Percent Recovery of Surrogate Toluene-d8 (TOL) VOCs Analyses.

V-6. Average Percent Recovery of Surrogate 4-Bromofluorobenzene (BFB) VOCs Analyses

V-7. Average Percent Recovery of Surrogate 1,2-Dichloroethane (DCA) VOCs Analyses.

N-1. Average Percent Recovery and RPD MS/MSDs Duplicates NH Organic Compounds Analyses ( $\mathrm{n}=20$ batches).

N-2. Average Percent Recovery LCS NH Organic Compounds Analyses ( $\mathrm{n}=21$ batches).

\section{TABLES}

1-1. First/Second-Stage Drums Sampled Prior to the WAP.

1-2. WAP Compliant Drums.

3-1. Characteristic (Toxicity) Hazardous Waste Codes Assigned to First/Second-Stage Sludge Based on AK.

3-2. Listed Hazardous Waste Codes Assigned to First/Second-Stage Sludge Based on AK

4-1. Headspace Gas Summary Data.

4-2. First/Second-Stage Sludge TICs and Summary Statistics.

4-3. First/Second-Stage Sludge WAP Compliant Sample Size Determination.

4-4. First/Second-Stage Sludge Summary Statistics for Analytes Without Regulatory Thresholds.

4-5. WAP Compliant Data Analysis for First/Second-Stage Sludge.

4-6. First/Second-Stage Sludge Summary Statistics for Analytes Without Regulatory Thresholds.

4-7. Total SVOC Summary data - Tentatively Identified Compounds.

M-1. ACL Metals Quality Control Average Percent Recovery of Metals MSs and MSDs. 
M-2. ACL Metals Quality Control Average Percent Recovery of Laboratory Control Samples......

SV-1. ACL SVOCs Quality Control Average Percent Recovery of VOCs MS/MSDs.

SV-2. ACL SVOCs Quality Control Average Percent Recovery of SVOCs LCSs.

V-1. ACL VOCs Quality Control Average Percent Recovery of VOCs MS/MSDs.

V-2. ACL VOCs Quality Control Average Percent Recovery of VOCs LCSs.

N-1. ACL NH Organic Compounds Quality Control Average Percent Recovery of Metals MSs/MSDs.

N-2. ACL NH Organic Compounds Quality Control Average Percent Recovery of NH Organic Compounds LCSs.

B-1. ACL Metals QC MSs and LCSs Summary by Element.

C-1. ACL SVOCs Quality Control MS and LCSs Summary by Compound.

C-2. ACL SVOCs Quality Control Average Percent Recovery of Surrogate Compounds by Batch.

D-1. ACL VOC Quality Control MS and MSD Summary by Compound......

D-2. ACL VOC Quality Control LCSs Summary by Compound...

D-3. ACL VOC Quality Control Average Percent Recovery of Surrogate Compounds by Batch... D-11

E-1. ACL NH Organic Compounds Quality Control MS and LCS Summary by Compound.

E-1 


\section{ACRONYMS}

\begin{tabular}{|c|c|}
\hline $\mathrm{Ag}$ & Silver \\
\hline $\mathrm{AK}$ & acceptable knowledge \\
\hline ANL-W & Argonne National Laboratory - West \\
\hline As & Arsenic \\
\hline $\mathrm{Ba}$ & Barium \\
\hline $\mathrm{Be}$ & Beryllium \\
\hline CAR & Corrective Action Report \\
\hline $\mathrm{CBFO}$ & Carlsbad Field Office \\
\hline $\mathrm{CCV}$ & Continuing Calibration Verification \\
\hline $\mathrm{Cd}$ & Cadmium \\
\hline $\mathrm{Cr}$ & Chromium \\
\hline DOE & Department of Energy \\
\hline DOT & Department of Transportation \\
\hline EDF & Engineering Design File \\
\hline EPA & Environmental Protection Agency \\
\hline $\mathrm{Hg}$ & Mercury \\
\hline HT & holding time \\
\hline ID & identification \\
\hline IDC & Item Description Code \\
\hline INEEL & Idaho National Engineering and Environmental Laboratory \\
\hline LCS & laboratory control sample \\
\hline MDL & Method Detection Limit \\
\hline MPC & Matrix Parameter Category \\
\hline MS & matrix spike \\
\hline MSD & matrix spike duplicate \\
\hline NH & non-halogenated \\
\hline $\mathrm{Ni}$ & Nickel \\
\hline NOD & Notice of Deficiency \\
\hline $\mathrm{Pb}$ & Lead \\
\hline
\end{tabular}




\begin{tabular}{|c|c|}
\hline PLN & Plan \\
\hline PRQL & program-required quantitation limit \\
\hline $\mathrm{PVC}$ & polyvinyl chloride \\
\hline QAPP & Quality Assurance Program Plan \\
\hline QC & Quality Control \\
\hline RCRA & Resource Conservation and Recovery Act \\
\hline RFP & Rocky Flats Plat \\
\hline RPD & relative percent differences \\
\hline RTL & regulatory threshold limit \\
\hline RTR & real-time radiography \\
\hline RWMC & Radioactive Waste Management Complex \\
\hline $\mathrm{Se}$ & Selenium \\
\hline $\mathrm{Sb}$ & Antimony \\
\hline SVOC & Semi-Volatile Organic Compound \\
\hline $\mathrm{TC}$ & Toxicity Characteristic \\
\hline TCLP & Toxicity Characteristic Leaching Procedure \\
\hline $\mathrm{Te}$ & Thallium \\
\hline TIC & tentatively identified compound \\
\hline TRU & transuranic \\
\hline TWCP & Transuranic Waste Characterization Program \\
\hline $\mathrm{V}$ & Vanadium \\
\hline VE & Visual Examination \\
\hline VOC & Volatile Organic Compoud \\
\hline WAC & Waste Acceptance Criteria \\
\hline WAP & Waste Analysis Plan \\
\hline WIPP & Waste Isolation Pilot Plant \\
\hline $\mathrm{Zn}$ & Zinc \\
\hline
\end{tabular}




\section{Hazardous Waste Code Determination for First/Second-Stage Sludge Waste Stream (IDCs 001, 002, 800)}

\section{INTRODUCTION}

Transuranic (TRU) and mixed TRU waste destined for disposal at the Waste Isolation Pilot Plant (WIPP) must be characterized in accordance with the WIPP Part B Permit (EPA No. NM4890 139088). Characterization requirements are derived from 40 CFR Parts 260, through 265, 268, and 270 and are documented within the permit in the Waste Analysis Plan (WAP). The WAP, issued October 27, 1999, specifies a characterization strategy based on acceptable knowledge (AK). AK information is used to identify waste steams and make U.S. Environmental Protection Agency (EPA) hazardous waste code assignments. Per WAP requirements, hazardous waste codes are then confirmed through headspace gas and homogenous solids sampling and analysis.

The Idaho National Engineering and Environmental Laboratory (INEEL) TRU Waste Characterization Program (TWCP) has evaluated solidified sampling data relative to AK confirmation of hazardous waste code assignments for the First/Second-Stage Sludge Waste Stream. The results of this evaluation are documented in this report. This report contains seven sections: Section 1, provides an overview describing the study scope, background information, and WAP compliance; Section 2, waste stream specific AK information is summarized; Section 3, provides hazardous waste code assignments based on AK; Section 4, provides confirmation of AK based on sampling and analysis; Section 5, provides nonconforming conditions, associated corrective actions, and mitigative factors; Section 6, discusses implications and future actions for subsequent waste streams; and Section 7, provides the conclusions.

\subsection{Scope}

The hazardous waste code determination provided herein applies to the First/Second-Stage Sludge [Item Description Codes (IDCs) 001, 002, 800] Waste Stream. This waste stream consists of a population of 6,752 drums generated by liquid waste treatment operations in Building 774, at the Rocky Flats Plant (RFP), located outside Denver, Colorado. These wastes were generated from 1972 through 1988 and currently reside at the INEEL Radioactive Waste Management Complex (RWMC).

\subsection{Background}

Prior to the WAP issuance date, the INEEL performed TRU waste sampling and analysis for homogenous solids under the Carlsbad Field Office (CBFO) TRU Waste Characterization Quality Assurance Program Plan (QAPP) requirements. In this document a "data set" is referred to as "preliminary data". Seventy-five First/Second-Stage Sludge Drums, given in Table 1-1, have been subjected to core sampling and analysis using the requirements defined in the QAPP. The drum selection process is discussed in detail in Engineering Design File (EDF)-909, Transuranic Waste Sampling Plan for the INEEL, Revision 2. The INEEL methodology consisted of Phase I and II sampling campaigns. Phase I was exploratory sampling used to determine appropriate sampling sizes for Phase II. Phase II sampling was undertaken to validate Phase I results and to verify AK relative to toxicity characteristics. A brief summary of pre-WAP INEEL sampling is provided below. 
Phase I samples were subject to a temporal selection spanning the years that the waste stream was generated. The diversity of sample selection ensured that the sample would be representative of the waste stream, as no known or expected relationship existed between the sample selection process and the contaminant concentrations. However, Phase I samples were not randomly chosen. A statistical reduction of Phase I results determined the number of randomly selected drums to be cored. These drums were designated as Phase II.

The procedure to select the required Phase II drums involved creating a list of all the containers in the waste stream, assigning serial numbers to each container on the list, using a random number generator to select the desired number of samples from the list of serial numbers, and then selecting containers to sample based on the serial number selection. A total of nine Phase II drums were selected, sampled, and analyzed (see Table 1-1).

In addition, seventeen drums were randomly selected (Phase II) as a result of a Notice of Deficiency (NOD) by the State of Idaho. At the time the sample selection was performed, the INEEL was under a NOD by the State of Idaho for not adequately characterizing TRU waste in each IDC by year of generation. As a result, samples were chosen to address the NOD by sampling the deficient years of generation for the given IDCs. The impacted IDCs $(001,007$, and 800) are part of the sludge waste streams and are included in the scope of this study. Seventeen drums were selected as a result of this effort (see Table 1-1).

Table 1-1. First/Second-Stage Drums Sampled Prior to the WAP.

\begin{tabular}{|c|c|c|c|c|}
\hline & $\begin{array}{c}\text { Drum } \\
\text { Identification (ID) }\end{array}$ & IDC & Phase \#/Description & Year Cored \\
\hline 1 & RF074112313 & 001 & $1 /$ Exploratory Sampling & 1996 \\
\hline 2 & RF074112445 & 001 & $1 /$ Exploratory Sampling & 1996 \\
\hline 3 & RF074112540 & 001 & $1 /$ Exploratory Sampling & 1996 \\
\hline 4 & RF074112570 & 001 & $1 /$ Exploratory Sampling & 1996 \\
\hline 5 & RF074221401 & 002 & $1 /$ Exploratory Sampling & 1996 \\
\hline 6 & RF741205927 & 800 & $1 /$ Exploratory Sampling & 1996 \\
\hline 7 & RF002500410 & 001 & $1 /$ Exploratory Sampling & 1996 \\
\hline 8 & RF074112301 & 001 & $1 /$ Exploratory Sampling & 1996 \\
\hline 9 & RF074112370 & 001 & $1 /$ Exploratory Sampling & 1996 \\
\hline 10 & RF074112864 & 001 & $1 /$ Exploratory Sampling & 1996 \\
\hline 11 & RF074112870 & 001 & $1 /$ Exploratory Sampling & 1996 \\
\hline 12 & RF741202658 & 001 & $1 /$ Exploratory Sampling & 1996 \\
\hline 13 & RF074112549 & 001 & $1 /$ Exploratory Sampling & 1996 \\
\hline 14 & RF741200327 & 001 & $1 /$ Exploratory Sampling & 1996 \\
\hline 15 & RF741203069 & 001 & $1 /$ Exploratory Sampling & 1996 \\
\hline 16 & RF074221390 & 002 & $1 /$ Exploratory Sampling & 1996 \\
\hline 17 & RF074221647 & 002 & $1 /$ Exploratory Sampling & 1996 \\
\hline & & & & \\
\hline
\end{tabular}


Table 1-1. (continued).

\begin{tabular}{|c|c|c|c|c|}
\hline & $\begin{array}{c}\text { Drum } \\
\text { Identification (ID) }\end{array}$ & IDC & Phase \#/Description & Year Cored \\
\hline 18 & RF074112299 & 001 & 1 / Exploratory Sampling & 1996 \\
\hline 19 & RF074112362 & 001 & 1 / Exploratory Sampling & 1996 \\
\hline 20 & RF074221436 & 002 & 1 / Exploratory Sampling & 1996 \\
\hline 21 & RF741205657 & 001 & 1 / Exploratory Sampling & 1996 \\
\hline 22 & RF074226148 & 002 & 1 / Exploratory Sampling & 1996 \\
\hline 23 & RF741205809 & 001 & 1 / Exploratory Sampling & 1996 \\
\hline 24 & RF741202039 & 001 & 1 / Exploratory Sampling & 1996 \\
\hline 25 & RF741206329 & 001 & 1 / Exploratory Sampling & 1996 \\
\hline 26 & RF741205140 & 001 & $2 /$ Year Directed NOD Selected Drums & 1996 \\
\hline 27 & RF741204312 & 001 & 2 / Year Directed NOD Selected Drums & 1996 \\
\hline 28 & RF741205155 & 001 & 2 / Year Directed NOD Selected Drums & 1996 \\
\hline 29 & RF741200665 & 001 & 2 / Year Directed NOD Selected Drums & 1996 \\
\hline 30 & RF741202714 & 001 & 2 / Year Directed NOD Selected Drums & 1996 \\
\hline 31 & RF741200628 & 001 & 2 / Year Directed NOD Selected Drums & 1996 \\
\hline 32 & RF741203499 & 001 & 1 / Exploratory Sampling & 1997 \\
\hline 33 & RF741204240 & 001 & 1 / Exploratory Sampling & 1997 \\
\hline 34 & RF741201623 & 001 & 1 / Exploratory Sampling & 1997 \\
\hline 35 & RF741201643 & 001 & 1 / Exploratory Sampling & 1997 \\
\hline 36 & RF741201893 & 001 & 1 / Exploratory Sampling & 1997 \\
\hline 37 & RF741205838 & 800 & 1 / Exploratory Sampling & 1997 \\
\hline 38 & RF741207281 & 800 & 1 / Exploratory Sampling & 1997 \\
\hline 39 & RF741207309 & 800 & 1 / Exploratory Sampling & 1997 \\
\hline 40 & RF741205339 & 001 & 1 / Exploratory Sampling & 1997 \\
\hline 41 & RF741205546 & 001 & 1 / Exploratory Sampling & 1997 \\
\hline 42 & RF741205876 & 001 & 1 / Exploratory Sampling & 1997 \\
\hline 43 & RF741221435 & 002 & 1 / Exploratory Sampling & 1997 \\
\hline 44 & RF741206889 & 800 & 1 / Exploratory Sampling & 1997 \\
\hline 45 & RF741206104 & 800 & 1 / Exploratory Sampling & 1997 \\
\hline 46 & RF741207047 & 800 & 1 / Exploratory Sampling & 1997 \\
\hline 47 & RF741202134 & 001 & 1 / Exploratory Sampling & 1997 \\
\hline 48 & RF741205902 & 800 & 1 / Exploratory Sampling & 1997 \\
\hline 49 & RF741206243 & 800 & 1 / Exploratory Sampling & 1997 \\
\hline
\end{tabular}


Table 1-1. (continued).

\begin{tabular}{|c|c|c|c|c|}
\hline & $\begin{array}{c}\text { Drum } \\
\text { Identification (ID) }\end{array}$ & IDC & Phase \#/Description & Year Cored \\
\hline 50 & RF001904233 & 002 & 1 / Exploratory Sampling & 1997 \\
\hline 51 & RF741204411 & 001 & 1 / Exploratory Sampling & 1997 \\
\hline 52 & RF741206182 & 800 & 1 / Exploratory Sampling & 1997 \\
\hline 53 & RF741207001 & 001 & 1 / Exploratory Sampling & 1997 \\
\hline 54 & RF741202128 & 001 & 1 / Exploratory Sampling & 1997 \\
\hline 55 & RF074221645 & 002 & 1 / Exploratory Sampling & 1997 \\
\hline 56 & RF741200837 & 001 & 2 / Year Directed NOD Selected Drums & 1997 \\
\hline 57 & RF741201101 & 001 & 2 / Year Directed NOD Selected Drums & 1997 \\
\hline 58 & RF741201215 & 001 & 2 / Year Directed NOD Selected Drums & 1997 \\
\hline 59 & RF741201223 & 001 & 2 / Year Directed NOD Selected Drums & 1997 \\
\hline 60 & RF741200343 & 001 & 2 / Year Directed NOD Selected Drums & 1997 \\
\hline 61 & RF741206046 & 800 & 2 / Year Directed NOD Selected Drums & 1997 \\
\hline 62 & RF741206080 & 800 & 2 / Year Directed NOD Selected Drums & 1997 \\
\hline 63 & RF741206623 & 800 & 2 / Year Directed NOD Selected Drums & 1997 \\
\hline 64 & RF741204961 & 001 & 2 / Year Directed NOD Selected Drums & 1997 \\
\hline 65 & RF741206622 & 800 & 2 / Year Directed NOD Selected Drums & 1997 \\
\hline 66 & RF741204082 & 001 & 2 / Year Directed NOD Selected Drums & 1997 \\
\hline 67 & RF741206858 & 800 & 2 / Randomly Selected & 1998 \\
\hline 68 & RF741206260 & 800 & 2 / Randomly Selected & 1998 \\
\hline 69 & RF741206466 & 800 & 2 / Randomly Selected & 1998 \\
\hline 70 & RF741207151 & 800 & 2 / Randomly Selected & 1998 \\
\hline 71 & RF741207208 & 800 & 2 / Randomly Selected & 1998 \\
\hline 72 & RF741204963 & 001 & 2 / Randomly Selected & 1998 \\
\hline 73 & RF741207203 & 800 & 2 / Randomly Selected & 1998 \\
\hline 74 & RF741204054 & 001 & 2 / Randomly Selected & 1998 \\
\hline 75 & RF741200640 & 001 & 2 / Randomly Selected & 1998 \\
\hline
\end{tabular}




\subsection{Existing Data (pre-WAP) Usage}

The INEEL intends to use the pre-WAP data, both Phase I and II (including NOD) drums, to provide the statistics needed to calculate the number of WAP compliant drums to be sampled. Use of existing data in this manner is consistent with the WAP Attachment B2 which states:

Preliminary estimates of the mean concentration and variance of each $R C R A$ regulated contaminant in the waste will be used to determine the number of waste containers to select for sampling and analysis. The preliminary estimates will be made by obtaining a preliminary number of samples from the waste stream or from previous sampling from the waste stream.

Section 4.2 of this report addresses preliminary data results. Preliminary data has also been used to provide matrix related indications of analyte performance (Appendix A).

\subsection{WAP Compliant Sampling and Analysis Data}

The INEEL TWCP has been subjected to two CBFO WAP certification audits during calendar year 2000. The purpose of these audits was to assess adequacy, implementation, and effectiveness. The audit conducted April 24-28, 2000 resulted in three CBFO generated Corrective Action Reports (CARs). All the CARs have been closed.

During the most recent audit addressing solidified sampling and analysis, conducted December 5-8, 2000, no CARs were issued by the CBFO. This reflects a strict programmatic adherence to WAP requirements. The INEEL TWCP has WAP complaint Resource Conservation and Recovery Act (RCRA) data it will use in confirming hazardous waste codes. Seven drums (see Table 1-2) have been randomly core sampled, selected, and analyzed in accordance with the WAP.

Table 1-2. WAP Compliant Drums.

\begin{tabular}{|c|c|c|c|c|}
\hline & ID & IDC & Description & Date Cored \\
\hline 1 & IDRF741201882 & 001 & $\begin{array}{c}\text { WAP Compliant Sampling } \\
\text { and Analysis }\end{array}$ & $10 / 16 / 00$ \\
\hline 2 & IDRF741205324 & 001 & $\begin{array}{c}\text { WAP Compliant Sampling } \\
\text { and Analysis }\end{array}$ & $12 / 03 / 00$ \\
\hline 3 & IDRF741205311 & 001 & $\begin{array}{c}\text { WAP Compliant Sampling } \\
\text { and Analysis }\end{array}$ & $12 / 17 / 00$ \\
\hline 4 & IDRF741200655 & 001 & $\begin{array}{c}\text { WAP Compliant Sampling } \\
\text { and Analysis }\end{array}$ & $12 / 17 / 00$ \\
\hline 5 & IDRF741202121 & 001 & $\begin{array}{c}\text { WAP Compliant Sampling } \\
\text { and Analysis }\end{array}$ & $10 / 13 / 00$ \\
\hline 6 & IDRF741202390 & 001 & $\begin{array}{c}\text { WAP Compliant Sampling } \\
\text { and Analysis }\end{array}$ & $12 / 05 / 00$ \\
\hline 7 & IDRF741202216 & 001 & $\begin{array}{c}\text { WAP Compliant Sampling } \\
\text { and Analysis }\end{array}$ & $12 / 08 / 00$ \\
\hline
\end{tabular}




\section{WASTE DESCRIPTION AND ACCEPTABLE KNOWLEDGE}

This chapter summarizes the AK concerning the First/Second-Stage Sludge Waste Stream. Additional detail may be found in the AK Document INEL-96/0280, INEEL Stored Transuranic Waste Rocky Flats Plant Waste, and EDF-1809, Waste Stream Summary Sheet - First/Second-Stage Sludge.

\subsection{History}

The waste evaluated in the scope of this study consists of accessibly stored solidified aqueous sludges generated in Building 774 at the RFP between 1972 and 1988. RFP Building 774 was built in 1952 to treat radioactive aqueous wastes generated in Building 771 . Building 771 treated solid TRU wastes generated at the plant; therefore, the liquid process waste streams feeding Building 774 contained most of the radioactive and chemical compounds used at the plant. The treatment process originally employed precipitation technology to remove radionuclides. Other liquid treatment technologies were installed as Building 774 operations evolved. The aqueous wastes were treated in first and second stage processes to remove radioactive and chemical contaminants. The effluent from these processes was solidified for disposal. Around 1965, an evaporator was installed to augment liquid treatment, including wastewater from solar ponds. This evaporator was removed in 1979 when the liquids were transferred to Building 374 for treatment. The most common radioactive materials consisted of weapons-grade plutonium, americium, enriched uranium, and depleted uranium. The wastes were subsequently shipped to the RWMC at the INEEL in 55-gallon drums. The 6,752 drums are currently pending further characterization and shipment to the WIPP.

\subsection{Waste Stream Identification}

The WAP defines a waste stream as "waste material generated from a single process or from an activity that is similar in material, physical form, and hazardous constituents." The INEEL approach identifying waste streams is documented in EDF-922, Identification of Transuranic Waste Streams. This approach combines IDCs that have a similar physical composition and the same regulated constituents. Since the waste was generated from a single process line, is of a similar material and physical form, and has identical hazardous waste codes, the First/Second-Stage Sludge Waste Stream (containing IDCs 001, 002, and 800) have logically been combined through this methodology. The resulting waste stream contains 6,752 drums.

\subsubsection{Waste Description}

The first- and second-stage sludges from the RFP Building 774 are assigned IDCs 001, 002, and 800. IDC assignment identifies nuclear material forms or process materials associated with waste generation. A detailed description of each IDC follows.

2.2.1.1 IDC 001: First-Stage Sludge. This waste consists of immobilized materials generated from first-stage treatment operations in Building 774. Aqueous liquids coming into the process originated from RFP Building 771 recovery operations. The liquids were made basic with sodium hydroxide to precipitate metals, plutonium, and americium hydrated oxides. The precipitate was filtered to produce a sludge that was placed in a drum with Portland cement. The Matrix Parameter Category (MPC) assigned to this IDC is S3121 (see EDF-805, Matrix Parameter Category Groups). As defined in the Department of Energy (DOE) Waste Treatability Group Guidance (DOE/LLW-2 17), this MPC consists of greater than 50 percent by volume secondary sludge, or filtercake from wastewater treatment processes or heavy metal sludges resulting from recovery processes. Additional items (less than 50 percent by volume) identified in the waste include Kimwipes, leaded rubber gloves, rubber gloves, and bottles. Absorbents 
added to the waste during packaging include: 3 to 5 pounds of Portland cement in the bottom of the drum; 3 to 5 pounds of Portland cement in the bottom of the drum bag; approximately 30 pounds of Portland cement in the bottom of the poly-vinylchloride (PVC) o-ring bag; 1 to 2 quarts of Oil Dri on top of outer, sealed polyethylene bag; Vermiculite used to fill space between the sealed polyethylene bag and liner; and 3 to 5 pounds of Portland cement on top of the sludge, inside the o-ring bag.

2.2.1.2 IDC 002: Second-Stage Sludge. This waste consists of immobilized materials generated from second-stage treatment operations in Building 774. Aqueous liquids to be treated originated from first-stage treatment and from numerous buildings on the RFP site. The liquids were treated in the same manner as the liquids from the first stage, and the resulting sludge was placed into a drum with Portland cement. The MPC group assigned to this IDC is S3121, as defined in DOE/LLW-2 17 and further documented in EDF-805. Additional items (less than 50 percent by volume) identified in the waste include Kimwipes, leaded rubber gloves, rubber gloves, and bottles. Until 1973, items such as, electric motors, bottles of liquid chemical wastes, mercury batteries, lithium batteries, and small amounts of contaminated mercury in pint bottles may also be contained in this waste. Absorbents added to the waste during packaging include: 3 to 5 pounds of Portland cement in the bottom of the drum; 3 to 5 pounds of Portland cement in the bottom of the drum bag; approximately 30 pounds of Portland cement layered throughout the drum; 1 to 2 quarts of Oil Dri on top of outer, sealed polyethylene bag; Vermiculite used to fill space between the sealed polyethylene bag and liner; and 3 to 5 pounds of Portland cement on top of the sludge, inside the plastic bag.

2.2.1.3 IDC 800: Solidified Sludge-BIdg. 774. This waste was generated from a process that was similar to the IDC 001 waste generation process. The difference between the two IDCs is in the immobilization process. For IDC 800, the sludge was co-fed into a drum with a diatomite and Portland cement mixture, forming a solid monolith after curing. The MPC assigned to this IDC is S3150 (see EDF-805). This MPC is defined to consist of greater than 50 percent by volume of solidified form such as a sludge waste immobilized with cement and cured into a solid (DOE/LLW-2 17). Absorbents added to the waste during packaging included Vermiculite used to fill the space between the sealed polyethylene bag and liner.

\subsubsection{Waste Generation Process}

The solidified aqueous waste from Building 774 was generated from a two-stage liquid treatment process. Aqueous treatment operations included neutralization, precipitation, filtration, flocculation, clarification, immobilization, and evaporation. These processes were used to remove radioactive and chemical contaminants and to convert the waste to a solid for disposal. A diagram depicting the aqueous treatment process is shown in Figure 2-1. Stage one treatment processes were performed on the following RFP waste streams:

- $\quad$ Plutonium ion column effluent

- Americium ion column effluent

- Thiocyanate waste solution

- Caustic scrubber solution

- $\quad$ Nitric, sulfuric, and hydrofluoric acids

- $\quad$ Nitric acid distillate from feed evaporator

- Water distillate from peroxide precipitation filtrate evaporator

- $\quad$ Steam condensate. 


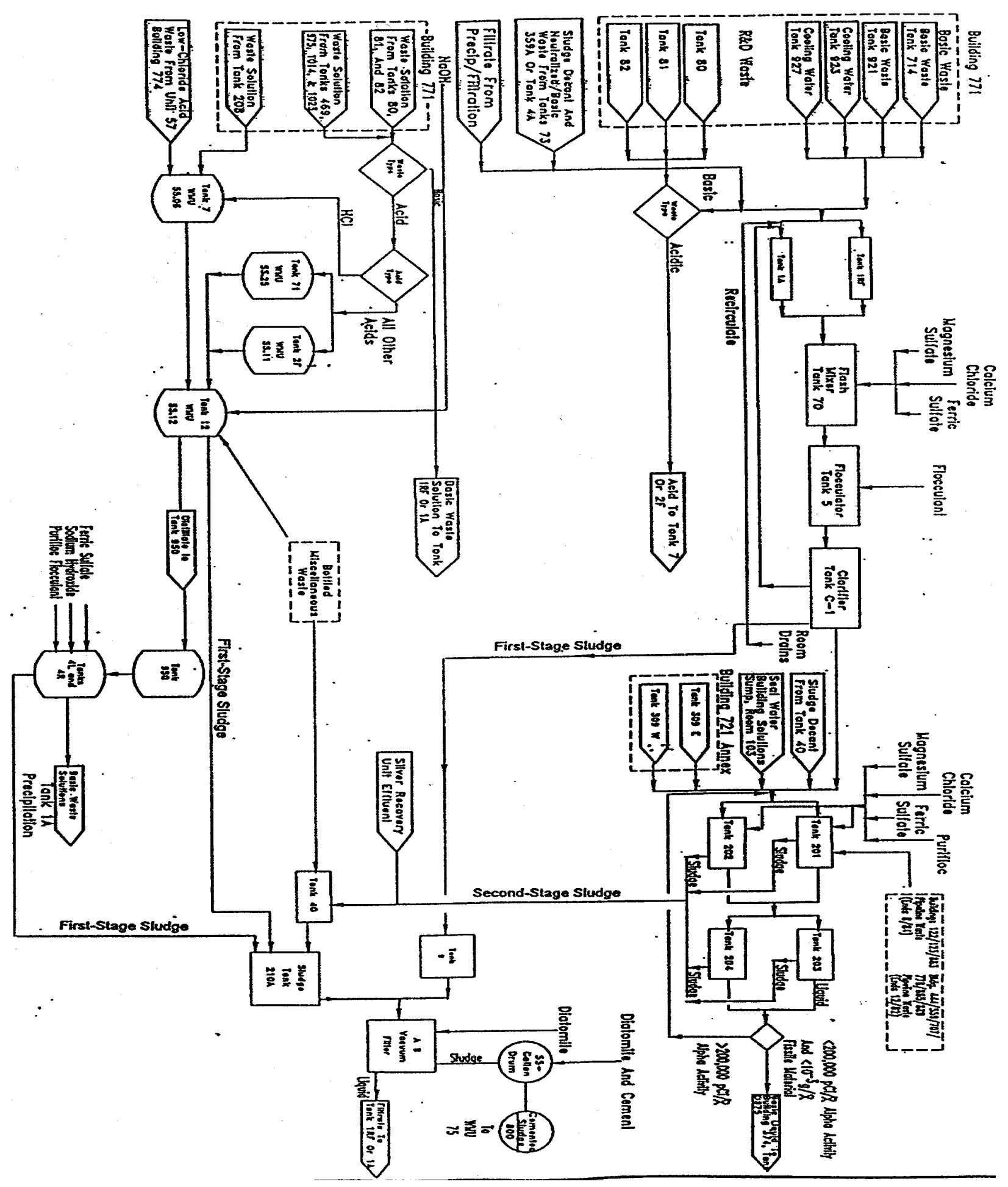

Figure 2-1. Aqueous Treatment Process. 
AK has identified the following compounds as potentially being present in aqueous sludges from first-stage treatment:

- $\quad$ Nitric acid

- Aluminum nitrate

- $\quad$ Calcium fluoride

- $\quad$ Potassium hydroxide

- Ferrous sulfamate

- $\quad$ Sulfuric acid

- Hydrogen peroxide

- Calcium

- $\quad$ Magnesium oxide

- Magnesium

- $\quad$ Sodium peroxide

- $\quad$ Potassium iodate

- Hydrogen fluoride

- $\quad$ Sodium nitrate

- Hydrochloric acid

- Hydrofluoric acid

- Sodium hypochlorite

- $\quad$ Potassium fluoride.

A vacuum inside a rotating filter drum drew slurry from first-stage treatment through diatomite filter media. The filter media and trapped solids were continually scraped off the drum filter and placed into a 55-gallon drum. Portland cement may also have been added to the top of the sludge. This sludge was assigned IDC 001. In 1986, the immobilization process changed and IDC 001 was discontinued.

The process of pulling the combined slurry through diatomite filter media remained unchanged. As the sludge was scraped off the drum filter, it was co-fed into a drum with a diatomite and Portland cement mixture that formed a solid monolith after curing. This waste was assigned IDC 800.

Second-stage treatment included liquids treated by first-stage treatment, decanted liquids from a slurry holding tank, and low-level or nonradioactive aqueous process wastes from numerous buildings at the RFP site (see the AK document, INEL-96/0280, for a list of source buildings). The second-stage process included two separate radioactive decontamination systems: (1) a batch precipitation system used to remove radioactive materials from wastes in which both the radioactive and chemical contaminants exceeded the standards, and (2) a continuous precipitation system used to remove radioactive materials from wastes meeting the standards for chemical, but not for radioactive contaminants. Second-stage sludge was precipitated in the same manner as first-stage sludge (IDC 001) and was assigned IDC 002. 


\section{ACCEPTABLE KNOWLEDGE HAZARDOUS WASTE CODE DETERMINATION}

The First/Second-Stage Sludge waste stream generated from Building 774 treatment processes, contains chemical constituents reflective of the operations performed throughout the plant. Process knowledge, summarized in Section 2, indicates the waste may contain both characteristic and listed constituents. However, the mere presence of hazardous constituents does not necessarily cause a waste to be hazardous, by definition, if such constituents do not result from a prescribed use or do not exceed regulatory limits in a representative sample. Below is a summary of AK relative to characteristic and listed constituents.

\subsection{Characteristic Determination}

\subsubsection{Corrosivity}

Based on testing and knowledge of the waste stream, it has been determined that the First/Second-Stage Waste Stream does not meet the definition of a characteristic waste due to corrosivity. To be a corrosive waste under RCRA, a material must possess either of the following properties:

- It is aqueous with a $\mathrm{pH} \leq 2$, or, $\geq 12.5$. To measure the $\mathrm{pH}$, the EPA prescribes the use of Method 9040 in the definition of corrosivity found at 40 CFR Section 261.22. This method requires that $>20 \%$ of the total waste volume is aqueous; or

- A liquid as determined by its ability to pass through a certain type of filter and will corrode steel at a rate of 0.25 inches per year.

As has been determined by radiography and confirmed by visual examination (VE), none of these drums contain $20 \%$ by volume, aqueous waste; thus, the corrosive characteristic does not apply. If a waste is not a liquid by definition, a determination of its ability to corrode steel would be inappropriate. Consequently, it is not appropriate to test the $\mathrm{pH}$ of the waste or its ability to corrode steel pursuant to the required methodologies.

\subsubsection{Toxicity}

To exhibit the toxicity characteristic, concentrations of certain metals or organics must equal or exceed the regulatory threshold limits (RTLs) in an extract generated using a test method known as the Toxicity Characteristic Leaching Procedure (TCLP). Results of the TCLP test are compared with levels that the EPA has identified as hazardous to projected receptors. In lieu of the TCLP, totals analysis can be used to estimate a worst-case situation. AK information shows evidence of toxic characteristic level for arsenic (As), barium (Ba), cadmium $(\mathrm{Cd})$, chromium $(\mathrm{Cr})$, lead $(\mathrm{Pb})$, mercury $(\mathrm{Hg})$, selenium $(\mathrm{Se})$, and silver (Ag). The EPA Hazardous Waste Codes assigned to the First/Second-Stage Sludge, based on AK, are listed in Table 3-1. 
Table 3-1. Characteristic (Toxicity) Hazardous Waste Codes Assigned to First/Second-Stage Sludge Based on AK.

\begin{tabular}{|l|l|l|c|}
\hline Hazardous Waste Code & \multicolumn{1}{|c|}{ Description } & \multicolumn{1}{c|}{ CAS Number } & $\begin{array}{c}\text { Regulatory Threshold } \\
\text { Level (mgIL) }\end{array}$ \\
\hline D004 & Arsenic & $7440-35-2$ & 5.0 \\
\hline D005 & Barium & $7440-39-3$ & 100.0 \\
\hline D006 & Cadmium & $7440-43-9$ & 1.0 \\
\hline D007 & Chromium & $7440-47-3$ & 5.0 \\
\hline D008 & Lead & $7439-92-1$ & 5.0 \\
\hline D009 & Mercury & $7439-97-6$ & 0.2 \\
\hline D010 & Selenium & $7782-49-2$ & 1.0 \\
\hline D011 & Silver & $7440-22-4$ & 5.0 \\
\hline
\end{tabular}

\subsubsection{Ignitibility}

Based on knowledge of the waste stream and generation processes, it has been determined that the waste does not meet the definition of an ignitable waste under RCRA. To be considered ignitable under RCRA, a material must possess any of the following properties:

- It is a liquid other than an aqueous solution containing $>24 \%$ alcohol and a flash point of $<140^{\circ} \mathrm{F}\left(60^{\circ} \mathrm{C}\right)$

- It is not a liquid but is capable of causing fire through friction, adsorption of moisture, or spontaneous chemical changes

- $\quad$ It is an ignitable compressed gas

- It is an oxidizer as defined by U.S. Department of Transportation (DOT) regulations.

As discussed above, the waste does not contain liquids. Nothing in the waste stream is a solid that has qualities likely to ignite through friction, moisture adsorption, or chemical changes. As has been determined through radiography and confirmed through VE, no compressed-gas cylinders exist in the waste. AK indicates that DOT oxidizers were not used in the process, therefore do not exist in the waste.

\subsubsection{Reactivity}

Based on knowledge of the waste stream and generation processes, it has been determined that the waste does not meet the definition of a reactive waste under RCRA. To be considered a reactive waste under RCRA, a material must possess any one of the following properties:

- It is unstable and can undergo violent change

- It reacts violently with water

- It forms potentially explosive mixtures with water

- It reacts with water to generate toxic gases, vapors, or fumes that are harmful

- It contains cyanide or sulfide that can generate toxic gases, vapors, or fumes

- It can detonate or explode at standard temperature and pressure

- It is a DOT forbidden or Class A or B explosive.

No material was used or generated in these processes that, under the conditions specified above, could react violently, form harmful gases, contain cyanide or sulfide, or meet the DOT explosive definitions prescribed. 


\subsection{Listed Determination}

Waste is potentially subject to RCRA regulation as a hazardous waste if it meets a listing description. Wastes in this waste stream were derived from the treatment of aqueous electroplating wastes, and aqueous wastes containing small quantities of halogenated- and non-halogenated (NH)solvents, resulting in an F-listed hazardous waste. Tetrachloroethylene, trichloroethylene, 1,1,1 -trichloroethane, 1,1,2-trichloro- 1,2,2-trifluoroethane, and carbon tetrachloride were used primarily for cleaning and degreasing, and small quantities of these constituents may be present in the waste. Methylene chloride was used primarily for paint removal. Acetone, methanol, xylene, benzene, and toluene were used as solvents primarily in laboratory operations.

At one time, Building 774 treated spent stripping, cleaning, and plating solutions from electroplating operations in which cyanides were used. Since the First/Second-Stage Sludge was derived from treatment of these wastes, the associated F-listed codes also apply. No other waste codes apply since this waste stream did not come from specific sources, and the waste does not contain discarded commercial chemical product, off-specification chemical species, container residue, or spill residue associated with such products. The EPA Hazardous Waste Codes assigned to the First/Second-Stage Sludge and based on the above AK discussion, are listed in Table 3-2 for F-listed constituents.

Table 3-2. Listed Hazardous Waste Codes Assigned to First/Second-Stage Sludge Based on AK.

\begin{tabular}{|c|c|c|}
\hline $\begin{array}{l}\text { Hazardous } \\
\text { Waste Code }\end{array}$ & Description & $\begin{array}{l}\text { Constituents Causing } \\
\text { Listing Using AK }\end{array}$ \\
\hline F001 & $\begin{array}{l}\text { Spent halogenated solvents used in degreasing, spent solvent } \\
\text { mixtures/blends used in degreasing (F001, F002, F004, F005 } \\
\text { constituents), still bottoms from the recovery of spent } \\
\text { solvents and spent solvent mixtures used in degreasing. }\end{array}$ & $\begin{array}{l}\text { Tetrachloroethylene, } \\
\text { trichloroethylene, } \\
\text { 1,1,1-trichloroethane, } \\
\text { carbon tetrachloride } \\
\text { methylene chloride }\end{array}$ \\
\hline F002 & $\begin{array}{l}\text { Spent halogenated solvents, spent solvent mixtures/blends } \\
\text { (F001, F002, F004, F005), still bottoms from the recovery of } \\
\text { these spent solvents and spent solvent mixtures. }\end{array}$ & $\begin{array}{l}\text { Tetrachloroethylene. } \\
\text { Trichloroethylene, } \\
\text { 1,1,1-trichloroethane, carbon } \\
\text { tetrachloride, methylene chloride, } \\
\text { 1,1,2-trichloroethane, } \\
\text { chlorobenzene, 1,1,2-trichloro- } \\
\text { 1,1,2-trifluoroethane }\end{array}$ \\
\hline F003 & $\begin{array}{l}\text { Spent non-halogenated solvents, spent solvent } \\
\text { mixtures/blends containing NH solvents and halogenated } \\
\text { solvents (F001, F002, F004, F005), still bottoms from the } \\
\text { recovery of these spent solvents and spent solvent mixtures. }\end{array}$ & $\begin{array}{l}\text { Xylene, ethylbenzene, methanol, } \\
\text { acetone }\end{array}$ \\
\hline F005 & $\begin{array}{l}\text { Spent NH solvents, spent solvent mixtures/blends containing } \\
\text { NH solvents and halogenated solvents (F001, F002, F004, } \\
\text { F005), still bottoms from the recovery of these spent solvents } \\
\text { and spent solvent mixtures. }\end{array}$ & Toluene, benzene \\
\hline F006 & Wastewater treatment sludges from electroplating operations & $\begin{array}{l}\text { Cadmium, hexavalent chromium, } \\
\text { cyanide (complexed) }\end{array}$ \\
\hline F007 & Spent cyanide plating operations & Cyanide (salts) \\
\hline F009 & $\begin{array}{l}\text { Spent stripping and cleaning bath solutions from } \\
\text { electroplating operations where cyanides are used in the } \\
\text { process. }\end{array}$ & Cyanide (salts) \\
\hline
\end{tabular}




\subsection{Additional WAP/Waste Acceptance Criteria (WAC) Characterization Data}

The WAP and WAC requires additional characterization to (a) verify the AK documented for this waste stream, and (b) support other WAP requirements. Included in this section are those intrusive and nonintrusive examinations and analyses conducted to ensure that the requirements for the disposal of waste in WAP were met, and confirm the AK hazardous waste determination.

\subsubsection{Radionuclides}

The aqueous wastes treated in Building 774 at the RFP received wastes from throughout the plant site. As a result, the First/Second-Stage Sludge that was generated during Building 774 waste treatment operations may contain any of the radioisotopes used at the plant. The most common radioactive materials handled were weapons-grade plutonium, americium-241, enriched uranium, and depleted uranium. All drums are subjected to radioassay to ensure compliance with WAC requirements prior to shipment to the WIPP.

\subsubsection{Radiography/VE}

All drums are physically characterized using real-time radiography (RTR). A statistically selected portion of this waste stream has been characterized through VE. These examinations provide confirmation that the waste consists of sludge, that the packaging is appropriate, and that there are no prohibited items within the waste. The RTR and VEs for this waste stream have confirmed expectations. 


\section{CONFIRMATION OF HAZARDOUS WASTE CODE ASSIGNMENTS BASED ON HEADSPACE GAS SAMPLING AND HOMOGENOUS SOLIDS ANALYSIS}

\subsection{Headspace Gas Sampling and Analysis Results}

The headspace analysis results for spent solvents have been assessed per the requirements in the WAP. Results of the WAP compliant headspace gas analyses for 28 drums are summarized in Table 4-1. Based on the results given in Table 4-1, two F-listed volatile organic solvents exceeded the program-required quantitation limit (PRQL) at the 90\%-confidence level. The $\mathrm{UCL}_{90}$ value for 1,1,1 trichloroethane was $81.1 \mathrm{ppmv}$ and $36.5 \mathrm{ppmv}$ for trichloroethylene. The F001 code has already been added (see Table 3-2). In addition, the occurrences of tentatively identified compounds (TICs) were evaluated. No TICs listed in Appendix VIII 40 CFR Part 261 were detected, therefore no hazardous waste codes were assigned based on TICs.

Table 4-1. Headspace gas summary data.

\begin{tabular}{|c|c|c|c|c|c|c|c|c|}
\hline Analyte & $\begin{array}{c}\text { Number } \\
\text { of } \\
\text { samples }\end{array}$ & $\begin{array}{c}\text { Number of } \\
\text { samples } \\
\text { above MDL }\end{array}$ & $\begin{array}{c}\text { Mean } \\
(\mathrm{ppmv})\end{array}$ & $\begin{array}{c}\text { Standard } \\
\text { deviation } \\
(\mathrm{ppm})\end{array}$ & $\begin{array}{l}\text { Maximum } \\
\text { concen. } \\
\text { (ppmv) }\end{array}$ & $\begin{array}{l}\text { Upper } 90 \% \\
\text { confidence } \\
\text { limit (ppmv) }\end{array}$ & $\begin{array}{l}\text { PRQL } \\
(\mathrm{ppmv})\end{array}$ & $\begin{array}{c}\text { EPA Code } \\
\text { Assigned based } \\
\text { on AK }\end{array}$ \\
\hline 1,1,1-Trichloroethane & 28 & 28 & 72.5 & 34.7 & 150 & 81.1 & 10 & F001/F002 \\
\hline 1,1,2,2-Tetrachloroethane & 28 & 0 & 0.240 & 0.150 & 0.7 & $\mathrm{~b}$ & 10 & $\mathrm{~N} / \mathrm{A}$ \\
\hline $\begin{array}{l}\text { 1,1,2-Trichloro- } \\
\text { 1,2,2-Trifluoroethane }\end{array}$ & 28 & 10 & 0.236 & 0.152 & 0.46 & 0.303 & 10 & F002 \\
\hline 1,1-Dichloroethane & 28 & 14 & 0.627 & 1.10 & 5.8 & 1.03 & 10 & $\mathrm{~N} / \mathrm{A}$ \\
\hline 1,1-Dichloroethylene & 28 & 18 & 1.41 & 2.11 & 11 & 2.07 & 10 & N/A \\
\hline 1,2,4-Trimethylbenzene & 28 & 1 & 0.161 & 0.128 & 0.7 & $\mathrm{~b}$ & 10 & N/A \\
\hline 1,2-Dichloroethane & 28 & 0 & 0.149 & 0.085 & 0.445 & $\mathrm{~b}$ & 10 & $\mathrm{~N} / \mathrm{A}$ \\
\hline 1,3,5-Trimethylbenzene & 28 & 6 & 0.195 & 0.132 & 0.44 & 0.274 & 10 & $\mathrm{~N} / \mathrm{A}$ \\
\hline Acetone & 28 & 27 & 2.39 & 2.27 & 13 & 2.96 & 100 & F003 \\
\hline Benzene & 28 & 3 & 0.180 & 0.208 & 1.1 & 0.407 & 10 & F005 \\
\hline Bromoform & 28 & 0 & 0.221 & 0.129 & 0.7 & $\mathrm{~b}$ & 10 & $\mathrm{~N} / \mathrm{A}$ \\
\hline Butanol & 28 & 10 & 1.11 & 0.857 & 3.2 & 1.48 & 100 & F003 \\
\hline Carbon tetrachloride & 28 & 19 & 0.696 & 2.61 & 14 & 1.49 & 10 & F001/F002 \\
\hline Chlorobenzene & 28 & 0 & 0.181 & 0.112 & 0.55 & $\mathrm{~b}$ & 10 & N/A \\
\hline Chloroform & 28 & 1 & 0.152 & 0.085 & 0.45 & $\mathrm{~b}$ & 10 & $\mathrm{~N} / \mathrm{A}$ \\
\hline cis-1,2-Dichloroethylene & 28 & 2 & 0.576 & 2.24 & 12 & 5.45 & 10 & N/A \\
\hline
\end{tabular}


Table 4-1. (continued).

\begin{tabular}{|c|c|c|c|c|c|c|c|c|}
\hline Analyte & $\begin{array}{c}\text { Number } \\
\text { of } \\
\text { samples }\end{array}$ & $\begin{array}{c}\text { Number of } \\
\text { samples } \\
\text { above MDL }\end{array}$ & $\begin{array}{c}\text { Mean } \\
(\mathrm{ppmv})\end{array}$ & $\begin{array}{c}\text { Standard } \\
\text { deviation } \\
(\mathrm{ppmv})\end{array}$ & $\begin{array}{l}\text { Maximum } \\
\text { concen. } \\
\text { (ppmv) }\end{array}$ & $\begin{array}{c}\text { Upper } 90 \% \\
\text { confidence } \\
\text { limit (ppmv) }\end{array}$ & $\begin{array}{l}\text { PRQL } \\
\text { (ppmv) }\end{array}$ & $\begin{array}{c}\text { EPA Code } \\
\text { Assigned based } \\
\text { on AK }\end{array}$ \\
\hline Cyclohexane & 28 & 0 & 0.100 & 0.057 & 0.295 & $\mathrm{~b}$ & 10 & N/A \\
\hline Ethyl benzene & 28 & 12 & 0.334 & 0.264 & 0.76 & 0.438 & 10 & F003 \\
\hline Ethyl ether & 28 & 0 & 0.341 & 0.203 & 1.1 & $\mathrm{~b}$ & 10 & N/A \\
\hline Methanol & 28 & 0 & 4.43 & 1.02 & 5 & $\mathrm{~b}$ & 100 & F003 \\
\hline Methyl ethyl ketone & 28 & 1 & 0.388 & 0.234 & 1.3 & $\mathrm{~b}$ & 100 & N/A \\
\hline Methyl isobutyl ketone & 28 & 5 & 0.185 & 0.122 & 0.6 & 0.269 & 100 & N/A \\
\hline Methylene chloride & 28 & 22 & 1.95 & 5.22 & 28 & 3.43 & 10 & F001/F002 \\
\hline Tetrachloroethylene & 28 & 10 & 46.9 & 246 & 1300 & 154 & 10 & F001 \\
\hline Toluene & 28 & 27 & 2.71 & 1.14 & 5.7 & 2.99 & 10 & F005 \\
\hline Trichloroethylene & 28 & 24 & 20.0 & 61.1 & 330 & 36.5 & 10 & F001/F002 \\
\hline m\&p-Xylene & 28 & 9 & 0.479 & 0.501 & 1.9 & 0.712 & 10 & F003 \\
\hline o-Xylene & 28 & 7 & 0.273 & 0.196 & 0.63 & 0.379 & 10 & F003 \\
\hline \multicolumn{3}{|c|}{ Did the data verify the Acceptable Knowledge? } & $\begin{array}{l}\text { Yes } \frac{X}{\text { Xrdous Was }} \\
\text { ardo }\end{array}$ & - No & & & & \\
\hline \multicolumn{9}{|c|}{$\begin{array}{l}\text { a. When a measurement is reported as below detection, one-half the analysis method detection limit (MDL) is used. Note that the MDL for } \\
\text { a given analyte may vary from sample to sample. }\end{array}$} \\
\hline \multicolumn{9}{|c|}{$\begin{array}{l}\text { The mean and standard deviation presented are the mean and standard deviation of the method detection limits (after dividing by } 2 \text { ) since } \\
\text { all measurements (or all but one) are below detection. Therefore, there are no degrees of freedom associated with the t statistic and the } \\
\text { upper } 90 \% \text { confidence limit cannot be calculated. }\end{array}$} \\
\hline
\end{tabular}




\subsection{Preliminary Data}

Preliminary first/second stage data generated prior to the WAP issuance has been evaluated. As discussed in Section 1.3, the preliminary data has been used to determine the WAP compliant sample size and provide matrix related indications of analyte performance. The preliminary data received WAP compliant project level validation and verification reviews prior to statistical reduction. NCRs have been generated on this data. If dispositions did not reject the data, the data were utilized "as-is". Due to the fact that the data was generated under the QAPP, there are anomalies present that do not affect data quality (for example, missing " $Z$ " flags for matrix spike recovery if metals were present at more than four times the spiking matrix spike levels). Therefore, the data have been accepted for use unless generated significantly after holding times expired.

In the following sections an assessment summary of the preliminary data is given. In each area Matrix Spike (MS)/Matrix Spike Duplicate (MSD), surrogate, and Laboratory Control Sample (LCS) performance was evaluated and conclusions drawn. A detailed preliminary data use assessment is given in Appendix A. In Appendix A, precision and accuracy performance indicators are addressed individually by analytical method, such as, metals, semi-volatile organic compounds (SVOCs), total volatile organic compounds (VOCs), and NH VOCs. The indicators include: LCS, MSs, MSDs, and surrogates (where applicable). Recoveries were complied and average recoveries calculated by analyte as well as relative percent differences (RPDs), as appropriate, and plotted. Error bars associated with the recovery averages were set at one standard deviation. These data are provided in tables and figures included in the appendix.

\subsubsection{Preliminary Metals Data Assessment Summary}

Relative to the characteristic metals, these results indicate that the preliminary data generated on the first/second-stage sludge waste stream can be used to evaluate WAP compliant sampling needs and/or determine potential bias. The LCS data were within the required accuracy window indicating that the laboratory methods were in control and any biases observed in the data were due to matrix effects. As a general rule MS/MSD and surrogate recoveries were well within both the accuracy and precision Quality Control (QC) limits. Exceptions are discussed in Appendix A.

\subsubsection{Preliminary SVOC Assessment Summary}

Based on the performance of the matrix dependent (MS/MSD and surrogates) and non-matrix dependent (LCS) indicators, the data are acceptable to assess additional sampling requirements and formulate impact to the waste stream profile.

The LCS average recoveries were within the WAP accuracy criteria demonstrating that the laboratory methods were in control. There is no indication that there were problems associated with the other target compounds not found in the LCS. This conclusion is reinforced by the performance of the MS/MSDs. The MS/MSD recoveries were generally within WAP criteria but recovered on the low end, with the exception of hexachloroethane. For details see Appendix A, Section A-2.1. All RPDs met WAP criteria.

The performance of two surrogates, nitrobenzene-d5 (NBZ) and 2-flurorbiphenyl (FBP), were acceptable. The two other surrogate recovery averages or associated error [2-flurorphenol $(2 \mathrm{FP})$ and 2,4,6-triborophenol (TBP)] generally reflected a low bias. Therefore, the phenol data may be biased low. 
Individual surrogate data points are plotted in Appendix A, Figures V-4 through V-7. Three sigma $(3-\sigma)$ limits specific to this waste stream (versus the limits determined over time by the laboratory spanning different waste streams) are reflected on each of the graphs. This provides a picture of surrogate performance specific to the IDC 001, 002, and 800 waste stream, that is, the acceptance criteria is based solely on data from this waste stream, confirming that these data are appropriate for use as preliminary data. These data also reflect the fact that the laboratory methods performed consistently.

\subsubsection{Preliminary Purgeable VOC Assessment Summary}

VOC MS/MSD performance, precision, and accuracy were acceptable and did not reflect any bias for this waste stream. LCS recoveries are also compliant. Individual surrogate data points are plotted in Appendix A, Figures V-4 through V-7. Three sigma (3- $\sigma$ ) limits specific to this waste stream are reflected on each of the graphs. These data also reflect the fact that the laboratory methods performed consistently.

\subsubsection{Preliminary NH VOC Data Assessment}

Based on the acceptable performance of the MS/MSD and LCS indicators, the preliminary NH VOC sample data is usable with no matrix effects noted.

\subsubsection{Preliminary Data TIC Assessment}

The WAP requires that TICs meeting criteria defined in the WAP and appearing in the Appendix VIII list be compared to AK data to determine if the TIC is a listed waste. A list of the TICs from Total VOC and SVOC analyses is given in Table 4-2. All TIC concentrations are low. One compound, bis (2-ethyhexyl) phthalate, appeared in $>25 \%$ of the preliminary samples and is an Appendix VIII list compound. This compound was not added to the target analyte list. The WAP allows for the exclusion to the target analyte list if the TIC is a constituent in an F-listed waste and its presence is attributable to waste packaging materials or radiolytic degradation. Bis (2-ethylhexyl) phthalate is a common organic contaminant whose presence is attributable to the presence of plastic packaging material in the drum. As a result, no code has been added nor was the compound added to the target analyte list.

Table 4-2. First/Second-Stage Sludge TICs and Summary Statistics.

\begin{tabular}{lccccc}
\multicolumn{1}{c}{ Analyte } & $\begin{array}{c}\text { Number of } \\
\text { samples }\end{array}$ & $\begin{array}{c}\text { Minimum } \\
(\mathrm{mg} / \mathrm{kg})\end{array}$ & $\begin{array}{c}\text { Maximum } \\
(\mathrm{mg} / \mathrm{kg})\end{array}$ & $\begin{array}{c}\text { Mean } \\
(\mathrm{mg} / \mathrm{kg})\end{array}$ & $\begin{array}{c}\text { Standard deviation } \\
(\mathrm{mg} / \mathrm{kg})\end{array}$ \\
\hline 2,5-Cyclohexadiene-1,4-dione, 1,6-bi & 1 & 4.1 & 4.1 & 4.10 & $\mathrm{a}$ \\
2-Methyl-2,3-pentanediol & 1 & 0.43 & 0.43 & 0.430 & $\mathrm{a}$ \\
2-Nitro-phenol & 7 & 0.4 & 3.2 & 1.06 & 1.04 \\
4-Nitro-Phenol & 2 & 0.4 & 0.71 & 0.555 & 0.219 \\
Bis(2-ethylhexyl)phthalate & 46 & 0.11 & 29.5 & 5.61 & 6.82 \\
Butanenitrile, 4-(dimethylanino) & 1 & 0.23 & 0.23 & 0.230 & $\mathrm{a}$ \\
Butylbenzyl phthalate & 4 & 0.28 & 0.56 & 0.405 & 0.117 \\
Di-n-butylphthalate & 18 & 0.39 & 11 & 3.43 & 2.67 \\
Fluoranthene & 4 & 0.42 & 17 & 7.50 & 8.34 \\
Phenol & 3 & 2.8 & 4.8 & 3.77 & 1.00 \\
\hline
\end{tabular}

a. Standard deviations cannot be calculated due to a sample size of one. 


\subsubsection{Preliminary Data Results and Sample Size Determination}

The results of preliminary data are summarized in Table 4-3. Table 4-3 also identifies the number of drums to be sampled per the WAP. The sample size calculation performed did not include contaminants associated with EPA spent solvent hazardous waste codes. If the solvent code was already applied to the waste stream as part of the AK evaluation (because solvent codes are listed codes), the code remains with the waste stream. Therefore, no additional sampling is required to confirm the EPA hazardous waste code assignment for spent solvent contaminants. In addition, if a toxicity code had been assigned based on AK the sample size was not determined. The INEEL will assign the code. Based on the results given in Table 4-3, five drums require coring to confirm preliminary results. 


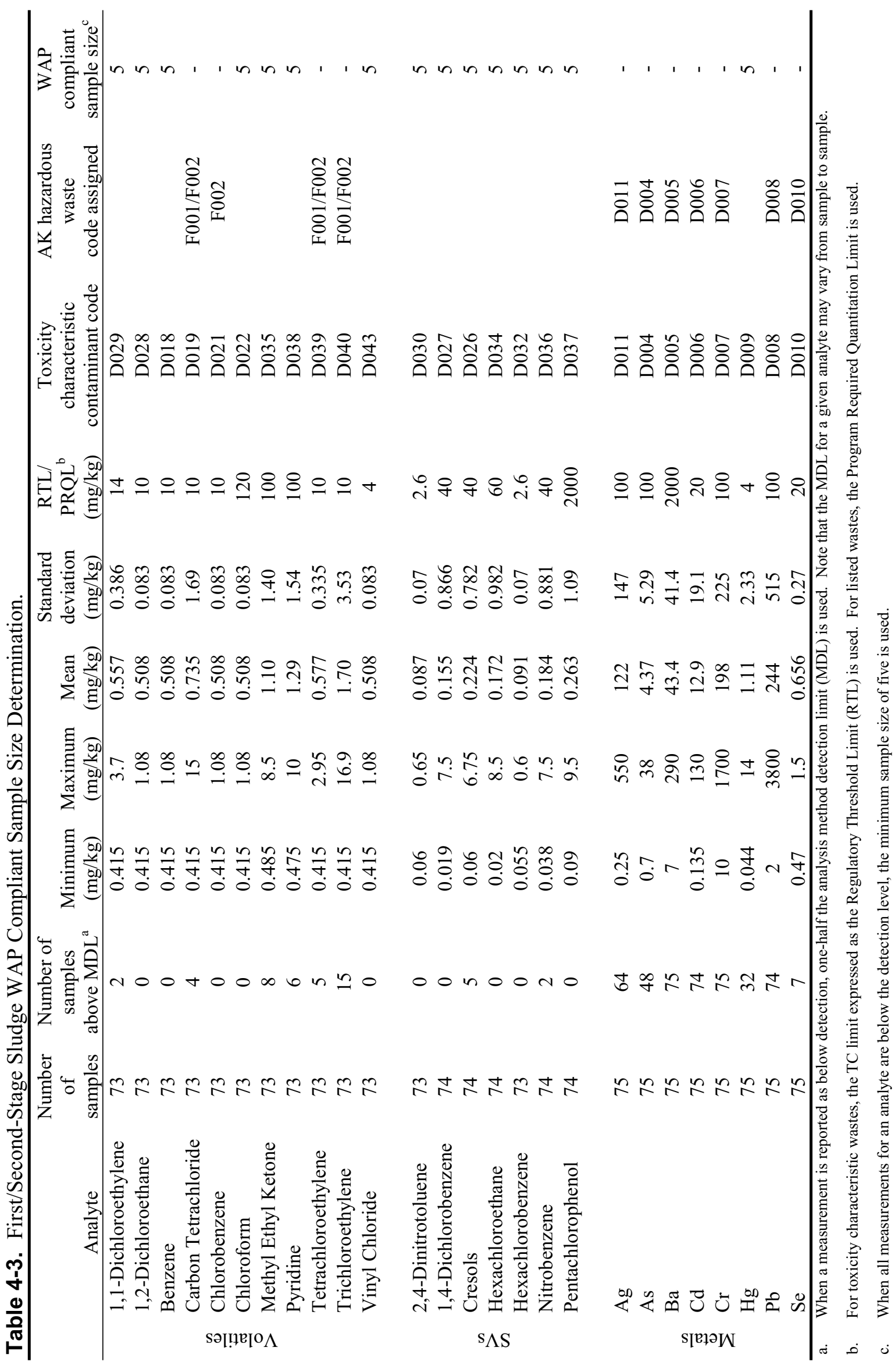




\subsubsection{Non-Toxic Characteristic Analytes}

For completeness, the summary statistics of non-toxic characteristic target analytes are given in Table 4-4 below.

Table 4-4. First/Second-Stage Sludge Summary Statistics for Analytes Without Regulatory Thresholds.

\begin{tabular}{|c|c|c|c|c|c|c|c|}
\hline & Analyte & $\begin{array}{c}\text { Number of } \\
\text { samples }\end{array}$ & $\begin{array}{c}\text { Number of samples } \\
\text { above MDL }^{\mathrm{a}}\end{array}$ & $\begin{array}{l}\text { Minimum } \\
(\mathrm{mg} / \mathrm{kg})\end{array}$ & $\begin{array}{c}\text { Maximum } \\
(\mathrm{mg} / \mathrm{kg})\end{array}$ & $\begin{array}{c}\text { Mean } \\
(\mathrm{mg} / \mathrm{kg})\end{array}$ & $\begin{array}{c}\text { Standard deviation } \\
(\mathrm{mg} / \mathrm{kg})\end{array}$ \\
\hline \multirow{17}{*}{$\frac{\frac{0}{0}}{\frac{\pi}{0}}$} & 1,1,1-Trichloroethane & 73 & 19 & 0.415 & 1025 & 16.7 & 120 \\
\hline & 1,1,2,2-Tetrachloroethane & 73 & 3 & 0.415 & 5.45 & 0.646 & 0.755 \\
\hline & $\begin{array}{l}\text { 1,1,2-Trichloro- } \\
1,2,2 \text {-Trifluoroethane }\end{array}$ & 73 & 3 & 0.415 & 171 & 2.89 & 20.0 \\
\hline & 1,1,2-Trichloroethane & 73 & 0 & 0.415 & 1.08 & 0.508 & 0.083 \\
\hline & Acetone & 73 & 43 & 0.335 & 14.5 & 2.73 & 3.00 \\
\hline & Bromoform & 73 & 0 & 0.415 & 1.08 & 0.508 & 0.083 \\
\hline & Butanol & 73 & 45 & 0.55 & 39 & 3.36 & 4.99 \\
\hline & Carbon Disulfide & 73 & 0 & 0.415 & 1.08 & 0.508 & 0.083 \\
\hline & Ethyl Ether & 73 & 2 & 0.335 & 4 & 1.37 & 0.634 \\
\hline & Ethylbenzene & 73 & 3 & 0.415 & 27 & 0.951 & 3.14 \\
\hline & Isobutanol & 73 & 9 & 0.468 & 46.5 & 1.59 & 5.50 \\
\hline & m\&p-Xylene & 73 & 5 & 0.415 & 116 & 2.46 & 13.6 \\
\hline & Methanol & 73 & 28 & 0.875 & 62.5 & 6.11 & 11.0 \\
\hline & Methylene Chloride & 73 & 10 & 0.415 & 24.5 & 1.10 & 3.08 \\
\hline & o-Xylene & 73 & 3 & 0.415 & 10.5 & 0.738 & 1.33 \\
\hline & Toluene & 73 & 3 & 0.415 & 53 & 1.23 & 6.14 \\
\hline & Trichlorofluoromethane & 73 & 0 & 0.453 & 10.8 & 4.29 & 1.91 \\
\hline \multirow{2}{*}{$i_{\infty}^{\infty}$} & 2,4-Dinitrophenol & 74 & 0 & 0.047 & 11 & 0.288 & 1.27 \\
\hline & ortho-Dichlorobenzene & 74 & 0 & 0.028 & 6 & 0.138 & 0.692 \\
\hline \multirow{6}{*}{$\frac{\frac{n}{\pi}}{\sum^{\frac{\pi}{0}}}$} & $\mathrm{Be}$ & 75 & 75 & 1.1 & 3400 & 617 & 823 \\
\hline & $\mathrm{Ni}$ & 75 & 75 & 23 & 760 & 115 & 105 \\
\hline & $\mathrm{Sb}$ & 75 & 46 & 0.55 & 79 & 10.7 & 16.2 \\
\hline & $\mathrm{Tl}$ & 75 & 30 & 0.7 & 11 & 2.88 & 2.36 \\
\hline & $\mathrm{V}$ & 75 & 75 & 3.6 & 150 & 25.2 & 27.8 \\
\hline & $\mathrm{Zn}$ & 74 & 74 & 25 & 1600 & 245 & 263 \\
\hline
\end{tabular}

a. When a measurement is reported as below detection, one-half the analysis method detection limit (MDL) is used. Note that the MDL for a given analyte may vary from sample to sample. 


\subsection{WAP Compliant Drum Analysis/Confirmation of Hazardous Waste Codes Assigned}

Based on the results given in Table 4-3, five drums required coring. Seven randomly selected drums from the First/Second-Stage Waste Stream have been cored and analyzed (see Table 1-2) in accordance with the WAP. These drums were randomly selected from the entire waste stream. The final mean and variance estimates and the $\mathrm{UCL}_{90}$ for the mean concentration for each contaminant has been determined and reported in Table 4-5. As shown in Table 4-5 the solified data results agreed well with the preliminary data and AK. The sample size determination are identical to the sample size determined with the preliminary data. Per the WAP, no additional sampling is required. In relation to AK, for those analytes whose $\mathrm{UCL}_{90}$ exceeded the regulatory threshold values the hazardous waste codes have already be added.

\subsubsection{Metals Data Assessment}

Four metals, $\mathrm{Ag}, \mathrm{Cd}, \mathrm{Cr}$, and $\mathrm{Pb}$ were detected at concentrations which exceeded the regulatory threshold (shown in Table 4-3). In each case, the appropriate toxicity code has been previously assigned based on $\mathrm{AK}$. For the remaining metal analytes, the $\mathrm{UCL}_{90}$ could not be determined (see Table 4-5, footnote b) or were at least an order of magnitude below the RTL. As a results, no hazardous waste codes are assigned based on WAP compliant sampling and analysis.

\subsubsection{SVOC Data Assessment}

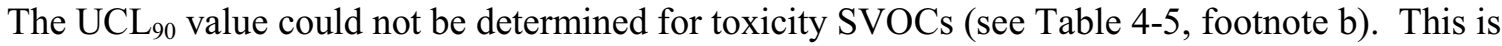
consistent with AK. As a result, no hazardous waste codes are assigned based on WAP compliant sampling and analysis.

\subsubsection{Purgeable VOC Assessment}

The UCL ${ }_{90}$ value could not be determined for toxicity VOCs. No hazardous waste codes will be assigned based on WAP compliant sampling and analysis (see Table 4-5, footnote b). However, AK has assigned F001/F002 code for carbon tetrachloride, chloroform, tetrochloroethylene, and tricholoroethylene. These codes will not be changed.

\subsubsection{NH VOC Assessment}

The UCL S0 $_{90}$ value could not be determined for toxicity NH VOCs (see Table 4-5, footnote b). No hazardous codes will be assigned based on WAP compliant sampling and analysis.

\subsubsection{WAP Compliant Non-Characteristic Analytes}

For completeness, the summary statistics of non-toxic characteristic target analytes are given in Table 4-6. 


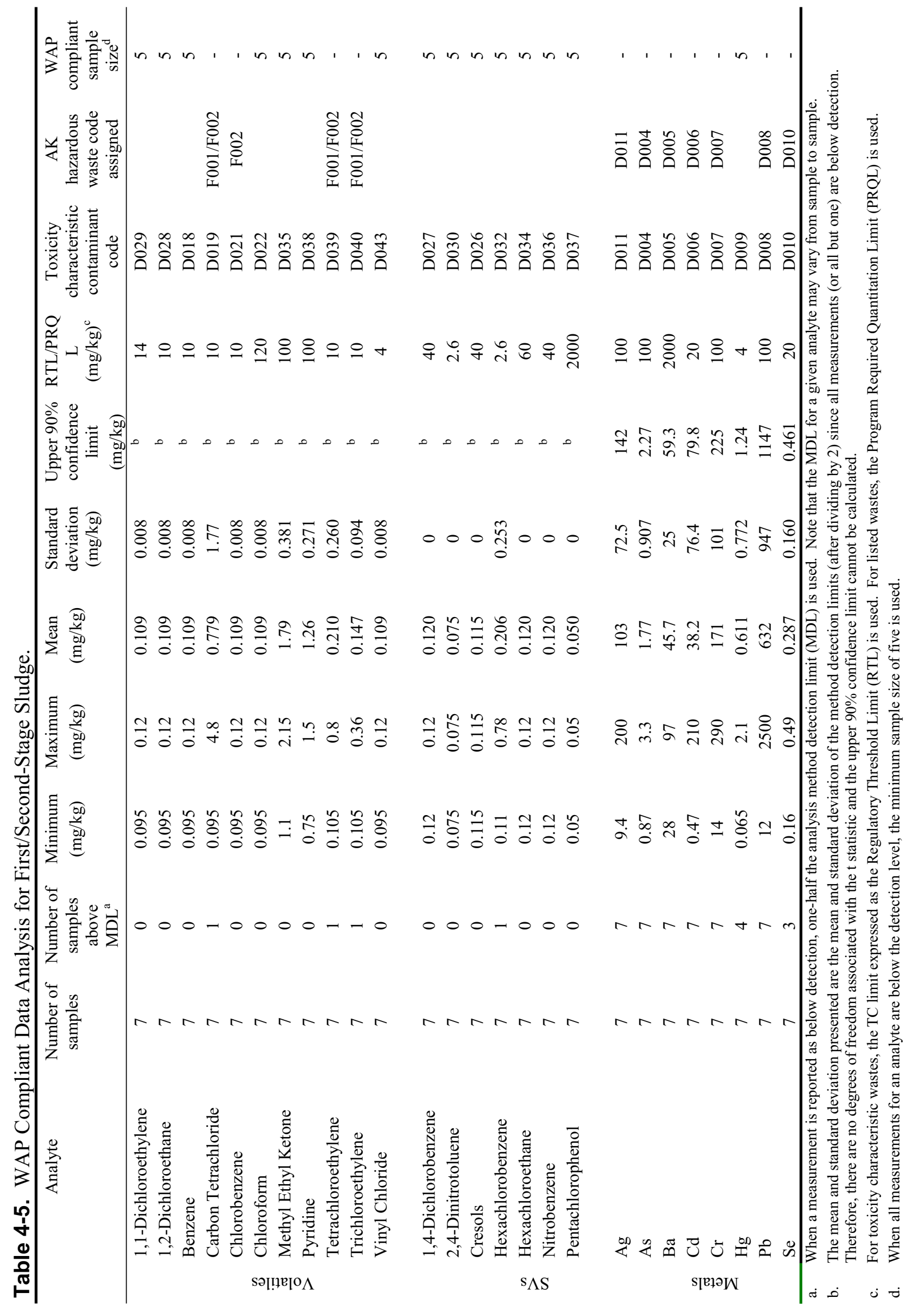




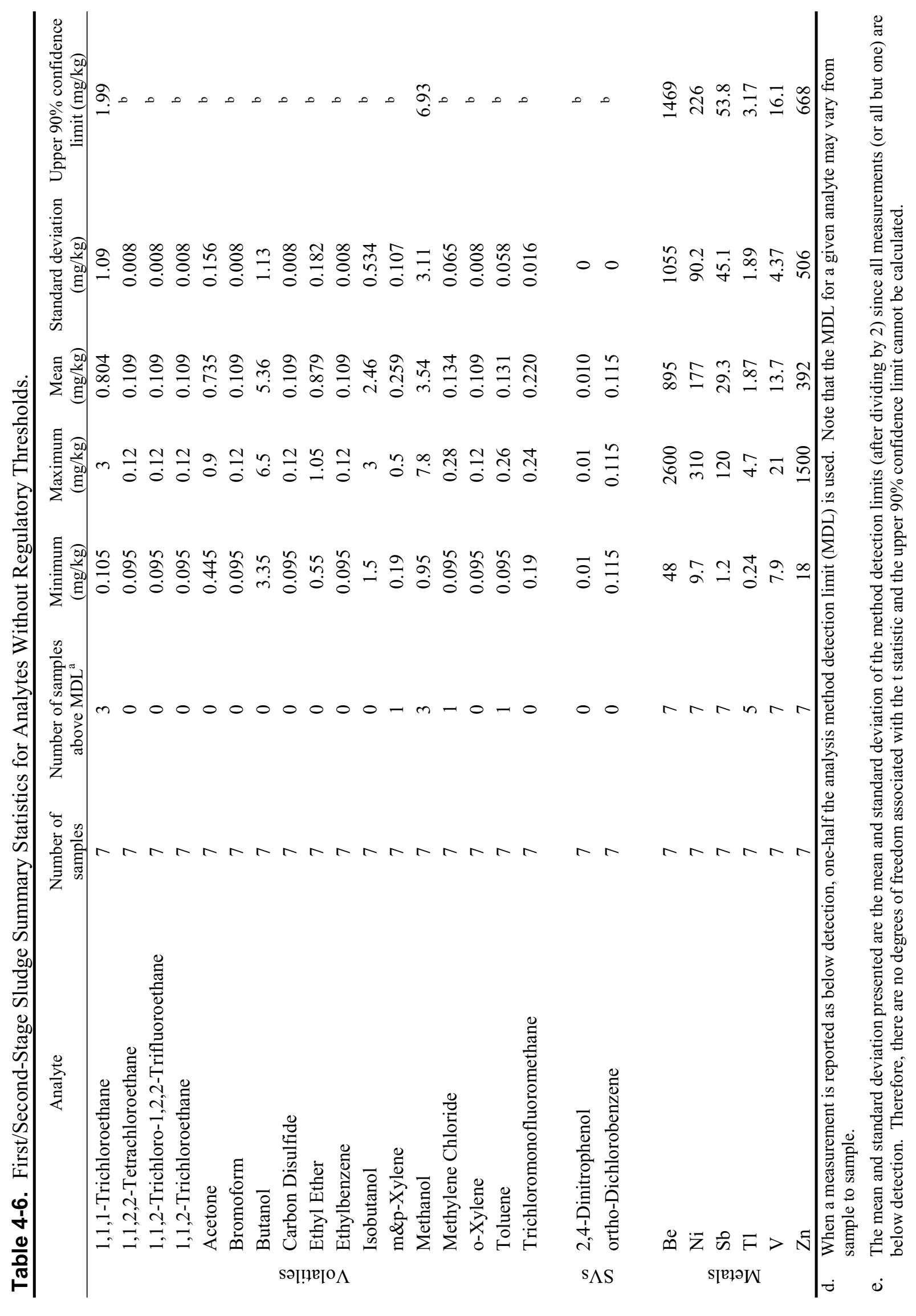




\subsubsection{TIC Assessment}

Given in Table 4-7 is a TIC summary for total SVOC compounds. No Appendix VIII VOC TICs were identified.

Table 4-7. Total SVOC Summary Data - TICs.

\begin{tabular}{|l|c|c|c|}
\hline \multicolumn{1}{|c|}{ TIC } & $\begin{array}{c}\text { Maximum Observed Estimated } \\
\text { Concentrations (mg/kg) }\end{array}$ & $\begin{array}{c}\text { \# of Samples } \\
\text { Containing TIC }\end{array}$ & \% Detected \\
\hline Bis(2-ethylhexyl)phthalate & 3.50 & 6 & 86 \\
\hline Fluoranthene & 9.50 & 3 & 43 \\
\hline Pentachorobenzene & 0.36 & 1 & 14 \\
\hline Phenanthrene & 1.10 & 1 & 18 \\
\hline Phenol & 0.67 & 1 & 14 \\
\hline Phenol,2-Nitro- & 0.40 & 1 & 14 \\
\hline Pyrene & 0.20 & No & \\
\hline $\begin{array}{l}\text { Did the data verify the AK? } \\
\text { If no, describe the basis for assigning the EPA Hazardous Waste Codes: N/A }\end{array}$ \\
\hline
\end{tabular}

a. All of the TICs listed in the above table appear in 40 CFR $\S 261$, Appendix VIII. However, none of these compounds will be added to the target list for this waste stream or will have hazardous waste numbers added. There is no additional solids sampling and analyses planned for this waste stream, therefore new target analytes cannot be added. The hazardous waste codes associated with these TICs are all either K codes (Hazardous waste from specific sources) or U codes (discarded commercial chemical products). These codes are not applicable to waste generated at RFP. 


\section{NONCONFORMANCES}

During the generation of the WAP compliant data, there were four NCRs generated: NCR 20694, 21492, 21262, and 21715. Three errors were identified with the sampling documentation associated with Argonne National Laboratory - West (ANL-W) sampling batch WCS-00-0002 resulting in NCRs 20694, 21492, and 21715. These errors have been corrected and the NCR dispositioned "use-as-is". There is no impact to data use ability. The remaining NCR, NCR 21262, dealt with the RT window for GC analysis. Retention time windows for GC analysis method ACMM-9441 (NH VOCs) used for analysis of samples in Data Report ACL0003N (analytical batch number 00101710) were not determined in accordance with Plan (PLN)-190 and WIPP WAP requirements. PLN-190 and the WAP require that RT windows be determined as plus/minus 3 standard deviations around the mean ICAL standard RTs. Retention times windows calculated by this method are impossibly narrow and cannot be met. The RT windows used were determined per ACMM-9441 by EPA SW-846 recommended protocol, using three standards analyzed over a period of 72 hours. The RT windows were set at plus/minus 3 standard deviations around the mean RT of these three standards for each analyte. Samples were successfully analyzed within the SW-846-determined RT windows.

The WAP requirements for the RT window determination are ambiguous. Use of SW-846 methods is required. Continuing calibration verification (CCV) RT requirements given in Tables B3-5 and B3-7 state that CCV RTs must be within 3 standard deviation from the ICAL. This issue was first identified during the gap analysis performed on WAP requirements in October 1999. ACMM-9441 was revised to comply with SW-846 RT widow determination requirements. This NCR was closed on December 04, 2000. The RT window determination was compliant with Item 9 of the November 28, 2000 Class 1 modification of the WAP. There is no impact to data usability. 


\section{IMPLICATIONS AND FUTURE ACTIONS}

Given the consistency between the preliminary data, AK, and WAP compliant data, the INEEL intends to assign hazardous waste codes for subsequent waste streams based on pre-WAP preliminary data. Use of preliminary data in this manner is believed to be acceptable after assessing for adequacy. Section B2-2a of the WAP states:

The preliminary estimates will be made by obtaining a preliminary number of samples for the waste stream or from previous sampling from the waste stream. Preliminary estimates will be based on samples from a minimum of 5 waste containers. Samples collected to establish preliminary estimates that are selected, sampled, and analyzed (in accordance with applicable provisions of the WAP) may be used as part of the required number of samples to be collected. The applicability of the preliminary estimates to the waste stream to be sampled shall be justified and documented.

WAP Attachment B2 goes on to state:

Upon collection and analysis of the preliminary samples, or at any time after the preliminary samples have been analyzed, the generator/storage site may assign hazardous waste codes to a waste stream. For waste streams with calculated upper confidence limits below the regulatory threshold, the site shall collect the required number of samples if the site intends to establish that the constituent is below the regulatory threshold.

This requirement states that the "required number of samples" must be collected if the generator site "intends to establish that the constituent is below the regulatory threshold." The WAP does not require collection of additional samples when considering constituents that preliminary data indicate are at or above the regulatory threshold, or for constituents where the preliminary data show concentrations below the regulatory threshold for which the site has no intention of establishing that result. In such a case, the waste may still be declared hazardous for the constituent consistent with RCRA regulations. In addition a WIPP WAP hotline question was submitted asking for concurrence with the above interpretation. The response is given below:

Yes, it is acceptable to use the existing preliminary data as the basis for confirming EPA hazardous waste codes. If the waste is determined to be hazardous based on the preliminary data (TRU-mixed) no further sampling is required. However, if the site wishes to demonstrate that the waste is non-hazardous (not TRU-mixed), then a minimum number of samples must be obtained in accordance with WAP equation B2-7.

Therefore, the INEEL TWCP intends to use existing data for subsequent waste streams as the basis for confirming EPA hazardous waste codes. 


\section{CONCLUSIONS}

The pre-WAP data have been found to correlate extremely well with AK and the WAP compliant data. The INEEL has established that the hazardous waste codes assigned to First/Second-Stage Waste Stream are accurate and complete. 


\section{REFERENCES}

AKWSS-99-003, INEEL Acceptable Knowledge Waste Stream Summary First/Second Stage Sludge, 7/13/99.

EPA NO. NM4890 139088, WIPP Part B Permit

INEL-96/0280, AK Document for INEEL Stored Transuranic Waste Rocky Flats Plant Waste

DOE/LLW-2 17, DOE Waste Treatability Group Guidance

EDF-805, Matrix Parameter Category Groups

EDF-922, Identification of Transuranic Waste Streams

EDF-909, Transuranic Waste Sampling Plan for INEEL

EDF-803, Chemical Constituents in Transuranic Storage Area (TSA) Waste

EDF-363, Description of the SWEPP Certified Waste Sampling Program

MCP-2525, Drum Core Sample Plan 


\section{APPENDICES}

Appendix A - Detailed Preliminary Data Assessment

Appendix B - Metals Back-up Data

Appendix C - SVOCs Back-up Data

Appendix D - VOC Back-up Data

Appendix E - NH VOC Back-up Data 


\section{Appendix A}

Detailed Preliminary Data Assessment 


\section{Detailed Preliminary Data Assessment}

Preliminary data generated under the Quality Assurance Program Plan (QAPP) and prior to the final Waste Analysis Plan (WAP) has been assessed. Per the WAP, preliminary data provides an estimated of additional sampling required to characterize a waste stream. The preliminary data assessed in this section will be used to estimate additional WAP compliant sampling. The waste stream addressed by this preliminary data is the First/Second-Stage Sludge Waste Stream, Item Description Codes (IDCs) 001,002 , and 800 .

Preliminary data were generated using the same SW-846 methods used to generate the WAP compliant data discussed in the body of this document. Precision and accuracy performance indicators are addressed individually in the following sub-sections by analytical method, such as, metals, semi-volatile organic compounds (SVOCs), total volatile organic compound (VOCs), and non-halogenated (NH) VOCs. The indicators include matrix independent, such as, laboratory control samples (LCS) and matrix dependent performance indicators, that is, matrix spikes (MS), matrix spike duplicates (MSDs) and surrogates (where applicable). Recoveries were compiled and average recoveries calculated by analyte as well as relative percent differences (RPDs) as appropriate. Error bars associated with the recovery averages were set at one standard deviation. These data are provided in tables and figures throughout Appendices A through E.

\section{A-1. PRELIMINARY METALS DATA: DATA USE ASSESSMENT}

As expected, several metals were detected at significant quantities throughout the preliminary data set associated with this waste stream. The data has been assessed from a waste stream perspective, that is, waste stream averages for the performance indicators were assessed for overall use of the data. Data results for individual elements whose averages and associated error indicated a potential bias are discussed individually and compared to AK expectations wherever possible.

The MS/MSD and LCS results discussed are summarized using a combination of tables and graphs. Figure M-1 depicts the average percent recoveries of each element for the MS/MSD pairs. The RPD for the MS/MSDs are included. The LCS results are illustrated in Figure M-2 and summarized in Table M-1. The data used to generate these graphs are presented by element in Table M-2. A standard deviation was determined and an error bar tied to each average data point. 
Table M-1. ACL Metals Quality Control Average Percent Recovery of Metals MSs and MSDs.

\begin{tabular}{ccccc}
\hline Element & $\begin{array}{c}\text { MS/MSD } \\
\text { (\% Recovery) }\end{array}$ & $\begin{array}{c}\text { MS/MSD } \\
\text { Standard Deviation }\end{array}$ & RPD & Data Points (n) \\
\hline $\mathrm{Sb}$ & 67.5 & 15.08 & 10.3 & 30 \\
$\mathrm{As}$ & 98.1 & 6.1 & 3.10 & 30 \\
$\mathrm{Ba}$ & 98.0 & 4.7 & 2.93 & 30 \\
$\mathrm{Be}$ & 136.4 & 173.0 & 5.87 & 30 \\
$\mathrm{Cd}$ & 81.7 & 24.6 & 8.54 & 30 \\
$\mathrm{Cr}$ & 102.3 & 49.9 & 7.66 & 30 \\
$\mathrm{~Pb}$ & 90.3 & 28.9 & 8.13 & 30 \\
$\mathrm{Hg}$ & 99.5 & 17.7 & 4.06 & 30 \\
$\mathrm{Ni}$ & 86.6 & 18.1 & 6.07 & 30 \\
$\mathrm{Se}$ & 97.2 & 7.0 & 5.65 & 30 \\
$\mathrm{Ag}$ & 99.4 & 12.0 & 4.33 & 30 \\
$\mathrm{Tl}$ & 79.2 & 7.3 & 2.71 & 30 \\
$\mathrm{~V}$ & 93.5 & 3.3 & 2.16 & 30 \\
$\mathrm{Zn}$ & 104.6 & 36.1 & 5.89 & 30 \\
\hline
\end{tabular}

Table M-2. ACL Metals Quality Control Average Percent Recovery of Laboratory Control Samples.

\begin{tabular}{cccc}
\hline Element & LCS (\% Recovery) & LCS Standard Deviation & Data Points $(\mathrm{n})$ \\
\hline $\mathrm{Sb}$ & 106.2 & 35.7 & 35 \\
$\mathrm{As}$ & 100.5 & 6.0 & 37 \\
$\mathrm{Ba}$ & 96.2 & 11.2 & 37 \\
$\mathrm{Be}$ & 100.8 & 5.6 & 37 \\
$\mathrm{Cd}$ & 101.4 & 9.5 & 37 \\
$\mathrm{Cr}$ & 99.2 & 6.7 & 37 \\
$\mathrm{~Pb}$ & 101.3 & 8.2 & 37 \\
$\mathrm{Hg}$ & 112.7 & 8.1 & 22 \\
$\mathrm{Ni}$ & 100.8 & 6.8 & 37 \\
$\mathrm{Se}$ & 102.0 & 6.2 & 37 \\
$\mathrm{Ag}$ & 100.6 & 6.6 & 37 \\
$\mathrm{Tl}$ & 99.0 & 12.8 & 37 \\
$\mathrm{~V}$ & 101.4 & 8.0 & 37 \\
$\mathrm{Zn}$ & 102.5 & 12.3 & 37 \\
\hline
\end{tabular}




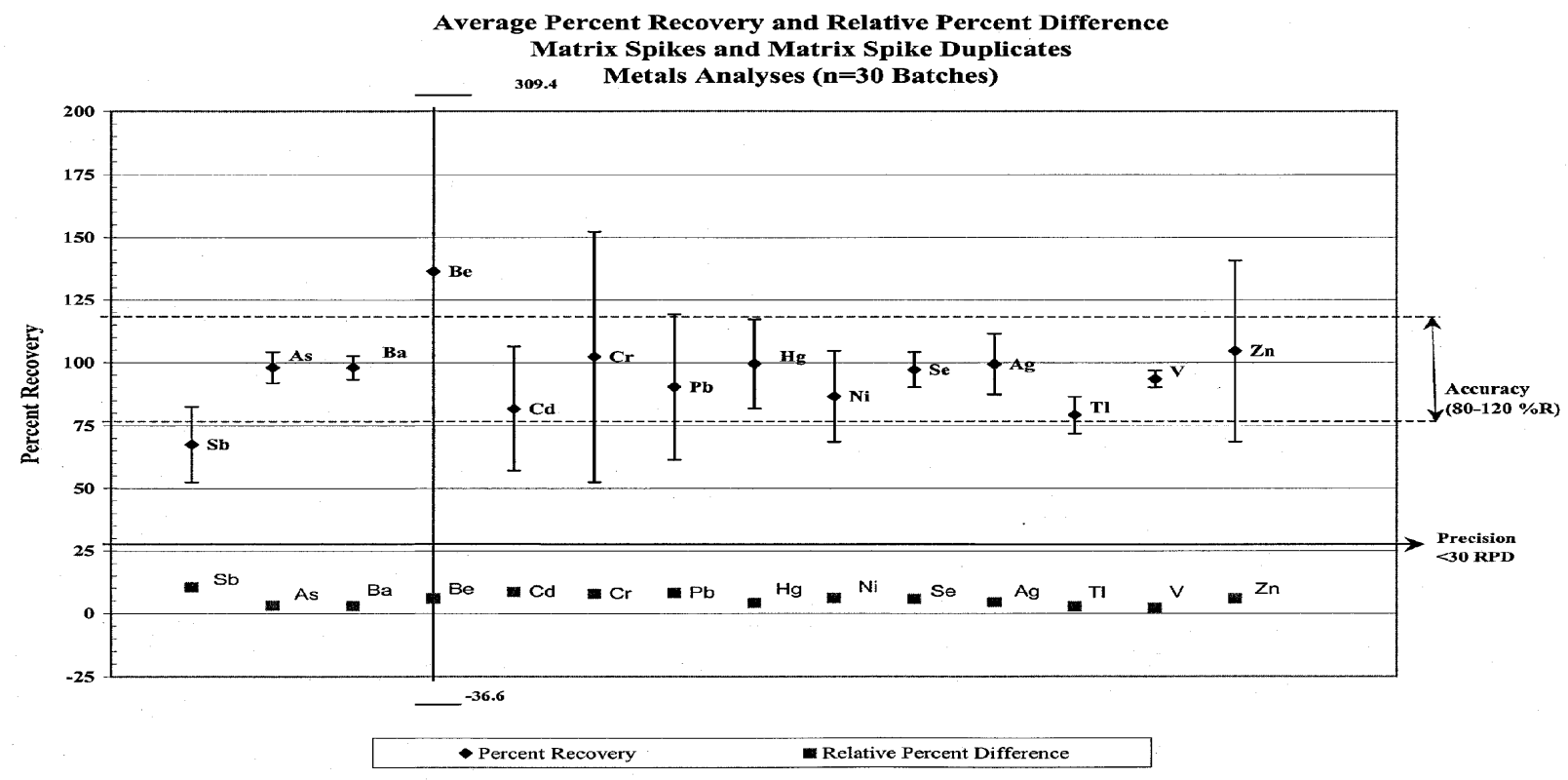

Figure M-1. Average Percent Recovery and RPD MSs and MSDs Metals Analyses

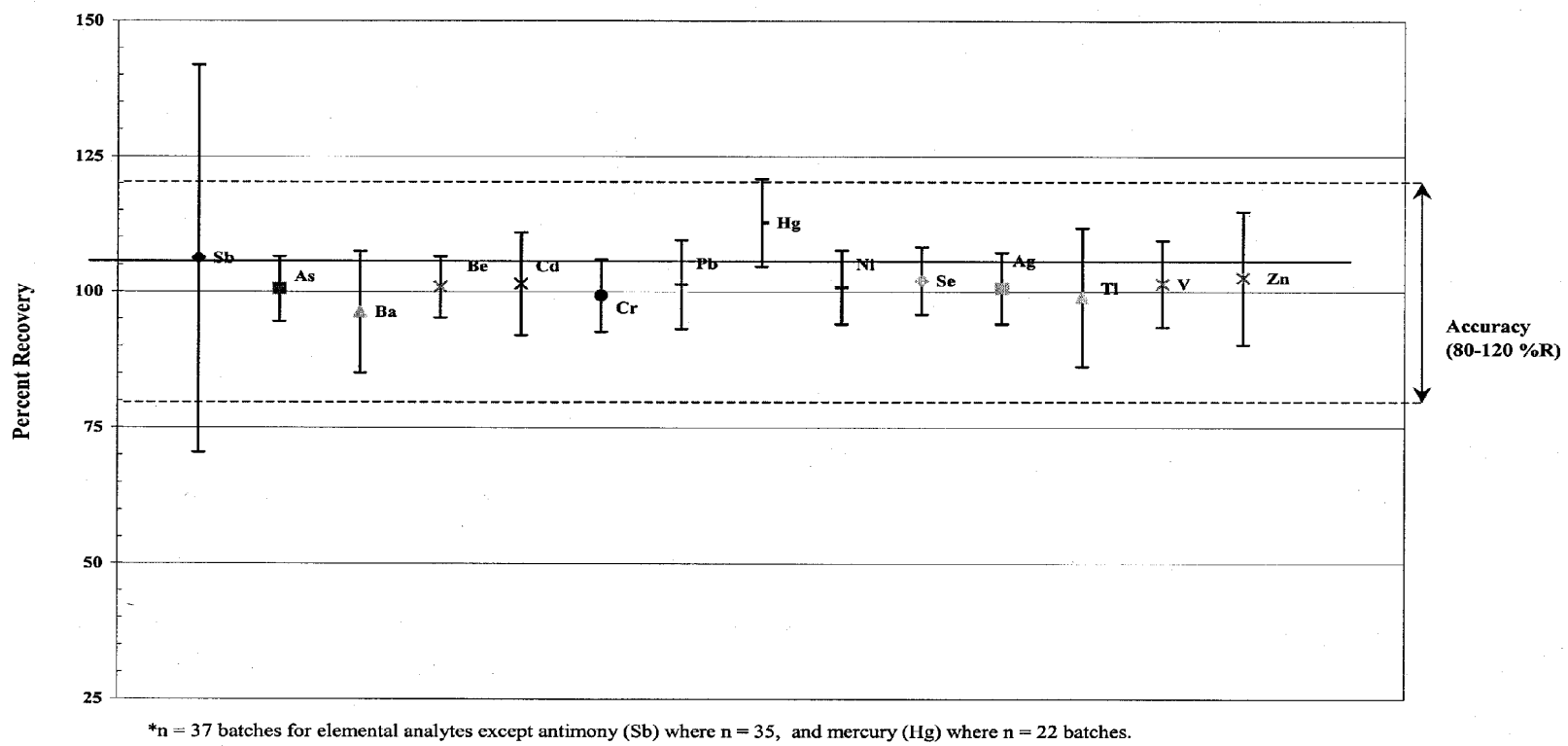

Figure M-2. Average Percent Recovery LCSs Metals Analyses.

The detailed Quality Control (QC) data by element are provided in Appendix B, Table B-1 for the MS/MSD and LCS data. The summary provided by Table B-1, Appendix B, allows a quick view of all the data associated with each element. Those data that individually did not meet WAP criteria are bolded.

Elements that reflected problems from a waste stream average perspective are discussed in Section A-1.1, first, from the matrix effects indicated, and second from a laboratory control perspective. Data use conclusions are included where appropriate. 


\section{A-1.1 Preliminary Metals Data: MS/MSD Data Assessment}

Table M-1 reflects the calculated averages (herein referred to as the waste stream average) with the associated error, and RPDs associated with the MS/MSD results by element. Fifteen MS/MSD pairs, or 30 data points, were used to calculate these averages. While MS/MSDs were run for every batch, the MS/MSDs from solidified wastes other than IDCs 001, 002, or 800 were not considered in this assessment. The data and associated error bars are represented in Figure M-1 by element, with the WAP acceptance limits indicated. Figure M-1 includes the acceptance limits for both recovery and RPD. Note that if the average RPD is below the acceptance limit shown on the graph, the data meet RPD criteria. Elements that, based on the MS/MSD average recoveries and/or associated error bars, do not meet the WAP criteria are discussed individually below. The base assumption is a bias is indicated if either the average or the error bar fall outside the WAP limits.

Antimony ( $\mathrm{Sb}$ ), which is not a toxicity characteristic (TC) element, is biased low (see Figure M-1). As shown, the waste stream MS/MSD average and associated error fall below the WAP acceptance criteria. Analysis of this element is difficult and recovery problems are not an uncommon occurrence. The summarized data in Appendix B, Table B-1 for Sb reflects that this element is problematic across all batches. The Sb data has a potential $30-50 \%$ low bias due to matrix effects. However, because this element does not effect the characterization of this waste stream from a waste stream profile perspective (such as, force the consideration of a RCRA code addition), no further discussion is necessary.

Beryllium (Be), also not a TC element, MS/MSD data reflect a large standard deviation (therefore a large error bar) and an average above the WAP criteria. The reason for this apparent variability in the recovery data is the concentration levels of Be found in the spiked samples. The concentration of Be in the samples spiked for MS/MSDs was significantly higher ( $>4$ times the spiking level -commonly referred to as the $4 \mathrm{X}$ rule) than the spike concentration. Because of this, the spikes are essentially hidden by the Be concentration in the sample. The Functional Guidelines recognizes this consequence of high sample analyte concentrations, and when the $4 \mathrm{X}$ rule applies to MS/MSD results, data is accepted "as-is" with no data use flag applied. Therefore, these data are sound for this intended use and may be used "as-is".

Cadmium (Cd) MS/MSD data reflect a possible low bias as indicated by the fact that the error bar falls below the WAP criteria. However, the waste stream MS/MSD average is within the WAP limit. Since this element was detected in the samples [the mean sample concentration for the whole waste stream is at approximately $1 / 2$ of the regulatory threshold limit (RTL)], and the MS/MSD data indicate a low bias, the data should be considered carefully (such as, possibly adding the D006 code). The addition of the code could negate the need for additional sampling and is an expected code per AK. The WAP compliant data will verify whether the code should be added.

Chromium (Cr) MS/MSD data reflects a fairly high variance as indicated by the error bar associated with the average. The waste stream average MS/MSD recovery is well within the WAP criteria. The levels of $\mathrm{Cr}$ in the samples that were spiked is significant, and was often present at $>4 \mathrm{X}$ the spiking levels, which would account for the spread in the data. High background levels of a target analyte will mask added spikes that are $<4$ times the background level. As stated previously, data may be used "as is" when MS/MSD recovery problems are due to high background levels of the analyte. These data are appropriate for preliminary data use. The mean concentration of $\mathrm{Cr}$ in the waste stream exceeds the TC limit and based on this preliminary data the D007 code should be added. The WAP compliant data and AK will be used to verify this conclusion. 
The MS/MSD lead $(\mathrm{Pb})$ waste stream average recovery is within the WAP criteria. Low bias is indicated since the lower end of the error bar falls below the criteria. The concentration of $\mathrm{Pb}$ in the spiked samples often exceeded 4 times the spiking level as well, which results in a recovery problem. The spike added was masked by a high background concentration of the analyte. The mean $\mathrm{Pb}$ concentration in the preliminary data exceeded the RTL. Therefore, the D008 code would apply. The WAP compliant drum data will be used to verify this conclusion which is consistent with AK expectations.

Nickel (Ni) is not a toxicity characteristic element. The average MS/MSD recovery is within the WAP criteria. The error associated with the average indicates a low bias, approximately $10 \%$. Since this element is not a TC element, the low bias has no negative impact on data use.

The average recovery for zinc $(\mathrm{Zn})$ falls within the WAP criteria. The error associated with the average extends outside the WAP criteria on both the high and low ends of the range. This is due to the fact that $\mathrm{Zn}$ concentrations in many of the spiked samples were significantly $(>4 \mathrm{X})$ higher than the spiking levels. Since it is not a TC element, no further discussion is necessary.

As reflected Figure M-1, the RDPs meet the WAP precision criteria for every element.

\section{A-1.2 Preliminary Metals Data: LCS Assessment}

The WAP, Table B3-8 footnote $b$, allows the laboratory to establish acceptance criteria for solidified waste LCSs. That is to say that solid LCS samples are not held to the $\pm 20 \%$ criteria. While Figure M-2 uses the $\pm 20 \%$ criteria for result comparison purposes, this figure must be interpreted carefully. Every LCS result generated by the laboratory for this preliminary data was within the laboratory established acceptance criteria, as allowed by the WAP. These data indicate that the laboratory was operating in control during the analysis of all the preliminary samples associated with the wastewater treatment sludge waste stream.

\section{A-2 Preliminary SVOC Data: Data Use Assessment}

The SVOC data have been assessed from a waste stream perspective, such as, waste stream averages, for the performance indicators MS/MSD and LCS. The performance of these indicators will demonstrate whether the preliminary SVOC data can be used for an assessment of additional sampling needs and/or waste stream profile conclusions. Data results for individual compounds whose averages indicate a potential bias, such as, the averages and/or associated error fall outside the WAP criteria, are discussed individually and compared to AK expectations wherever possible.

The MS/MSD and LCS are summarized using a combination of tables and graphs. The average data used to generate the MS/MSD graphs, Figures SV-1 and SV-2 are presented in Table SV-1. The figures contain the percent recoveries for the MS/MSDs and the RPDs respectively. The LCS results are illustrated in Figure SV-3 and summarized in Table SV-2 The data used to generate the LCS and MS/MSD graphs are presented by compound in Appendix C, Table C-1. The summary provided by Table C-1, Appendix C, allows a quick view of all the data associated with each compound. Those data that individually did not meet WAP criteria are bolded. 
Table SV-1. ACL SVOCs Quality Control Average Percent Recovery of VOCs MS/MSDs.

\begin{tabular}{lcccc}
\multicolumn{1}{c}{ Compound } & $\begin{array}{c}\text { \% Recovery } \\
\text { MS/MSD }\end{array}$ & $\begin{array}{c}\text { MS/MSD } \\
\text { Standard Deviation }\end{array}$ & RPD & Spikes (n) \\
\hline 1,4-Dichlorobenzene & 48.1 & 15.5 & 24.4 & 20 \\
2,4-Dinitrotoluene & 56.4 & 12.9 & 25.9 & 20 \\
Hexachloroethane & 50.5 & 16.6 & 24.5 & 20 \\
Nitrobenzene & 50.5 & 17.0 & 26.3 & 20
\end{tabular}

Table SV-2. ACL SVOCs Quality Control Average Percent Recovery of SVOCs LCSs.

\begin{tabular}{lccc}
\multicolumn{1}{c}{ Compound } & \% Recovery LCS & LCS Standard Deviation & Count (n) \\
\hline 1,4-Dichlorobenzene & 96.7 & 19.1 & 21 \\
2,4-Dinitrophenol & 106.5 & 4.9 & 2 \\
2,4-Dinitrotoluene & 87.0 & 18.4 & 21 \\
Hexachlorobenzene & 95.4 & 3.7 & 2 \\
Hexachloroethane & 96.6 & 15.8 & 21 \\
m/p-Methylphenol & 92.5 & 3.5 & 2 \\
Nitrobenzene & 92.0 & 22.0 & 22 \\
o-Methylphenol & 98.7 & 8.5 & 3 \\
o-Dichlorobenzene & 95.9 & 4.0 & 3 \\
Pentachlorophenol & 100.0 & 26.7 & 3
\end{tabular}

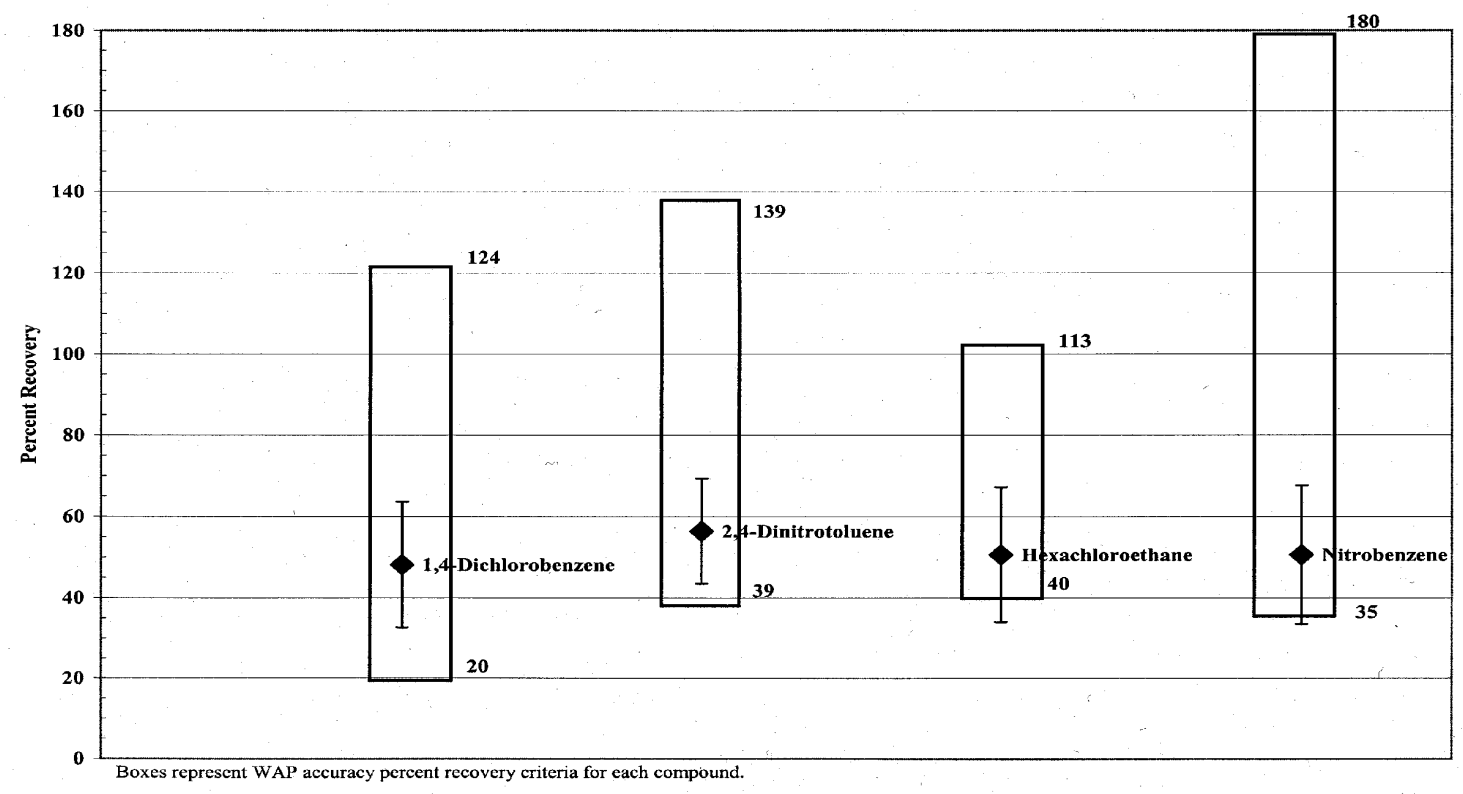

Figure SV-1. Average Percent Recovery MS/MSDs SVOCs Analyses ( $\mathrm{n}=20$ ). 


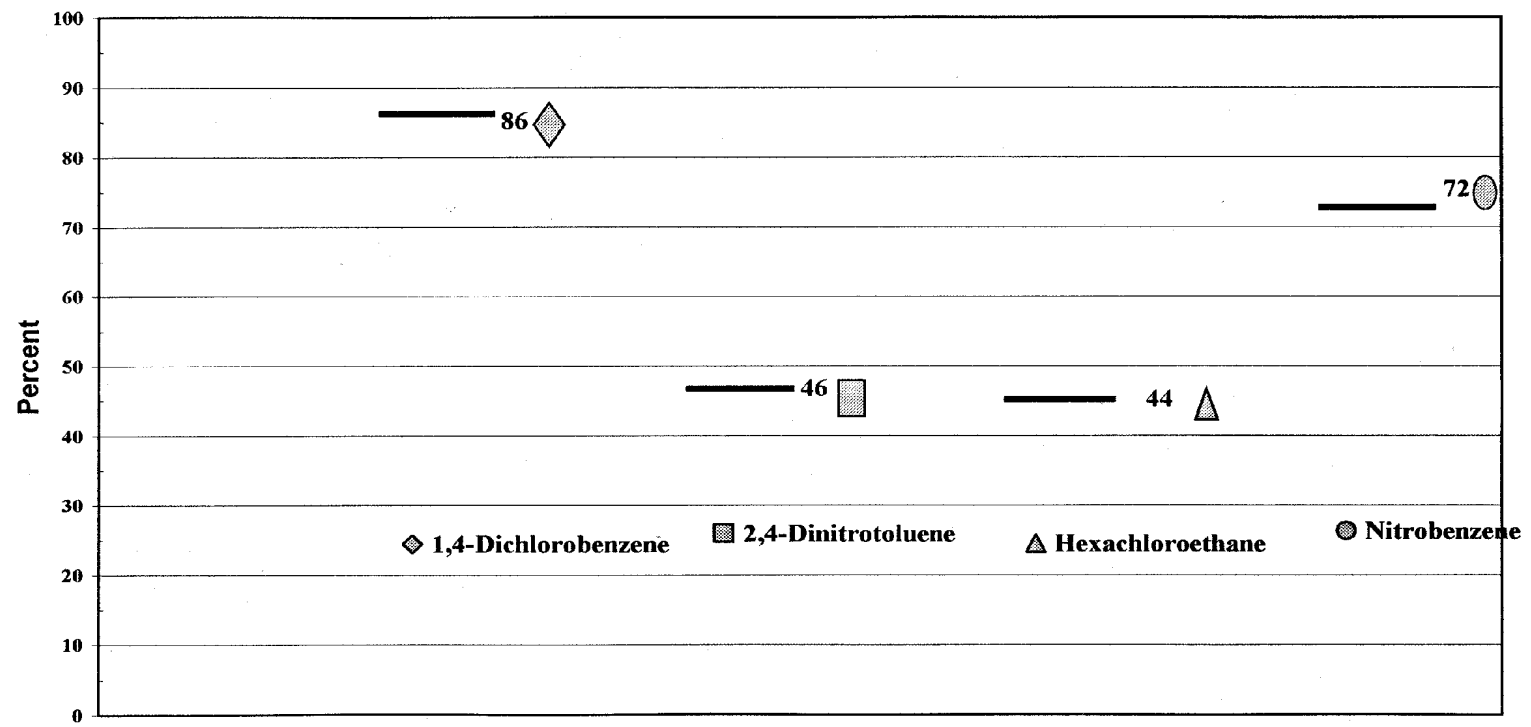

Horizontal bars represent WAP precision criteria for relative percent difference of each compound. ( $<$ RPD)

Figure SV-2. Average RPD MS/MSDs SVOCs Analyses (N=20).

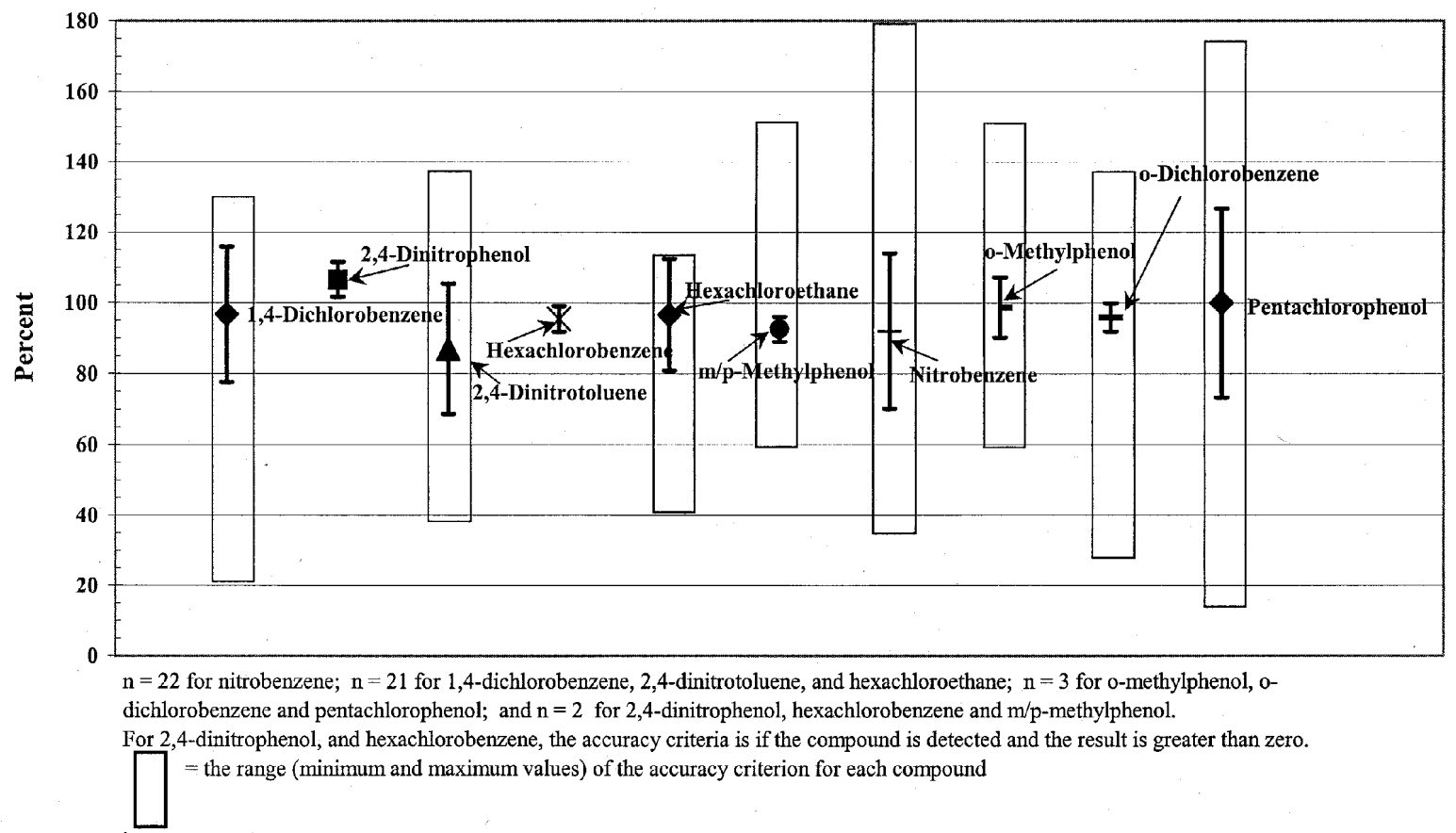

Figure SV-3. Average Percent Recovery LCSs SVOCs Analyses.

Compounds that reflected problems from a waste stream average perspective are discussed individually below, first, from the matrix effects indicated, and second from a laboratory control perspective. 


\section{A-2.1 Preliminary SVOC Data: MS/MSD Data Assessment}

All the average MS/MSD data points were within the WAP criteria for each spiked compound. All of the RPD averages met criteria, as shown Figure SV-2. Figure SV-1 shows a potential low bias due to the error associated with the hexachloroethane MS/MSD average data. This low bias was the result of low recoveries in Batches ACL96005SV, ACL97004SV, and ACL97009SV.

Hexachloroethane MS/MSD performance data reflecting a low bias is summarized below. The sample results for this analyte were all non-detects. The mean sample-specific detection limit concentration of this compound in the waste stream is three orders of magnitude below the RTL. Based in this performance indicator, the data are appropriate for use as preliminary data for the assessment of sampling requirements. Batches that indicated a matrix effect are addressed below:

- Batch ACL96005SV - The MS/MSD average recovery was within WAP limits, but the error bar fell below the criteria. The potential low bias is approximately $10 \%$. The sample results for this compound were all non-detects. Holding times were exceeded from extraction to analysis (by 20 days). However, since the hexachloroethane data from this batch are comparable to data generated in other batches, the bias appears to be independent of the holding time issue. The probability of analyte loss from the extract is low, and therefore the data are appropriate for use as preliminary data.

- $\quad$ Batch ACL97004SV - This batch reflects an approximate 5-12\% low bias on the MS/MSD; all samples in the batch were non-detects. The data are useable as preliminary data.

- $\quad$ Batch ACL97009SV - the MS/MSD data was biased low by 3-10\%. All samples in this batch were non-detects for this compound. The data are useable as preliminary data.

The RPD averages, as shown in Figure SV-2, for the MS/MSDs meet the WAP criteria without exception. Note that if the averages are below the solid lines on the graph, the compound RPD is acceptable.

\section{A-2.2 Preliminary SVOC Data: Surrogate Compound Data Assessment}

The surrogate averages from IDC 001, 002, and 800 samples are addressed in the following section by surrogate compound. Table SV-4 summarizes and Figures SV-4 through SV-7 illustrate surrogates nitrobenzene-d5 (NBZ), 2-fluorobiphenyl (FBP), 2-fluorophenol (2FP), and 2,4,6-tribromophenol (TBP), respectively. The data were compiled, the mean and standard deviation determined, and acceptance limits set at 3 sigma. The NBZ surrogate recoveries fall within the established criteria for all batches. Surrogates for which some data points fell outside the acceptance criteria are addressed individually below.

Surrogate FBP recoveries, Figure SV-5, fell within the 3 sigma acceptance criteria with the exception of one data point which fell just above the upper limit. Since the bias indicated by this is high (the data point could be an outlier), use of the data is conservative. 


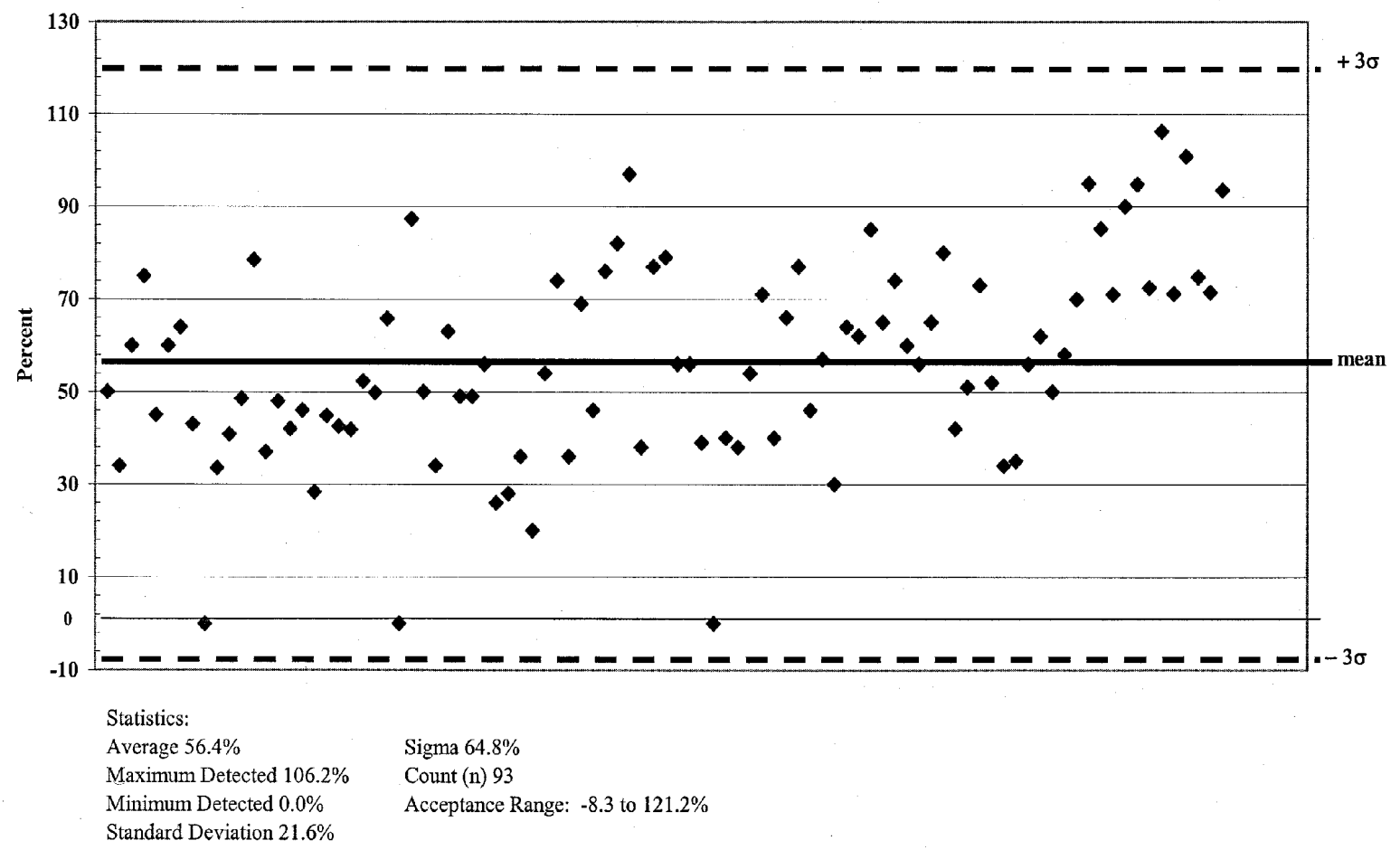

Figure SV-4. Average Percent Recovery of SVOCs Analyses Surrogate Nitrobenzene-d5 (NBZ).

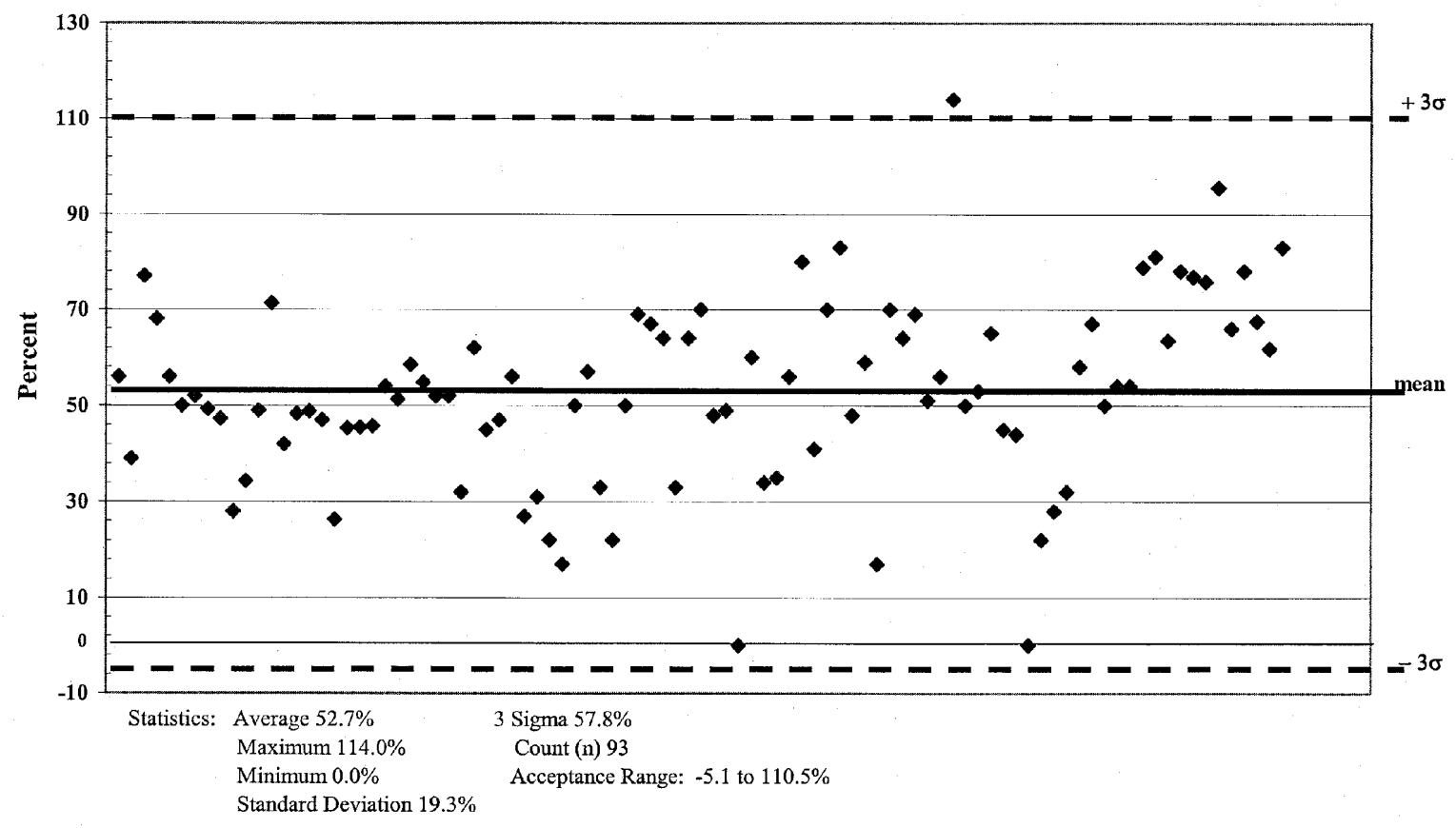

Figure SV-5. Average Percent Recovery of SVOCs Analyses Surrogate 2-Fluorobiphenyl (FBP). 


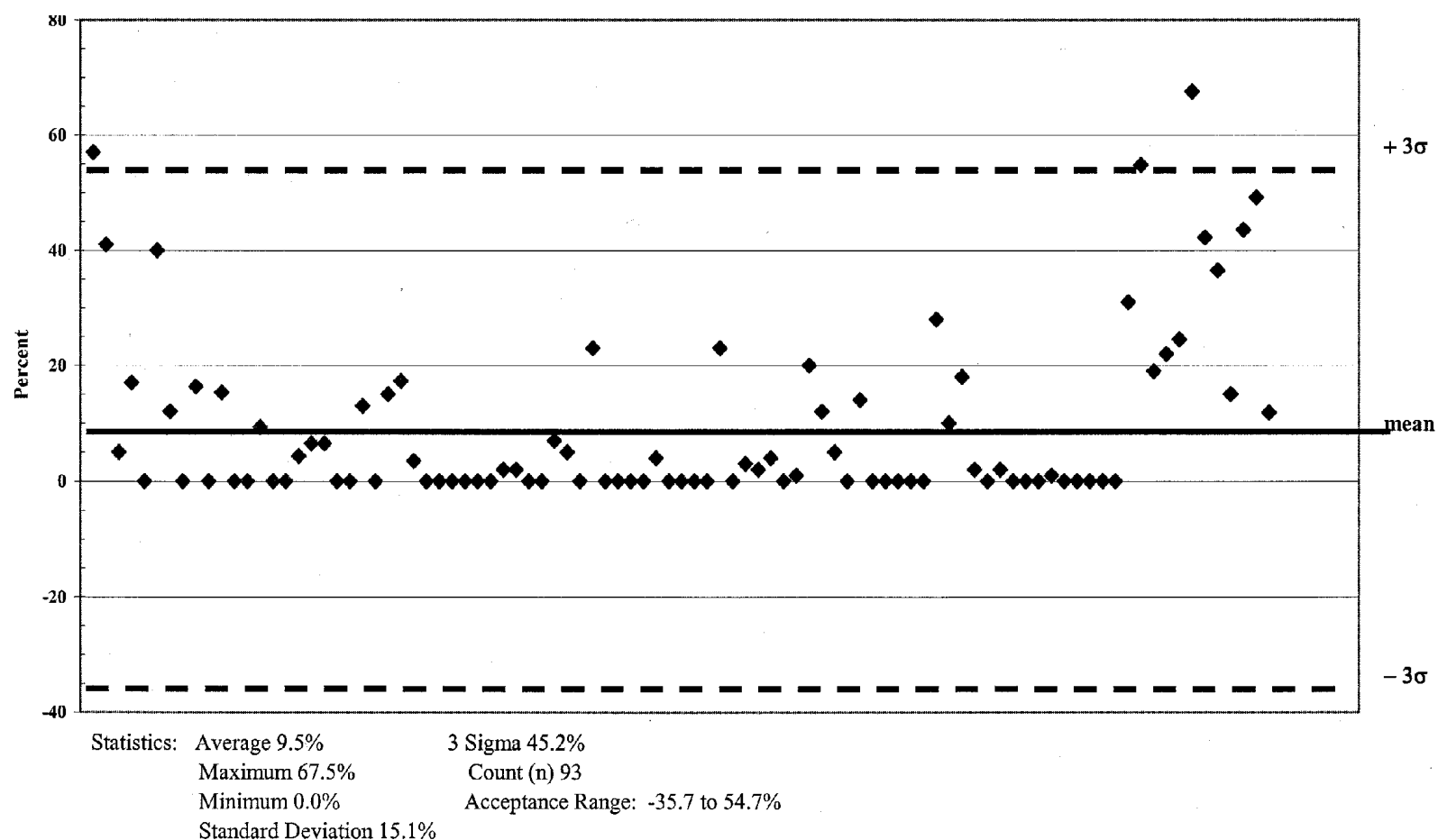

Figure SV-6. Average Percent Recovery of SVOCs Analyses Surrogate 2-Fluorophenol (2FP).

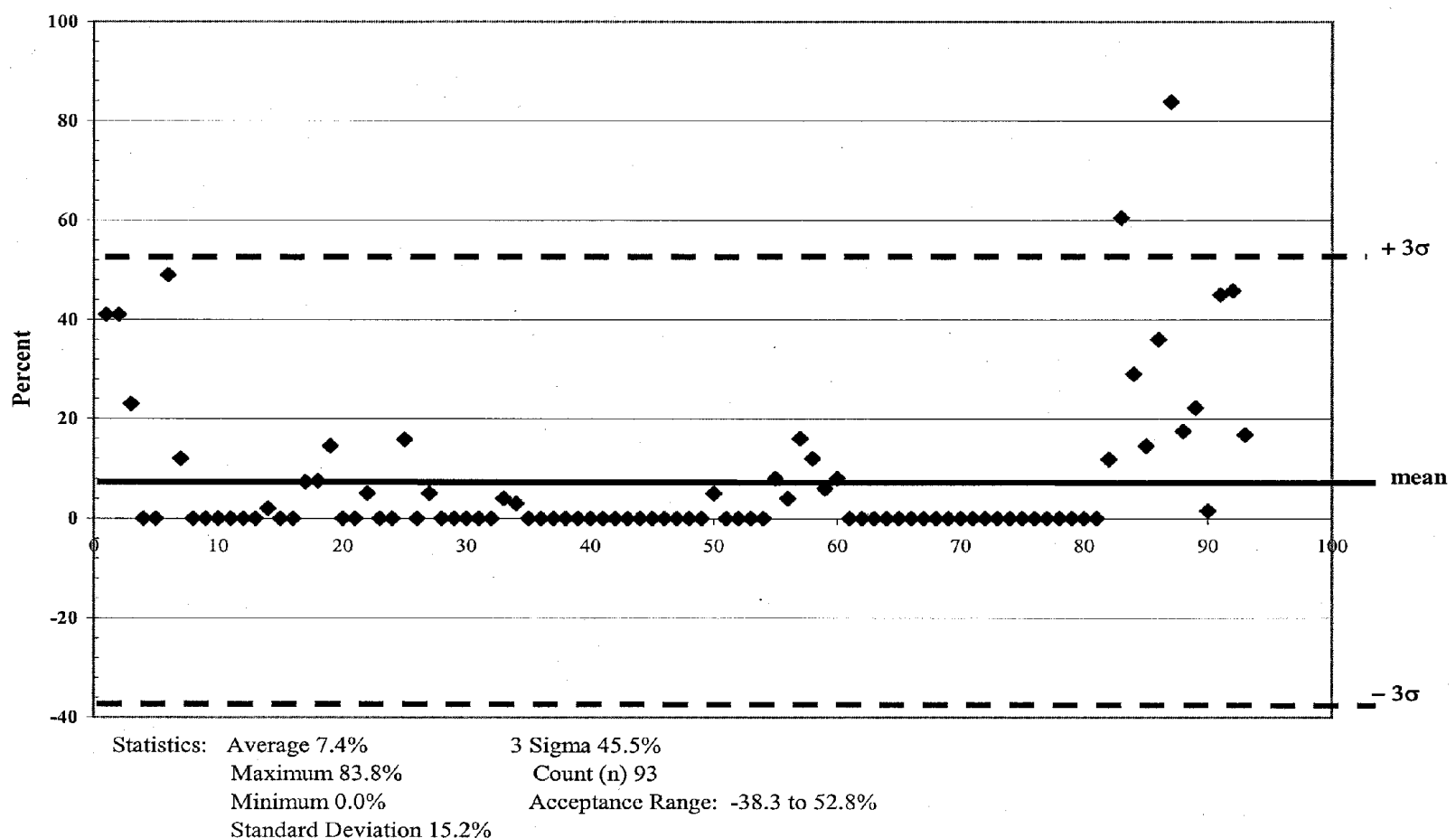

Figure SV-7. Average Percent Recovery of SVOCs Analyses Surrogate 2,4,6-Tribromophenol (TBP). 
Recovery of surrogate 2FP was generally low as shown in Figure SV-6. The established acceptance criteria, per the WAP, falls below $0 \%$, indicating that the low bias is expected and acceptable. Three data points actually fall above the upper acceptance criteria value, indicating some high bias in the data. However, the general trend, while acceptable, was low recovery of this surrogate. Phenol data could be biased low in general for this waste stream.

Figure SV-7 details the performance of TBP. The general bias for this surrogate is low, however, all recoveries fall within the 3 sigma acceptance criteria established for this data. Two data points actually fell above the +3 sigma criteria. However, because the recoveries, while acceptable, were generally low, all phenols may be biased low for this waste stream.

\section{A-2.3 Preliminary SVOC Data: LCS Data Assessment}

All averages and associated standard deviations for the LCS, as shown in Appendix B, Figure SV-3, meet the WAP criteria.

\section{A-3. Preliminary Purgeable VOC Data: Data Use Assessment}

The purgeable VOC data have been assessed from a waste stream perspective, such as, waste stream averages, for the performance indicators MS/MSD, LCS, and surrogates. The performance of these indicators will demonstrate whether the preliminary VOC data can be used to assess additional sampling needs and/or impacts to the waste stream profile. Data results for individual compounds whose averages indicate a potential bias, such as., the averages and associated error bars fall outside the WAP criteria, are discussed individually and compared to AK expectations wherever possible.

The MS/MSD and LCS results discussed in this appendix are summarized using a combination of tables and graphs. The average data used to generate the MS/MSD graph, Figure V-1, are presented in Table V-1. Figure V-2 reflects the RPD results for the MS/MSD averages. The LCS results are illustrated in Figure V-3 and summarized by compound in Table V-2. The data used to generate these graphs are presented by compound in Appendix D, Tables D-1 and D-2. The summaries provided by Tables D-1 and D-2, Appendix D, allow a quick view of the data associated with each compound. Those data that individually did not meet WAP criteria are bolded.

Table V-1. ACL VOCs Quality Control Average Percent Recovery of VOCs MS/MSDs.

\begin{tabular}{lcccc} 
Compound & $\begin{array}{c}\text { \% Recovery } \\
\text { MS/MSD }\end{array}$ & $\begin{array}{c}\text { MS } \\
\text { Standard Deviation }\end{array}$ & RPD & Count (n) \\
\hline 1,1-Dichloroethylene & 104.6 & 77.4 & 30.1 & 26 \\
Benzene & 85.2 & 4.8 & 4.0 & 26 \\
Chlorobenzene & 96.8 & 11.4 & 4.4 & 24 \\
Toluene & 95.2 & 8.6 & 5.1 & 24 \\
Trichloroethylene & 87.3 & 8.8 & 7.7 & 24
\end{tabular}


Table V-2. ACL VOCs Quality Control Average Percent Recovery of VOCs LCSs.

LCS LCS

Compound

$\%$ Recovery

91.7

Standard Deviation

10.7

11.7

18.2

7.0

7.5

6.6

5.4

6.7

17.0

13.6

100.4

Toluene

o-Xylene

97.5

89.4

13.6

Count (n)

24

24

24

23

24

24

24

24

24

24

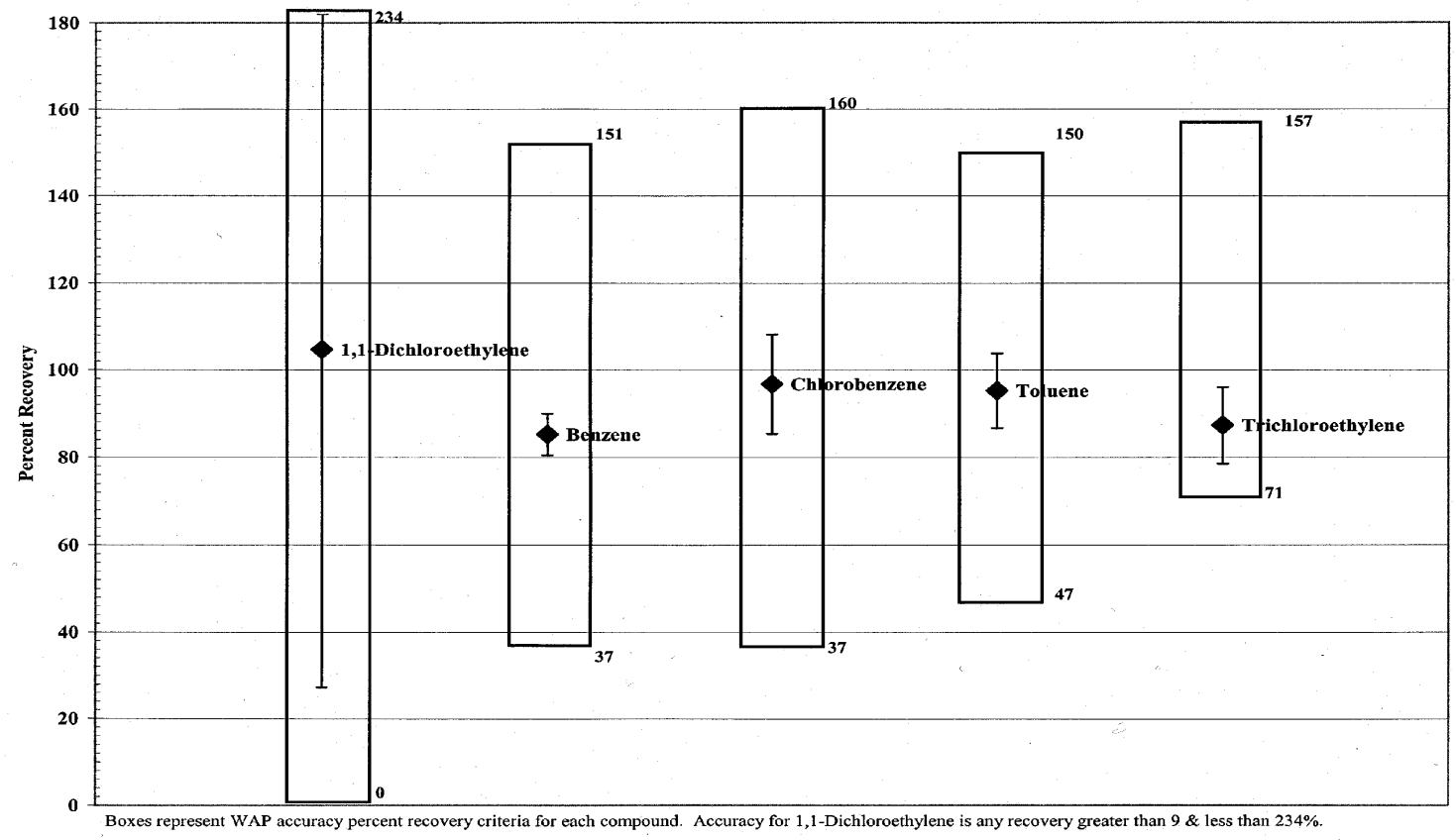

Figure V-1. Average percent recovery MS/MSDs VOC analyses ( $\mathrm{n}=24$ batches). 


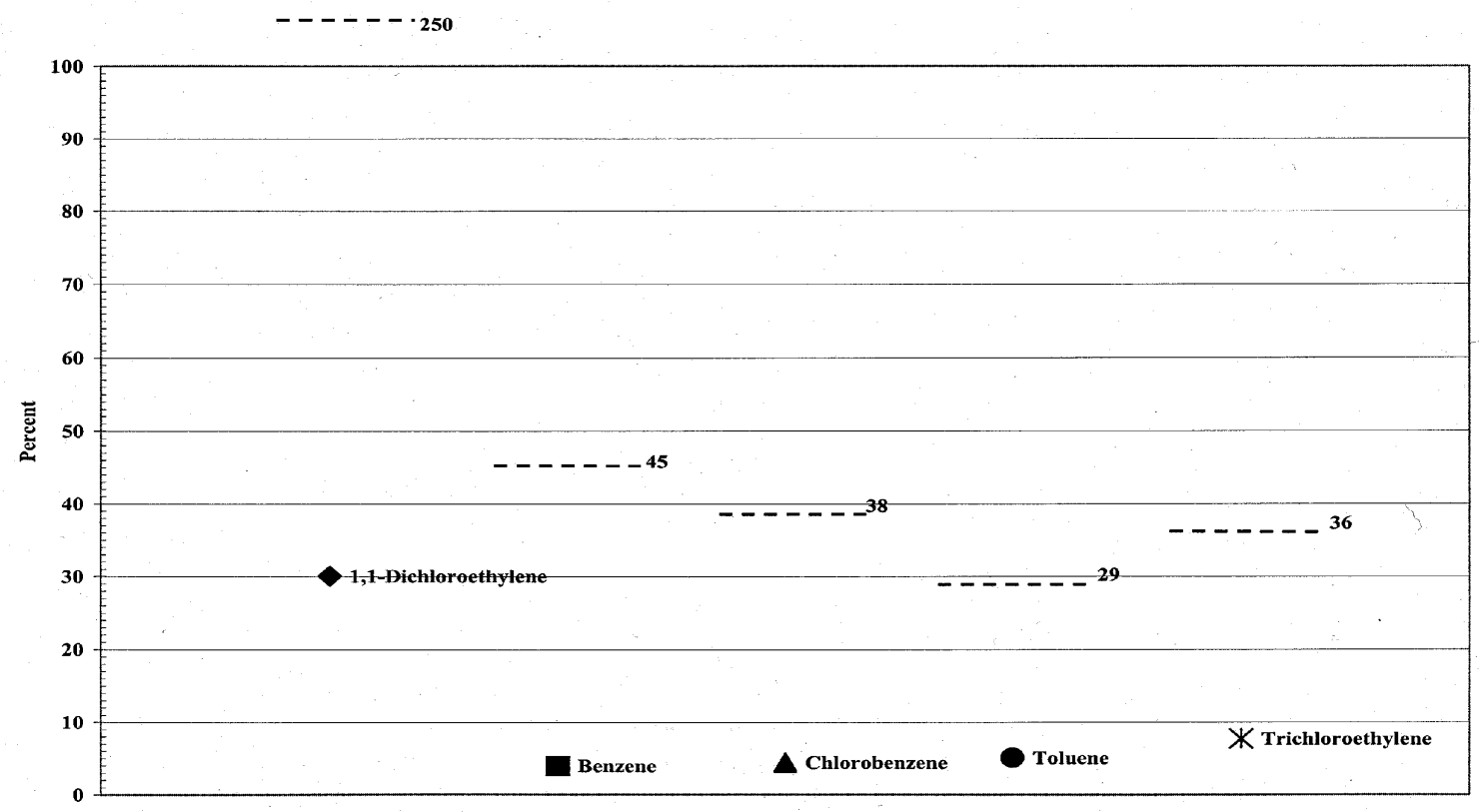

Figure V-2. Relative percent difference MS/MSDs VOCs analyses ( $\mathrm{n}=24$ batches).

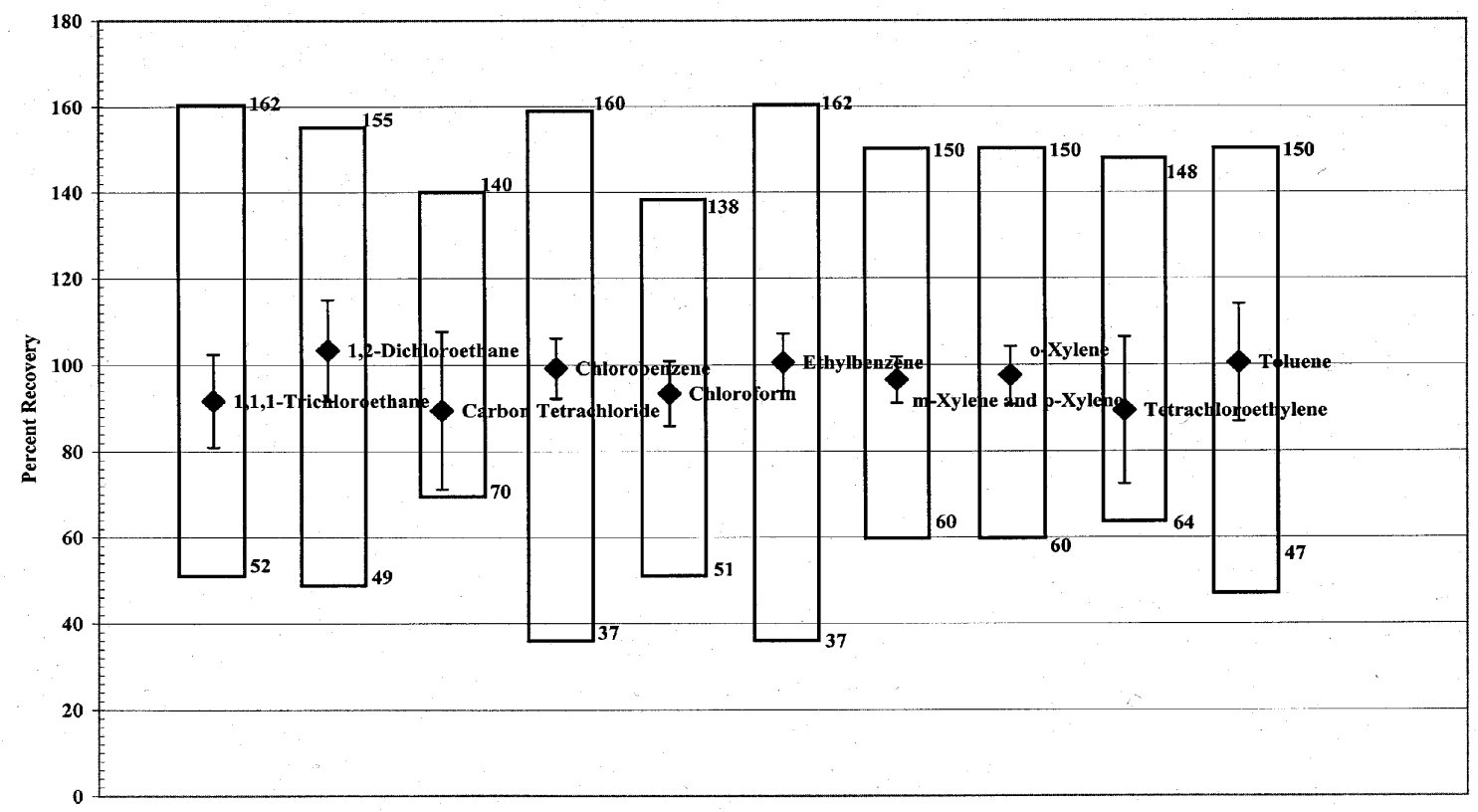

Figure V-3. Average percent recovery LCSs VOCs analyses ( $\mathrm{n}=24$ batches).

The recovery data for the four surrogate compounds are presented in detail in Appendix D, Table D-3, and was used to generate graphs (Figures V-4, V-5, V-6 and V-7).

In general, those data that individually did not meet WAP criteria are bolded or indicated with an “**” as appropriate. Any NCRs generated throughout the analysis were considered and if the disposition for the data was "reject" the data were not used. 
Compounds that reflected problems from a waste stream average perspective are discussed individually, first, from the matrix effects indicated, and second from a laboratory control perspective. The overall data use is then summarized.

\section{A-3.1 Preliminary Purgeable VOC: MS/MSD Data Assessment}

The data graphically shown in Figure V-1 illustrate that the average MS/MSD results with the associated errors all fall within the WAP criteria. Upper and lower limits for individual compounds are represented by solid lines (each compound has a unique limit). Figure V-2 reflects the RPD results and WAP acceptance criteria are represented by dotted lines. Note that the average RPD data are all below the WAP acceptance criteria shown on the graph, demonstrating that the data meet WAP precision requirements.

\section{A-3.2 Preliminary Purgeable VOC: Surrogate Compound Data Assessment}

Most of the surrogate compound recoveries were within the acceptance criteria, as reflected in Figures V-4 through Figure V-7. The surrogates used were dibromofluoromethane (BFM), toluene-d5, 4bromofluorobenzene (BFB), and 1,2-dichloroethane (DCA). The preliminary surrogate recoveries are plotted by compound. These data were used to generate a mean, standard deviation, and 3 sigma values to set the waste stream-specific acceptance criteria (per the WAP). Exceptions are discussed individually below.

Surrogate BFM, reflected in Figure V-4, recoveries were within the laboratory generated criteria with the exception of one date point which fell above the acceptance range. The performance of this surrogate is within the bounds of the method. There is no apparent bias due to matrix effects in this waste stream based on the performance of this surrogate.

The performance of the TOL surrogate, Figure V-5, is also acceptable. Only one recovery fell outside the acceptance criteria and this data point was biased high. Since the bias was high, use of this data is conservative. There is no apparent bias due to matrix effects in this waste stream based on the performance of this surrogate. 


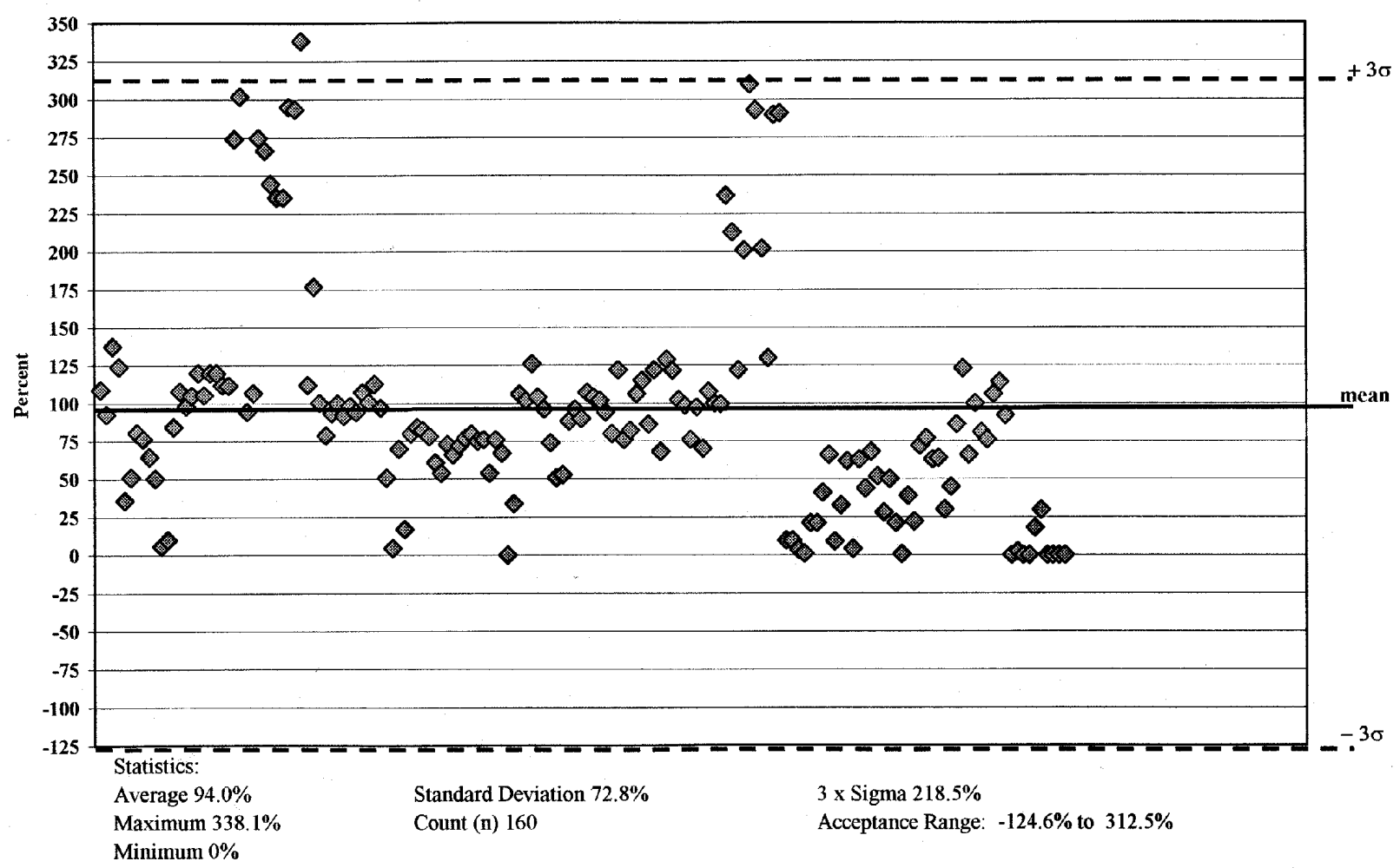

Figure V-4. Average Percent Recovery of Surrogate Dibromofluoromethane (BFM) VOCs Analyses.

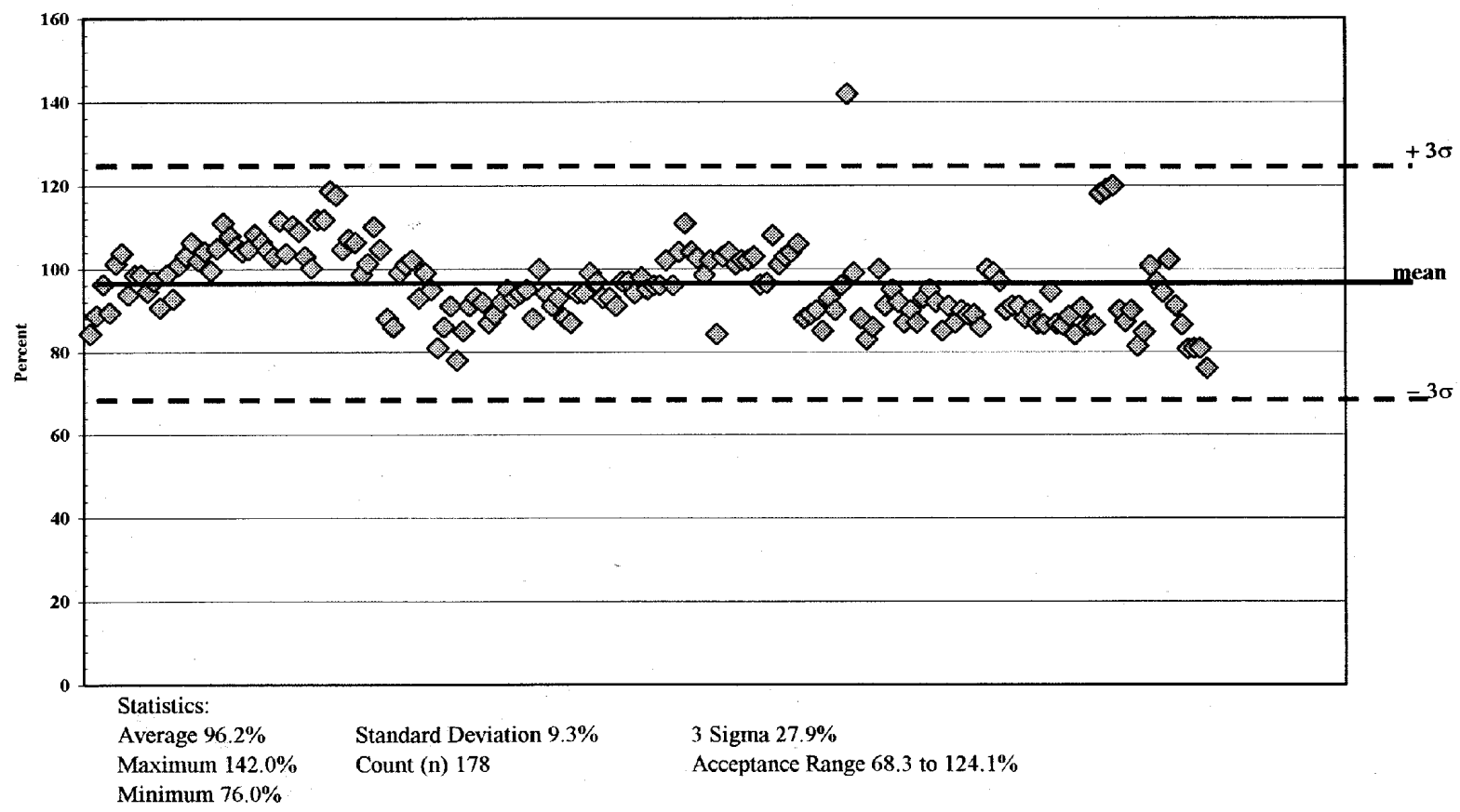

Figure V-5. Average Percent Recovery of Surrogate Toluene-d8 (TOL) VOCs Analyses. 


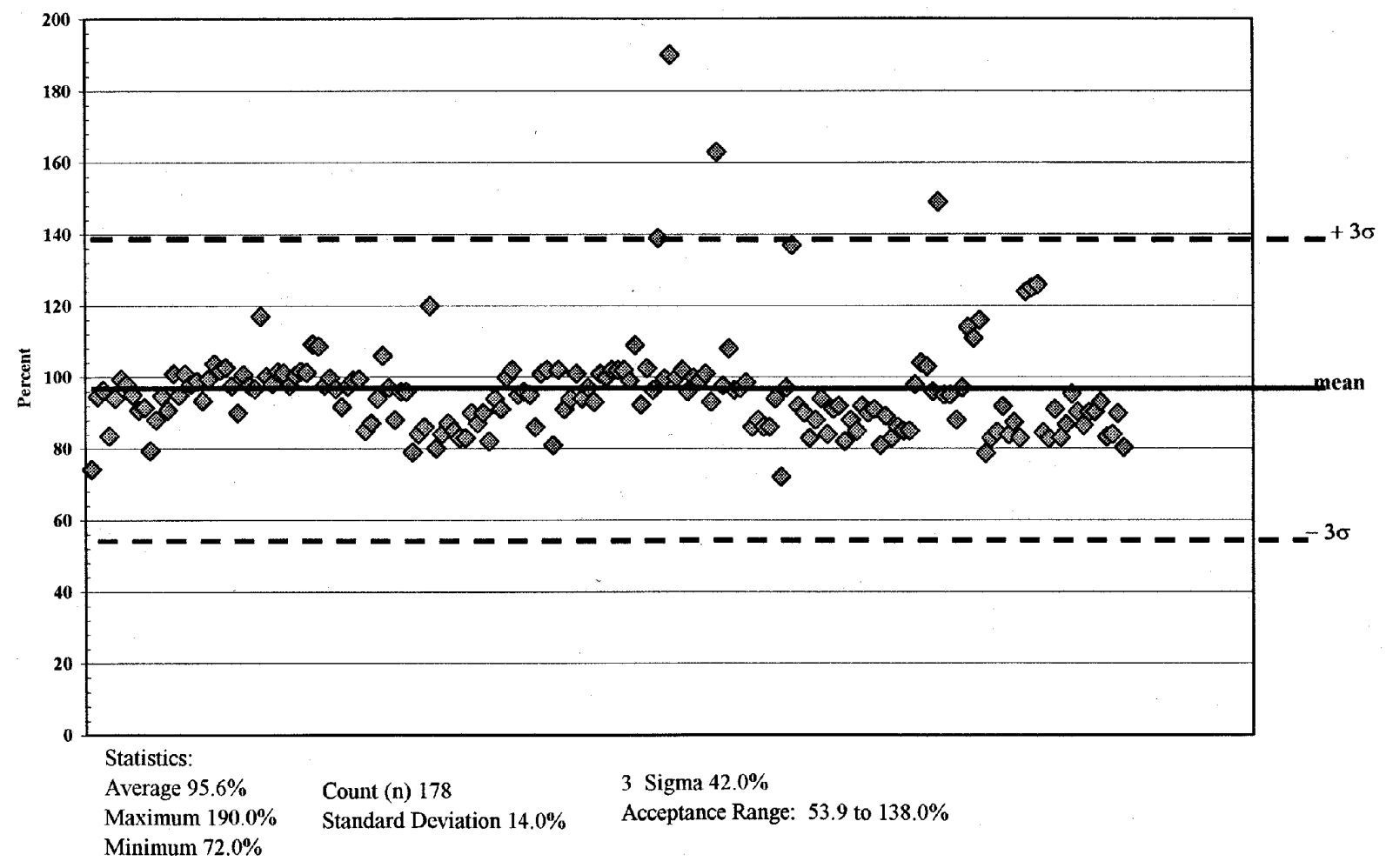

Figure V-6. Average Percent Recovery of Surrogate 4-Bromofluorobenzene (BFB) VOCs Analyses.

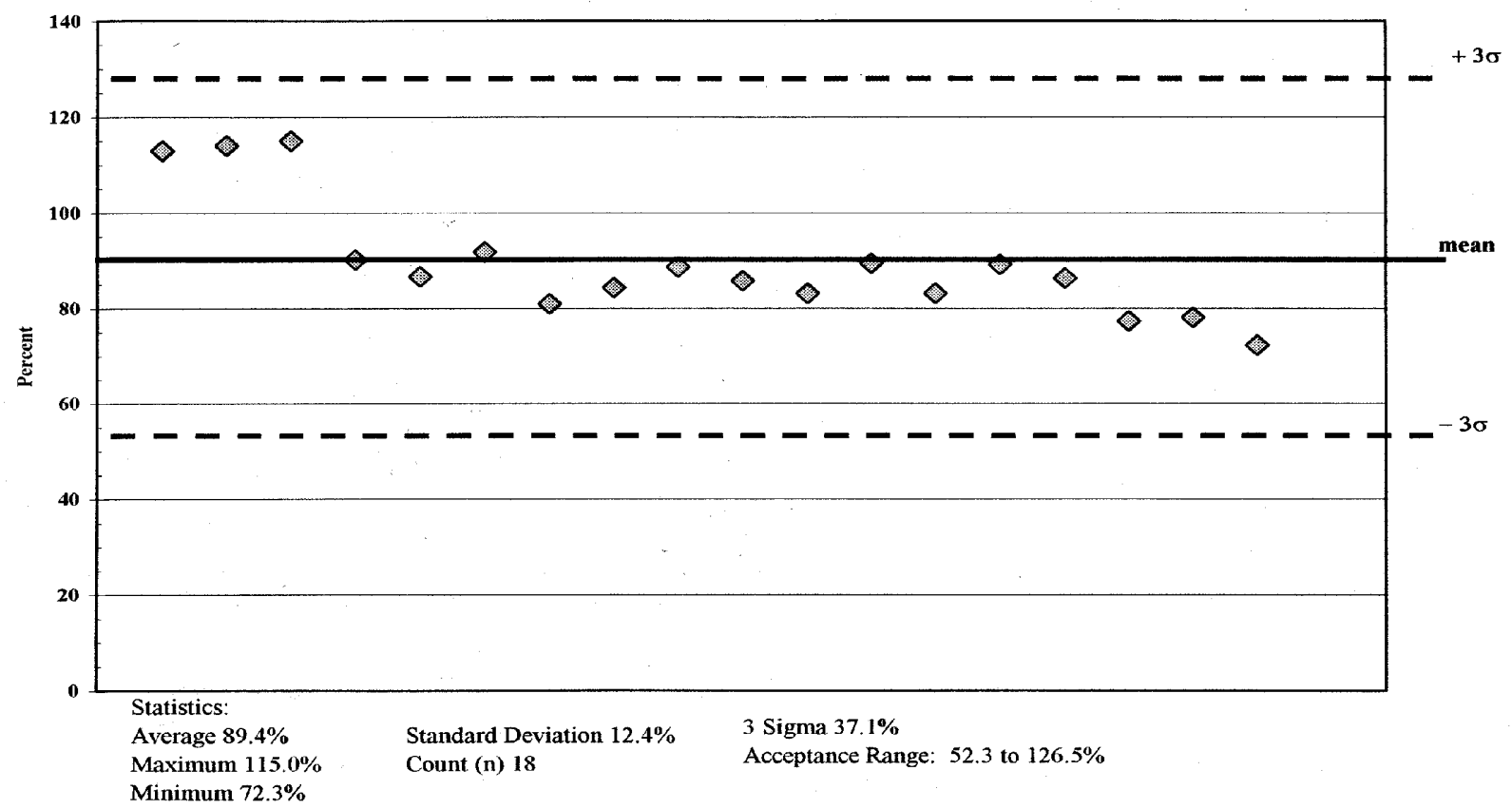

Figure V-7. Average Percent Recovery of Surrogate 1,2-Dichloroethane (DCA) VOCs Analyses. 
Four data points for the BFB surrogate, Figure V-6, fall above the acceptance criteria. Surrogates from samples in batches ACL96008V and ACL98005V recovered high and therefore indicated a possible high bias associated with matrix effects. There is no apparent bias due to matrix effects in this waste stream based on the performance of this surrogate.

- $\quad$ Three samples (three drums) in batch ACL96008V had high recoveries $(139,163$ and $190 \%$ ). Because the bias was high, use of the data is conservative and the data are appropriate for use as preliminary data.

- One sample in batch ACL98005V was above the acceptance criteria (126\%). However, the error was large due to the range of recoveries $(82.8-126 \%)$. Since the bias was high, use of the data is conservative and the data are appropriate for use as preliminary data.

In 1998, the BFM surrogate was changed to DCA, impacting five batches (four 1998 and one 1999) associated with this waste stream. All recoveries associated with this surrogate fall within the determined acceptance criteria.

\section{A-3.3 Preliminary Purgeable VOC: LCS Data Assessment}

The LCS averages and associated standard deviations were within the WAP criteria. Based on the performance of this matrix independent standard, the laboratory method was performing consistently and in control.

\section{A-4. Preliminary NH VOC Data: Data Use Assessment}

The NH VOC data has been assessed from a waste stream perspective, such as, waste stream averages, for the performance indicators MS/MSD and LCS. The performance of these indicators show that the NH VOC data is acceptable for use as preliminary data. In all cases, individual compound averages and associated errors (derived from the standard deviations) fell within the WAP criteria.

The MS/MSD and LCS results discussed in this section are summarized using a combination of tables and graphs. The average data used to generate the MS/MSD graph, Figure N-1, are summarized in Table N-1. The LCS results are illustrated in Figure N-2 and summarized in Table N-2. The data used to generate these graphs are presented by compound in Appendix E, Table E-1. The summary provided in Table E-1, Appendix E, allows for a quick view of all the data associated with each compound. Those data that individually did not meet WAP criteria are bolded.

Table N-1. ACL NH Organic Compounds Quality Control Average Percent Recovery of Metals MSs/MSDs.

\begin{tabular}{lcccc} 
Compound & $\begin{array}{c}\text { Average Percent } \\
\text { Recovery MS/MSD }\end{array}$ & $\begin{array}{c}\text { Standard } \\
\text { Deviation }\end{array}$ & RPD & Batches (n) \\
\hline Acetone & 98.0 & 7.5 & 2.8 & 20 \\
Butanol & 101.7 & 8.5 & 4.0 & 20 \\
Ethyl ether & 75.3 & 22.8 & 5.1 & 20 \\
Isobutanol & 103.5 & 8.7 & 3.2 & 20 \\
Methanol & 100.1 & 11.6 & 3.8 & 20 \\
Methyl ethyl ketone & 98.4 & 8.8 & 2.7 & 20 \\
Pyridine & 97.1 & 6.0 & 4.6 & 20
\end{tabular}


Table N-2. ACL NH Organic Compounds Quality Control Average Percent Recovery of NH Organic Compounds LCSs.

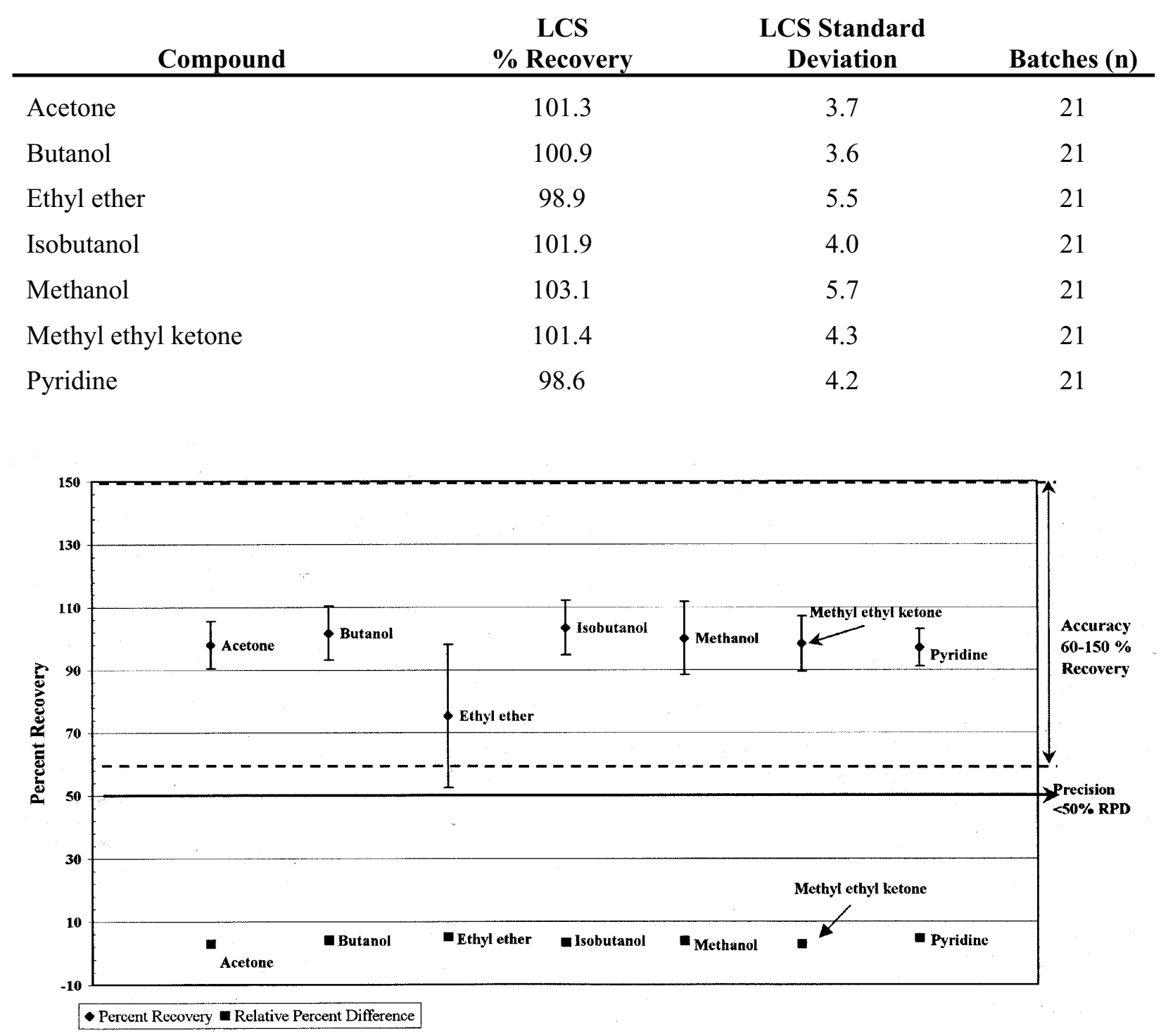

Figure N-1. Average percent recovery and RPD MS/MSDs duplicates NH organic compounds analyses ( $\mathrm{n}=20$ batches). 


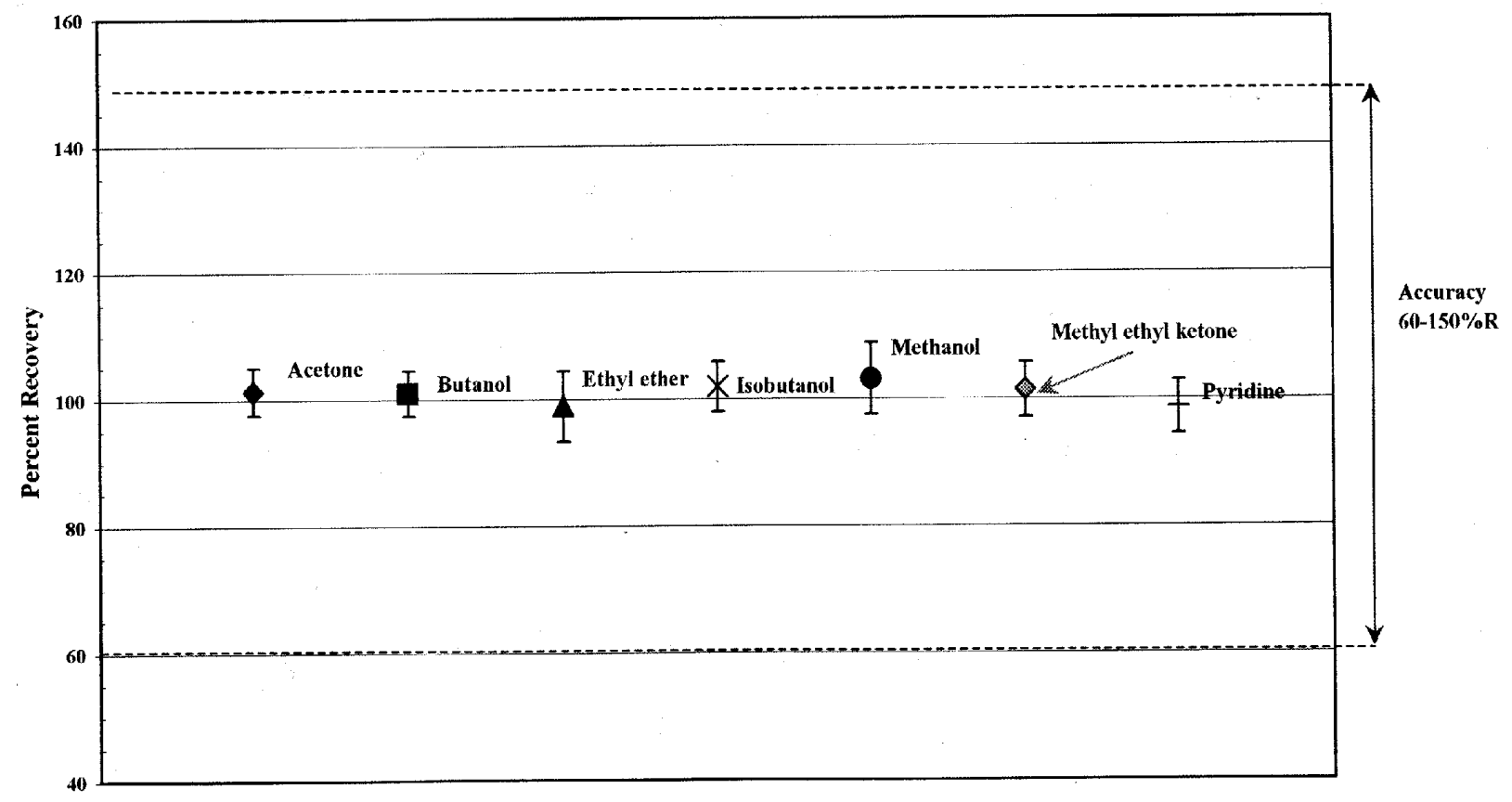

Figure N-2. Average percent recovery LCS NH organic compounds analyses ( $\mathrm{n}=21$ batches).

\section{A-4.1 Preliminary NH VOC Data: MS/MSD Assessment}

All the MS/MSD averages and associated errors fall within the WAP criteria of $60-150 \%$ recovery as reflected in Figure N-1. This performance data indicate that the associated sample data are appropriate for use as preliminary data.

The average RPDs associated with the NH VOC MS/MSD data, also illustrated in Figure N-1, meet the WAP criteria without exception. Note that if the data points fall below the solid line of the graph, the compound met the RPD criteria.

\section{A-4.2 Preliminary NH VOC Data: LCS Assessment}

The preliminary LCS average data and associated standard deviations were all well within the WAP criteria of $60-150 \%$ (illustrated in Figure N-2). This demonstrates that the laboratory was performing this analysis consistently and in control throughout the analysis of the preliminary samples. 


\section{Appendix B}

Metals Back-up Data 
Table B-1. ACL Metals QC MSs and LCSs Summary by Element.

\begin{tabular}{|c|c|c|c|c|c|c|c|}
\hline \multirow[b]{2}{*}{ Element } & \multirow[b]{2}{*}{ Batch No } & \multicolumn{2}{|c|}{ MS $(80-120 \%)$} & \multirow[b]{2}{*}{ RPD (30\%) } & \multicolumn{3}{|c|}{ LCS* } \\
\hline & & $\begin{array}{c}\text { MS } \\
\text { (\% Recovery) }\end{array}$ & $\begin{array}{c}\text { MSD } \\
\text { (\% Recovery) }\end{array}$ & & $\begin{array}{c}\text { LCS } \\
(\% \mathrm{R}) \\
\end{array}$ & $\begin{array}{l}\text { LCSD } \\
(\% \mathrm{R}) \\
\end{array}$ & $\begin{array}{c}\text { LCSD2 } \\
(\% \mathrm{R}) \\
\end{array}$ \\
\hline \multirow[t]{21}{*}{ Antimony } & ACL96002M & 67.8 & 65.5 & 5.1 & 80.3 & 77.1 & \\
\hline & ACL96004M & 53.3 & 56.4 & 3.5 & 70.1 & & \\
\hline & ACL96005M & 36 & 66.2 & 55.4 & 71.5 & & \\
\hline & ACL96007M & 51.1 & 54.8 & 10.2 & 52.6 & 65.4 & \\
\hline & ACL96008M & 42.2 & 48.3 & 12 & 96.4 & & \\
\hline & ACL97001M & 76.7 & 83.8 & 9.8 & 227 & 149.9 & \\
\hline & ACL97002M & & & & 103.5 & 111.4 & \\
\hline & ACL97003M & & & & 141.5 & 137.6 & 126 \\
\hline & ACL97004M & 65.1 & 64 & 0.4 & 121.6 & 125.8 & 124.5 \\
\hline & ACL97005M & & & & 12.8 & 105.3 & \\
\hline & ACL97006M & 82.7 & 102.6 & 15.6 & 131.3 & 128.7 & \\
\hline & ACL97007M & & & & 90 & 119.3 & \\
\hline & ACL97008M & & & & 115.3 & 91.9 & \\
\hline & ACL97009M & 74.5 & 76 & 0.3 & 119.9 & 83.5 & \\
\hline & ACL97012M & 74.3 & 74.1 & 3.3 & 129.1 & 128.4 & \\
\hline & ACL98005M & & & & 86.4 & & \\
\hline & ACL98007M & 88.8 & 93.3 & 5.8 & 115.8 & & \\
\hline & ACL98010M & 66.7 & 61.2 & 7.8 & 88.7 & & \\
\hline & ACL98012M & 51.2 & 84.1 & 21.1 & 116.3 & & \\
\hline & ACL98013M & 70.6 & 70.9 & 0.5 & 100.4 & & \\
\hline & ACL99001M & 63 & 60.7 & 3.8 & 70.4 & & \\
\hline \multicolumn{2}{|c|}{ MS/MSD Average } & 67.5 & & 10.3 & 106.2 & & \\
\hline \multicolumn{2}{|c|}{ Standard Deviation } & 15.1 & & & 35.7 & & \\
\hline \multicolumn{2}{|c|}{ Count (n) } & 30 & & 15 & 35 & & \\
\hline \multicolumn{8}{|c|}{$\begin{array}{l}\text { Antimony had very few matrix spike or matrix spike duplicate results within the } \% \mathrm{R} \text { range for the WAP accuracy criterion ( } 80 \text { to } 120 \% \mathrm{R}) \text {. } \\
\text { However none of the matrix spike duplicates exceeded the WAP precision criterion ( } 30 \% \mathrm{RPD}) \text {. (Bolded results indicate those outside the } \\
\text { ranges specified) }\end{array}$} \\
\hline \multirow[t]{21}{*}{ Arsenic } & ACL96002M & 85.8 & 80.1 & 8.8 & 99.2 & 97.7 & \\
\hline & ACL96004M & 98.7 & 95.9 & 4.7 & 93.7 & & \\
\hline & ACL96005M & 95.7 & 97.3 & 2.2 & 96.8 & 99 & \\
\hline & ACL96007M & 92.5 & 90.4 & 1.7 & 99.6 & 97.9 & \\
\hline & ACL96008M & 100 & 99.3 & 1.6 & 100 & 104.1 & \\
\hline & ACL97001M & 94.6 & 96.5 & 6.1 & 121.1 & 107.2 & \\
\hline & ACL97002M & & & & 100 & 102.1 & \\
\hline & ACL97003M & & & & 101.7 & 99.9 & 105.1 \\
\hline & ACL97004M & 100.3 & 98.3 & 0.1 & 97.1 & 98.4 & 94 \\
\hline & ACL97005M & & & & 97.7 & 102.9 & \\
\hline & ACL97006M & 94.2 & 97.8 & 1.2 & 99.4 & 95.1 & \\
\hline & ACL97007M & & & & 95.1 & 103.1 & \\
\hline & ACL97008M & & & & 97 & 100.6 & \\
\hline & ACL97009M & 95.2 & 96.8 & 0.1 & 97.4 & 96.3 & \\
\hline & ACL97012M & 102.9 & 99 & 0.3 & 103.4 & 101.3 & \\
\hline & ACL98005M & & & & 89.2 & & \\
\hline & ACL98007M & 95.9 & 106.3 & 11.1 & 93.9 & & \\
\hline & ACL98010M & 101.6 & 105.2 & 3.3 & 111.2 & & \\
\hline & ACL98012M & 102.1 & 103.3 & 1.2 & 103.4 & & \\
\hline & ACL98013M & 111 & 106.9 & 3 & 115.4 & & \\
\hline & ACL99001M & 100 & 99.4 & 0.8 & 101.5 & & \\
\hline \multicolumn{2}{|c|}{ MS/MSD Average } & 98.1 & & 3.1 & 100.5 & & \\
\hline \multicolumn{2}{|c|}{ Standard Deviation } & 6.1 & & & 6.0 & & \\
\hline \multicolumn{2}{|c|}{ Count (n) } & 30 & & 15 & 37 & & \\
\hline
\end{tabular}

All of the matrix spike and matrix spike duplicate results were within both accuracy and precision criteria. 
Table B-1. (continued).

\begin{tabular}{|c|c|c|c|c|c|c|c|}
\hline \multirow[b]{2}{*}{ Element } & \multirow[b]{2}{*}{ Batch No } & \multicolumn{2}{|c|}{ MS $(80-120 \%)$} & \multirow[b]{2}{*}{ RPD $(30 \%)$} & \multicolumn{3}{|c|}{ LCS* } \\
\hline & & $\begin{array}{c}\text { MS } \\
\text { (\% Recovery) } \\
\end{array}$ & $\begin{array}{c}\text { MSD } \\
\text { (\% Recovery) } \\
\end{array}$ & & $\begin{array}{c}\text { LCS } \\
(\% \mathrm{R}) \\
\end{array}$ & $\begin{array}{l}\text { LCSD } \\
(\% \mathrm{R}) \\
\end{array}$ & $\begin{array}{c}\text { LCSD2 } \\
(\% \mathrm{R}) \\
\end{array}$ \\
\hline \multirow[t]{21}{*}{ Barium } & ACL96002M & 86.9 & 89.5 & 1.1 & 76.6 & 73.5 & \\
\hline & ACL96004M & 94.8 & 98.4 & 1.8 & 75 & & \\
\hline & ACL96005M & 104.9 & 103.5 & 5.2 & 82.5 & 85.4 & \\
\hline & ACL96007M & 96.1 & 95.9 & 3.7 & 78 & 78.8 & \\
\hline & ACL96008M & 97.1 & 91.8 & 7.2 & 104 & 101.5 & \\
\hline & ACL97001M & 101.9 & 101.1 & 1.2 & 114.1 & 120.3 & \\
\hline & ACL97002M & & & & 97.7 & 92.8 & \\
\hline & ACL97003M & & & & 95.5 & 94.1 & 106.8 \\
\hline & ACL97004M & 96.7 & 98.4 & 3.8 & 92.7 & 101.4 & 94.4 \\
\hline & ACL97005M & & & & 108.7 & 104 & \\
\hline & ACL97006M & 96.3 & 97.4 & 3.8 & 100.9 & 100.4 & \\
\hline & ACL97007M & & & & 106.7 & 106.7 & \\
\hline & ACL97008M & & & & 93.4 & 91.7 & \\
\hline & ACL97009M & 103.7 & 106 & 0.6 & 96.1 & 97.4 & \\
\hline & ACL97012M & 97.5 & 92.5 & 1.7 & 113.2 & 106.6 & \\
\hline & ACL98005M & & & & 87.2 & & \\
\hline & ACL98007M & 96.2 & 96.5 & 1.1 & 93.8 & & \\
\hline & ACL98010M & 97.6 & 94.1 & 3.6 & 94.1 & & \\
\hline & ACL98012M & 103.9 & 102.9 & 0.7 & 104.4 & & \\
\hline & ACL98013M & 99.3 & 105.9 & 6.8 & 96.1 & & \\
\hline & ACL99001M & 96.2 & 98 & 1.7 & 94.4 & & \\
\hline \multirow{3}{*}{\multicolumn{2}{|c|}{$\begin{array}{l}\text { MS/MSD Average } \\
\text { Standard Deviation } \\
\text { Count (n) }\end{array}$}} & 98.0 & & 2.9 & 96.2 & & \\
\hline & & 4.7 & & & 11.2 & & \\
\hline & & 30 & & 15 & 37 & & \\
\hline \multicolumn{8}{|c|}{ All of the matrix spike and matrix spike duplicate results were within both accuracy and precision criteria. } \\
\hline \multirow[t]{21}{*}{ Berylium } & ACL96002M & 76.7 & 89.4 & 5.5 & 105.8 & 102.5 & \\
\hline & ACL96004M & 88.7 & 90.4 & 0 & 110 & & \\
\hline & ACL96005M & 106 & 103.5 & 4.2 & 101 & 93.1 & \\
\hline & ACL96007M & 90.4 & 95 & 6.8 & 94.9 & 95.7 & \\
\hline & ACL96008M & 99.7 & 103.6 & 0.9 & 96.2 & 94.5 & \\
\hline & ACL97001M & 97.4 & 86.7 & 3.4 & 107.1 & 102.8 & \\
\hline & ACL97002M & & & & 100.9 & 97.7 & \\
\hline & ACL97003M & & & & 98.2 & 96 & 99.6 \\
\hline & ACL97004M & 0 & 0 & 3.8 & 102.8 & 107.8 & 99.5 \\
\hline & ACL97005M & & & & 100 & 98.7 & \\
\hline & ACL97006M & 96.2 & 93.5 & 6.8 & 96.3 & 94.6 & \\
\hline & ACL97007M & & & & 104.8 & 101 & \\
\hline & ACL97008M & & & & 106 & 95.5 & \\
\hline & ACL97009M & 590.8 & 763.5 & 11.5 & 97.6 & 96.7 & \\
\hline & ACL97012M & 95.1 & 95.1 & 2.6 & 108.5 & 100.3 & \\
\hline & ACL98005M & & & & 90.3 & & \\
\hline & ACL98007M & 86.7 & 115.3 & 17.6 & 97.4 & & \\
\hline & ACL98010M & 113 & 103.2 & 3.9 & 109.7 & & \\
\hline & ACL98012M & 102.4 & 97.9 & 4.2 & 105.4 & & \\
\hline & ACL98013M & 42.8 & 532.9 & 12.7 & 116.9 & & \\
\hline & ACL99001M & 2.9 & 34.6 & 4.2 & 104.4 & & \\
\hline \multicolumn{2}{|c|}{ MS/MSD Average } & 136.4 & & 5.9 & 100.8 & & \\
\hline \multicolumn{2}{|c|}{ Standard Deviation } & 173.0 & & & 5.6 & & \\
\hline Count (n) & & 30 & & 15 & 37 & & \\
\hline
\end{tabular}


Table B-1. (continued).

\begin{tabular}{|c|c|c|c|c|c|c|c|}
\hline \multirow[b]{2}{*}{ Element } & \multirow[b]{2}{*}{ Batch No } & \multicolumn{2}{|c|}{$\operatorname{MS}(80-120 \%)$} & \multirow[b]{2}{*}{ RPD (30\%) } & \multicolumn{3}{|c|}{ LCS* } \\
\hline & & $\begin{array}{c}\text { MS } \\
\text { (\% Recovery) }\end{array}$ & $\begin{array}{c}\text { MSD } \\
\text { (\% Recovery) }\end{array}$ & & $\begin{array}{c}\text { LCS } \\
(\% \text { R) }\end{array}$ & $\begin{array}{l}\text { LCSD } \\
(\% \text { R) }\end{array}$ & $\begin{array}{c}\text { LCSD2 } \\
\text { (\% R) }\end{array}$ \\
\hline \multirow[t]{21}{*}{ Cadmium } & ACL96002M & 90.5 & 72.6 & 15.7 & 129.7 & 102 & \\
\hline & ACL96004M & 132.6 & 28.2 & 24.9 & 97.9 & & \\
\hline & ACL96005M & 83.2 & 98.7 & 5.4 & 110.6 & 111.7 & \\
\hline & ACL96007M & 87.4 & 96.9 & 11 & 103.7 & 100.1 & \\
\hline & ACL96008M & 94.3 & 91.9 & 3.6 & 97 & 94.7 & \\
\hline & ACL97001M & 49.7 & 61 & 8.8 & 128.7 & 121.5 & \\
\hline & ACL97002M & & & & 102.8 & 100.5 & \\
\hline & ACL97003M & & & & 97.6 & 89.5 & 102.1 \\
\hline & ACL97004M & 83.9 & 83 & 1 & 88.2 & 91.7 & 95.9 \\
\hline & ACL97005M & & & & 103.9 & 101.8 & \\
\hline & ACL97006M & 91.6 & 96.4 & 0.1 & 103.1 & 97.7 & \\
\hline & ACL97007M & & & & 91.3 & 101.5 & \\
\hline & ACL97008M & & & & 92.2 & 93.9 & \\
\hline & ACL97009M & 102.3 & 91 & 8.2 & 99.8 & 100.6 & \\
\hline & ACL97012M & 91 & 93.2 & 4.1 & 101.8 & 95.2 & \\
\hline & ACL98005M & & & & 93.7 & & \\
\hline & ACL98007M & 81.1 & 89.7 & 9.5 & 95.4 & & \\
\hline & ACL98010M & 84.3 & 82.3 & 1.9 & 107.3 & & \\
\hline & ACL98012M & 0 & 105.8 & 30.3 & 95.4 & & \\
\hline & ACL98013M & 52.2 & 62.6 & 3.1 & 109.5 & & \\
\hline & ACL99001M & 87.3 & 87 & 0.5 & 102.3 & & \\
\hline \multirow{3}{*}{\multicolumn{2}{|c|}{$\begin{array}{l}\text { MS/MSD Average } \\
\text { Standard Deviation } \\
\text { Count (n) }\end{array}$}} & 81.7 & & 8.5 & 101.4 & & \\
\hline & & 24.6 & & & 9.5 & & \\
\hline & & 30 & & 15 & 37 & & \\
\hline \multirow[t]{21}{*}{ Chromium } & ACL96002M & 82 & 115.9 & 4 & 99.8 & 96.2 & \\
\hline & ACL96004M & 106.8 & 88.2 & 9.1 & 96 & & \\
\hline & ACL96005M & 90.7 & 111.6 & 6.9 & 98.2 & 98.3 & \\
\hline & ACL96007M & 88.6 & 83.8 & 0.8 & 96.6 & 96.3 & \\
\hline & ACL96008M & 98.6 & 91.7 & 3.3 & 102.2 & 99.2 & \\
\hline & ACL97001M & 101.8 & 122.4 & 3 & 127.8 & 109.4 & \\
\hline & ACL97002M & & & & 100.5 & 102.8 & \\
\hline & ACL97003M & & & & 95.9 & 94.9 & 106.9 \\
\hline & ACL97004M & 91 & 67.2 & 9.1 & 95.1 & 95.5 & 95.9 \\
\hline & ACL97005M & & & & 102.5 & 103.5 & \\
\hline & ACL97006M & 88.3 & 105.4 & 4.2 & 100.3 & 94.2 & \\
\hline & ACL97007M & & & & 92 & 96.9 & \\
\hline & ACL97008M & & & & 93.5 & 99.1 & \\
\hline & ACL97009M & 172.1 & 26.1 & 23.7 & 93.2 & 96.3 & \\
\hline & ACL97012M & 91.9 & 89.1 & 0.1 & 107.1 & 98.4 & \\
\hline & ACL98005M & & & & 90.5 & & \\
\hline & ACL98007M & 115.2 & 336.9 & 27.5 & 90.3 & & \\
\hline & ACL98010M & 88.1 & 87.3 & 0.4 & 102.7 & & \\
\hline & ACL98012M & 76.9 & 94.5 & 9.9 & 98.3 & & \\
\hline & ACL98013M & 70.3 & 96.3 & 8.8 & 107.3 & & \\
\hline & ACL99001M & 90.9 & 99.9 & 4.1 & 98.6 & & \\
\hline \multicolumn{2}{|c|}{ MS/MSD Average } & 102.3 & & 7.7 & 99.2 & & \\
\hline \multicolumn{2}{|c|}{ Standard Deviation } & 49.9 & & & 6.7 & & \\
\hline Count (n) & & 30 & & 15 & 37 & & \\
\hline
\end{tabular}


Table B-1. (continued).

\begin{tabular}{|c|c|c|c|c|c|c|c|}
\hline \multirow[b]{2}{*}{ Element } & \multirow[b]{2}{*}{ Batch No } & \multicolumn{2}{|c|}{ MS (80 - $120 \%)$} & \multirow[b]{2}{*}{ RPD (30\%) } & \multicolumn{3}{|c|}{ LCS* } \\
\hline & & $\begin{array}{c}\text { MS } \\
\text { (\% Recovery) } \\
\end{array}$ & $\begin{array}{c}\text { MSD } \\
\text { (\% Recovery) } \\
\end{array}$ & & $\begin{array}{c}\text { LCS } \\
(\% \mathbf{R}) \\
\end{array}$ & $\begin{array}{c}\text { LCSD } \\
(\% \mathbf{R}) \\
\end{array}$ & $\begin{array}{c}\text { LCSD2 } \\
(\% \mathbf{R}) \\
\end{array}$ \\
\hline \multirow[t]{21}{*}{ Lead } & ACL96002M & 86.3 & 85.1 & 2 & 96.6 & 101.5 & \\
\hline & ACL96004M & 94.7 & 98.2 & 0.5 & 93.6 & & \\
\hline & ACL96005M & 84.7 & 105.5 & 6.5 & 108.3 & 106.1 & \\
\hline & ACL96007M & 91.7 & 105.1 & 11.1 & 94.9 & 93.8 & \\
\hline & ACL96008M & 92 & 97.8 & 2.7 & 100.3 & 96.8 & \\
\hline & ACL97001M & 122.7 & 126.8 & 1.4 & 120.6 & 133.9 & \\
\hline & ACL97002M & & & & 97.3 & 94.8 & \\
\hline & ACL97003M & & & & 97.6 & 90.2 & 108.9 \\
\hline & ACL97004M & 94.7 & 69.1 & 15.3 & 96.5 & 93.4 & 99 \\
\hline & ACL97005M & & & & 103.5 & 101.2 & \\
\hline & ACL97006M & 94.5 & 95.5 & 2.8 & 106.3 & 103.5 & \\
\hline & ACL97007M & & & & 91.5 & 99.9 & \\
\hline & ACL97008M & & & & 98.9 & 98.6 & \\
\hline & ACL97009M & 69.1 & 9.5 & 15.8 & 99.5 & 101.6 & \\
\hline & ACL97012M & 98.3 & 94.2 & 0.5 & 106.9 & 101.8 & \\
\hline & ACL98005M & & & & 98 & & \\
\hline & ACL98007M & 87.6 & 108.9 & 18.1 & 94.7 & & \\
\hline & ACL98010M & 87.7 & 87.8 & 0.1 & 106.2 & & \\
\hline & ACL98012M & 0 & 143.4 & 32.2 & 98.3 & & \\
\hline & ACL98013M & 67.9 & 132.3 & 8.2 & 111.2 & & \\
\hline & ACL99001M & 87.2 & 92 & 4.8 & 103.9 & & \\
\hline \multirow{3}{*}{\multicolumn{2}{|c|}{$\begin{array}{l}\text { MS/MSD Average } \\
\text { Standard Deviation } \\
\text { Count (n) } \\
\end{array}$}} & 90.3 & & 8.1 & 101.3 & & \\
\hline & & 28.9 & & & 8.2 & & \\
\hline & & 30 & & 15 & 37 & & \\
\hline \multirow[t]{21}{*}{ Mercury } & ACL96002M & 110.5 & 115 & 1.3 & 102 & 101.3 & \\
\hline & ACL96004M & 130.5 & 110.7 & 9.9 & 109.9 & & \\
\hline & ACL96005M & 98 & 90.8 & 1.6 & 117.5 & & \\
\hline & ACL96007M & 108.6 & 112.8 & 11 & & 112.3 & \\
\hline & ACL96008M & 106.9 & 103.9 & 1.3 & 113.6 & & \\
\hline & ACL97001M & 104.4 & 103.7 & 0.3 & 124.8 & & \\
\hline & ACL97002M & & & & 116.1 & & \\
\hline & ACL97003M & & & & 118.8 & & \\
\hline & ACL97004M & 106.2 & 105.8 & 0.7 & 110.7 & & \\
\hline & ACL97005M & & & & 99.8 & & \\
\hline & ACL97006M & 110.3 & 108.7 & 0.3 & 114.7 & & \\
\hline & ACL97007M & & & & 116.7 & & \\
\hline & ACL97008M & & & & 119.2 & & \\
\hline & ACL97009M & 39 & 64.6 & 17.5 & 116.3 & & \\
\hline & ACL97012M & 76.8 & 81.6 & 1.4 & & 116.3 & \\
\hline & ACL98005M & & & & 96.7 & & \\
\hline & ACL98007M & 94.9 & 97.9 & 3 & 115.6 & & \\
\hline & ACL98010M & 91.8 & 91.1 & 0.7 & 118.7 & & \\
\hline & ACL98012M & 107.1 & 112.5 & 5 & 112.2 & & \\
\hline & ACL98013M & 112.5 & 115.9 & 3 & 100.2 & & \\
\hline & ACL99001M & 88.4 & 85 & 3.9 & 126.9 & & \\
\hline \multicolumn{2}{|c|}{ MS/MSD Average } & 99.5 & & 4.1 & 112.7 & & \\
\hline \multicolumn{2}{|c|}{ Standard Deviation } & 17.7 & & & 8.1 & & \\
\hline Count (n) & & 30 & & 15 & 22 & & \\
\hline
\end{tabular}


Table B-1. (continued).

\begin{tabular}{|c|c|c|c|c|c|c|c|}
\hline \multirow[b]{2}{*}{ Element } & \multirow[b]{2}{*}{ Batch No } & \multicolumn{2}{|c|}{ MS (80 - $120 \%)$} & \multirow[b]{2}{*}{ RPD $(30 \%)$} & \multicolumn{3}{|c|}{ LCS* } \\
\hline & & $\begin{array}{c}\text { MS } \\
\text { (\% Recovery) } \\
\end{array}$ & $\begin{array}{c}\text { MSD } \\
\text { (\% Recovery) } \\
\end{array}$ & & $\begin{array}{c}\text { LCS } \\
(\% \mathrm{R}) \\
\end{array}$ & $\begin{array}{c}\text { LCSD } \\
(\% \mathbf{R}) \\
\end{array}$ & $\begin{array}{c}\text { LCSD2 } \\
(\% \mathbf{R}) \\
\end{array}$ \\
\hline \multirow[t]{21}{*}{ Nickel } & ACL96002M & 87.6 & 83.6 & 3.9 & 94.1 & 90.4 & \\
\hline & ACL96004M & 112.9 & 92.4 & 15.6 & 93.9 & & \\
\hline & ACL96005M & 85.9 & 96.4 & 4 & 97.1 & 96.8 & \\
\hline & ACL96007M & 87.9 & 90.5 & 3.9 & 99.4 & 96.8 & \\
\hline & ACL96008M & 109.2 & 93.8 & 5.5 & 99 & 107.4 & \\
\hline & ACL97001M & 94.4 & 101 & 5.2 & 120.4 & 110.5 & \\
\hline & ACL97002M & & & & 97.8 & 100.1 & \\
\hline & ACL97003M & & & & 100.9 & 94.9 & 101.1 \\
\hline & ACL97004M & 88.7 & 75.6 & 7 & 96 & 92.4 & 95.1 \\
\hline & ACL97005M & & & & 102.5 & 100 & \\
\hline & ACL97006M & 33 & 35 & 0.2 & 102.5 & 96.7 & \\
\hline & ACL97007M & & & & 96.5 & 108.2 & \\
\hline & ACL97008M & & & & 100.1 & 99.4 & \\
\hline & ACL97009M & 99.6 & 84.7 & 7.3 & 96.1 & 98.4 & \\
\hline & ACL97012M & 86.3 & 96.2 & 5.2 & 107.1 & 102.1 & \\
\hline & ACL98005M & & & & 95.7 & & \\
\hline & ACL98007M & 83.4 & 110 & 10.5 & 99.6 & & \\
\hline & ACL98010M & 83.2 & 83.9 & 0.5 & 113.1 & & \\
\hline & ACL98012M & 59.2 & 106 & 20 & 101.1 & & \\
\hline & ACL98013M & 80.1 & 77 & 1 & 118.9 & & \\
\hline & ACL99001M & 89.2 & 91.3 & 1.3 & 107.5 & & \\
\hline \multirow{3}{*}{\multicolumn{2}{|c|}{$\begin{array}{l}\text { MS/MSD Average } \\
\text { Standard Deviation } \\
\text { Count (n) } \\
\end{array}$}} & 86.6 & & 6.1 & 100.8 & & \\
\hline & & 18.1 & & & 6.8 & & \\
\hline & & 30 & & 15 & 37 & & \\
\hline \multirow[t]{21}{*}{ Selenium } & ACL96002M & 90.7 & 82.6 & 11.3 & 97.8 & 95.8 & \\
\hline & ACL96004M & 98.1 & 95.2 & 4.9 & 96.3 & & \\
\hline & ACL96005M & 92.9 & 95.5 & 1.2 & 96.3 & 99.3 & \\
\hline & ACL96007M & 95.1 & 91.3 & 0.2 & 97 & 96.5 & \\
\hline & ACL96008M & 95.9 & 98.7 & 1.3 & 102.3 & 101.3 & \\
\hline & ACL97001M & 100.7 & 104.3 & 7.7 & 122 & 110.7 & \\
\hline & ACL97002M & & & & 102.2 & 99.1 & \\
\hline & ACL97003M & & & & 99.7 & 98.1 & 107.5 \\
\hline & ACL97004M & 100.3 & 95.6 & 2.7 & 101.3 & 103.9 & 99.4 \\
\hline & ACL97005M & & & & 104.6 & 103.7 & \\
\hline & ACL97006M & 98.7 & 104 & 0.2 & 107.3 & 102.4 & \\
\hline & ACL97007M & & & & 99.1 & 103.6 & \\
\hline & ACL97008M & & & & 99 & 95.3 & \\
\hline & ACL97009M & 100.3 & 100.9 & 1.1 & 96.5 & 100.7 & \\
\hline & ACL97012M & 112.2 & 111.8 & 3.2 & 105.3 & 105.6 & \\
\hline & ACL98005M & & & & 89 & & \\
\hline & ACL98007M & 87.4 & 101.1 & 15.3 & 97.7 & & \\
\hline & ACL98010M & 100.3 & 95.7 & 4.8 & 116 & & \\
\hline & ACL98012M & 102.9 & 79 & 22.3 & 105.9 & & \\
\hline & ACL98013M & 95 & 97.3 & 3.1 & 111.5 & & \\
\hline & ACL99001M & 98.9 & 93.8 & 5.4 & 105.2 & & \\
\hline \multicolumn{2}{|c|}{ MS/MSD Average } & 97.2 & & 5.6 & 102.0 & & \\
\hline \multicolumn{2}{|c|}{ Standard Deviation } & 7.0 & & & 6.2 & & \\
\hline Count (n) & & 30 & & 15 & 37 & & \\
\hline
\end{tabular}


Table B-1. (continued).

\begin{tabular}{|c|c|c|c|c|c|c|c|}
\hline \multirow[b]{2}{*}{ Element } & \multirow[b]{2}{*}{ Batch No } & \multicolumn{2}{|c|}{ MS (80 - $120 \%)$} & \multirow[b]{2}{*}{ RPD (30\%) } & \multicolumn{3}{|c|}{ LCS* } \\
\hline & & $\begin{array}{c}\text { MS } \\
\text { (\% Recovery) } \\
\end{array}$ & $\begin{array}{c}\text { MSD } \\
\text { (\% Recovery) } \\
\end{array}$ & & $\begin{array}{c}\text { LCS } \\
(\% \mathbf{R}) \\
\end{array}$ & $\begin{array}{c}\text { LCSD } \\
(\% \mathbf{R}) \\
\end{array}$ & $\begin{array}{c}\text { LCSD2 } \\
(\% \mathbf{R}) \\
\end{array}$ \\
\hline \multirow[t]{21}{*}{ Silver } & ACL96002M & 88 & 95.1 & 1.8 & 92.3 & 106.6 & \\
\hline & ACL96004M & 82.6 & 84.8 & 0.6 & 110 & & \\
\hline & ACL96005M & 94.7 & 94.8 & 3.8 & 101.5 & 101.2 & \\
\hline & ACL96007M & 87.9 & 95.9 & 10.7 & 94.5 & 95.4 & \\
\hline & ACL96008M & 107.9 & 112.1 & 2.2 & 94.9 & 96.1 & \\
\hline & ACL97001M & 107 & 110.1 & 0.9 & 100.2 & 126.3 & \\
\hline & ACL97002M & & & & 99.8 & 104 & \\
\hline & ACL97003M & & & & 97.4 & 93.6 & 99.5 \\
\hline & ACL97004M & 86 & 91.1 & 5.9 & 98 & 102.1 & 104.8 \\
\hline & ACL97005M & & & & 93.9 & 97.8 & \\
\hline & ACL97006M & 102.8 & 96.4 & 7.9 & 99.6 & 97.7 & \\
\hline & ACL97007M & & & & 101.2 & 103.4 & \\
\hline & ACL97008M & & & & 105.5 & 105.8 & \\
\hline & ACL97009M & 105.8 & 102.4 & 4.2 & 101.5 & 98.4 & \\
\hline & ACL97012M & 89.7 & 97.5 & 4.9 & 108 & 105.8 & \\
\hline & ACL98005M & & & & 87.3 & & \\
\hline & ACL98007M & 88.7 & 124.5 & 14.6 & 102.7 & & \\
\hline & ACL98010M & 99.1 & 98.3 & 0.4 & 96.9 & & \\
\hline & ACL98012M & 100.7 & 99.1 & 1.5 & 96.4 & & \\
\hline & ACL98013M & 131.8 & 124.1 & 1.3 & 107.8 & & \\
\hline & ACL99001M & 89.4 & 93.8 & 4.2 & 95.9 & & \\
\hline \multirow{3}{*}{\multicolumn{2}{|c|}{$\begin{array}{l}\text { MS/MSD Average } \\
\text { Standard Deviation } \\
\text { Count (n) } \\
\end{array}$}} & 99.4 & & 4.3 & 100.6 & & \\
\hline & & 12.0 & & & 6.6 & & \\
\hline & & 30 & & 15 & 37 & & \\
\hline \multirow[t]{21}{*}{ Thallium } & ACL96002M & 88 & 95.1 & 1.8 & 69.1 & 71.6 & \\
\hline & ACL96004M & 78.9 & 78.6 & 2.3 & 75.4 & & \\
\hline & ACL96005M & 72.8 & 74.1 & 2.2 & 77.2 & 83.7 & \\
\hline & ACL96007M & 80.3 & 77.4 & 0.2 & 82.6 & 82.9 & \\
\hline & ACL96008M & 80.6 & 85.2 & 4 & 91.8 & 102.2 & \\
\hline & ACL97001M & 81.3 & 83.9 & 7.4 & 106.6 & 99.2 & \\
\hline & ACL97002M & & & & 110.4 & 109.2 & \\
\hline & ACL97003M & & & & 118.7 & 116.7 & 115.5 \\
\hline & ACL97004M & 76.6 & 74.6 & 0.5 & 93.9 & 97.1 & 96.4 \\
\hline & ACL97005M & & & & 97.1 & 108.9 & \\
\hline & ACL97006M & 72.9 & 77.4 & 1 & 97.1 & 101.4 & \\
\hline & ACL97007M & & & & 94.1 & 109.1 & \\
\hline & ACL97008M & & & & 108.5 & 113.4 & \\
\hline & ACL97009M & 79.1 & 82.4 & 2.5 & 94.6 & 98.7 & \\
\hline & ACL97012M & 86.2 & 87.4 & 4.9 & 117.3 & 106.1 & \\
\hline & ACL98005M & & & & 100.9 & & \\
\hline & ACL98007M & 75.8 & 79.7 & 5.8 & 102.4 & & \\
\hline & ACL98010M & 83.1 & 81.9 & 1.4 & 99.1 & & \\
\hline & ACL98012M & 60.6 & 57.1 & 5.6 & 105.5 & & \\
\hline & ACL98013M & 80.3 & 79.9 & 0.1 & 105.1 & & \\
\hline & ACL99001M & 83.1 & 82.4 & 1 & 104.4 & & \\
\hline \multicolumn{2}{|c|}{ MS/MSD Average } & 79.2 & & 2.7 & 99.0 & & \\
\hline \multicolumn{2}{|c|}{ Standard Deviation } & 7.3 & & & 12.8 & & \\
\hline Count (n) & & 30 & & 15 & 37 & & \\
\hline
\end{tabular}


Table B-1. (continued).

\begin{tabular}{|c|c|c|c|c|c|c|c|}
\hline \multirow[b]{2}{*}{ Element } & \multirow[b]{2}{*}{ Batch No } & \multicolumn{2}{|c|}{ MS (80 - $120 \%)$} & \multirow[b]{2}{*}{ RPD (30\%) } & \multicolumn{3}{|c|}{ LCS* } \\
\hline & & $\begin{array}{c}\text { MS } \\
\text { (\% Recovery) } \\
\end{array}$ & $\begin{array}{c}\text { MSD } \\
(\% \text { Recovery }) \\
\end{array}$ & & $\begin{array}{l}\text { LCS } \\
(\% \mathrm{R}) \\
\end{array}$ & $\begin{array}{l}\text { LCSD } \\
(\% \text { R) } \\
\end{array}$ & $\begin{array}{c}\text { LCSD2 } \\
(\% \mathbf{R}) \\
\end{array}$ \\
\hline \multirow[t]{21}{*}{ Vanadium } & ACL96002M & 85.7 & 83.8 & 2.9 & 97.7 & 95.5 & \\
\hline & ACL96004M & 91.2 & 92.9 & 0.1 & 96.5 & & \\
\hline & ACL96005M & 91.9 & 93.2 & 2.3 & 102.9 & 106.8 & \\
\hline & ACL96007M & 93.8 & 91.4 & 1.2 & 102.5 & 102.4 & \\
\hline & ACL96008M & 97.5 & 96 & 2.9 & 98.6 & 94 & \\
\hline & ACL97001M & 95.4 & 94 & 1.8 & 133 & 114.8 & \\
\hline & ACL97002M & & & & 101.5 & 104.1 & \\
\hline & ACL97003M & & & & 105.5 & 103.3 & 100.2 \\
\hline & ACL97004M & 95.1 & 95.1 & 1.7 & 96.9 & 104.5 & 92.7 \\
\hline & ACL97005M & & & & 97 & 98.7 & \\
\hline & ACL97006M & 93.2 & 92.1 & 4.6 & 101.5 & 97.3 & \\
\hline & ACL97007M & & & & 110.1 & 110.2 & \\
\hline & ACL97008M & & & & 95.3 & 94.2 & \\
\hline & ACL97009M & 94.4 & 98.2 & 2.2 & 97.4 & 97.3 & \\
\hline & ACL97012M & 95.5 & 96.3 & 3.9 & 105.7 & 98.8 & \\
\hline & ACL98005M & & & & 85.1 & & \\
\hline & ACL98007M & 94.2 & 94.8 & 1.2 & 96.3 & & \\
\hline & ACL98010M & 92.2 & 91 & 1.1 & 101.9 & & \\
\hline & ACL98012M & 93.1 & 90.4 & 0.9 & 102.7 & & \\
\hline & ACL98013M & 101.3 & 95 & 4.4 & 113.9 & & \\
\hline & ACL99001M & 92.2 & 93.6 & 1.2 & 96 & & \\
\hline \multirow{3}{*}{\multicolumn{2}{|c|}{$\begin{array}{l}\text { MS/MSD Average } \\
\text { Standard Deviation } \\
\text { Count (n) }\end{array}$}} & 93.5 & & 2.2 & 101.4 & & \\
\hline & & 3.3 & & & 8.0 & & \\
\hline & & 30 & & 15 & 37 & & \\
\hline \multirow[t]{21}{*}{ Zinc } & ACL96002M & 111.7 & 82 & 10 & 135.5 & 117.6 & \\
\hline & ACL96004M & 95.5 & 87.8 & 2.1 & 121 & & \\
\hline & ACL96005M & 85.7 & 89.2 & 0 & 124.2 & 117.8 & \\
\hline & ACL96007M & 89.9 & 95.1 & 5.3 & 100.4 & 98.8 & \\
\hline & ACL96008M & 97.9 & 96.7 & 1.2 & 95 & 95.1 & \\
\hline & ACL97001M & 79.8 & 93.4 & 6.6 & 130.3 & 108.5 & \\
\hline & ACL97002M & & & & 92.9 & 94.9 & \\
\hline & ACL97003M & & & & 101.1 & 95.3 & 101.6 \\
\hline & ACL97004M & 97.5 & 78.7 & 7.4 & 93.4 & 92.1 & 93.1 \\
\hline & ACL97005M & & & & 102 & 97 & \\
\hline & ACL97006M & 98.4 & 108.7 & 1.4 & 98.9 & 93.5 & \\
\hline & ACL97007M & & & & 86.4 & 95.1 & \\
\hline & ACL97008M & & & & 89 & 90.4 & \\
\hline & ACL97009M & 249.7 & 203.6 & 8.7 & 93.6 & 95.6 & \\
\hline & ACL97012M & 126.9 & 131.3 & 0.7 & 101 & 95.5 & \\
\hline & ACL98005M & & & & 97.2 & & \\
\hline & ACL98007M & 84.8 & 101.9 & 15.1 & 96.3 & & \\
\hline & ACL98010M & 90.4 & 77.3 & 4 & 109.5 & & \\
\hline & ACL98012M & 84.6 & 105.4 & 9.7 & 115 & & \\
\hline & ACL98013M & 89.6 & 116.3 & 11.5 & 122.6 & & \\
\hline & ACL99001M & 91.5 & 97.3 & 4.7 & 106.3 & & \\
\hline \multicolumn{2}{|c|}{ MS/MSD Average } & 104.6 & & 5.9 & 102.5 & & \\
\hline \multicolumn{2}{|c|}{ Standard Deviation } & 36.1 & & & 12.3 & & \\
\hline \multicolumn{2}{|c|}{ Count (n) } & 30 & & 15 & 37 & & \\
\hline \multicolumn{8}{|c|}{$\begin{array}{l}\text { MS \& MSD samples for the following batches were not IDC } 001,002 \text { or } 800 \text { and were not included. } \\
\text { ACL97002M, } 97003 \mathrm{M}, 97005 \mathrm{M}, 97007 \mathrm{M}, 97008 \mathrm{M} \text { and } 98005 \mathrm{M}\end{array}$} \\
\hline \multicolumn{8}{|c|}{$\begin{array}{l}\text { ** Control limits are laboratory established per the WAP. } \\
\text { Reference: WAP Table B3-8, footnote b. }\end{array}$} \\
\hline
\end{tabular}




\section{Appendix C}

SVOCs Back-up Data 
Table C-1. ACL SVOCs Quality Control MS and LCSs Summary by Compound.

\begin{tabular}{|c|c|c|c|c|c|c|}
\hline \multirow[b]{2}{*}{ Compound } & \multirow[b]{2}{*}{ Batch \# } & \multicolumn{2}{|c|}{ Matrix Spikes } & \multirow[b]{2}{*}{ RPD } & \multicolumn{2}{|c|}{ LCS } \\
\hline & & $\begin{array}{c}\text { \% Recovery } \\
\text { MS } \\
\end{array}$ & $\begin{array}{c}\begin{array}{c}\% \text { Recovery } \\
\text { MSD }\end{array} \\
\end{array}$ & & $\begin{array}{c}\text { \% Recovery } \\
\text { LCS }\end{array}$ & $\begin{array}{c}\text { \% Recovery } \\
\text { LCS-2 } \\
\end{array}$ \\
\hline \multirow[t]{20}{*}{ 1,4-Dichlorobenzene } & ACL96002S & 40.3 & 37.5 & 7.1 & 99.3 & \\
\hline & ACL96004O & 53 & 49 & 8 & 97 & \\
\hline & ACL96005S & 50 & 33.3 & 40 & 96 & \\
\hline & ACL96007S & 42.6 & 49.1 & 14.2 & 97.5 & \\
\hline & ACL96008S & 53.8 & 42.4 & 23.6 & 95 & 104 \\
\hline & ACL97001S & 70.3 & 39 & 57.2 & 101.3 & \\
\hline & ACL97002S & & & & 108 & \\
\hline & ACL97003S & & & & 109.7 & \\
\hline & ACL97004S & 39 & 27.3 & 35.5 & 111.5 & \\
\hline & ACL97005S & & & & 97.8 & \\
\hline & ACL97006S & & & & 90.5 & \\
\hline & ACL97007S & & & & 99.3 & \\
\hline & ACL97008S & & & & 19 & \\
\hline & ACL97009S & 23.5 & 31.6 & 29.3 & 109.7 & \\
\hline & ACL97012S & & & & 88 & \\
\hline & ACL98005S & & & & 110.4 & \\
\hline & ACL98007S & 70 & 77 & 10 & 107 & \\
\hline & ACL98012S & & & & 97 & \\
\hline & ACL98013S & & & & 103.8 & \\
\hline & ACL99001S & 72.8 & 60 & 19.3 & 89 & \\
\hline Average & & 48.1 & & 24.4 & 96.7 & \\
\hline Standard Deviation & & 15.5 & & 16.2 & 19.1 & \\
\hline Count (n) & & 20 & & 10 & 21 & \\
\hline \multirow[t]{2}{*}{ 2,4-Dinitrophenol } & ACL98013S & & & & 103 & \\
\hline & ACL99001S & & & & 110 & \\
\hline Average & & & & & 106.5 & \\
\hline Standard Deviation & & & & & 4.9 & \\
\hline Count (n) & & & & & 2 & \\
\hline \multirow[t]{15}{*}{ 2,4-Dinitrotoluene } & ACL96002S & 55 & 51.5 & 6.6 & 82.8 & \\
\hline & ACL96004O & 49 & 63 & 25 & 80 & \\
\hline & ACL96005S & 66.3 & 44.2 & 40 & 94.8 & \\
\hline & ACL96007S & 69.2 & 81 & 15.7 & 91 & \\
\hline & ACL96008S & 65.5 & 43.7 & 40 & 85.3 & 81.3 \\
\hline & ACL97001S & 75 & 51 & 38.1 & 83.3 & \\
\hline & ACL97002S & & & & 80.3 & \\
\hline & ACL97003S & & & & 107.5 & \\
\hline & ACL97004S & 47 & 32.3 & 37.2 & 101 & \\
\hline & ACL97005S & & & & 86.5 & \\
\hline & ACL97006S & & & & 89.8 & \\
\hline & ACL97007S & & & & 82.3 & \\
\hline & ACL97008S & & & & 16.8 & \\
\hline & ACL97009S & 48 & 62.9 & 26.8 & 97.3 & \\
\hline & ACL97012S & & & & 80.3 & \\
\hline
\end{tabular}


Table C-1. (continued).

\begin{tabular}{|c|c|c|c|c|c|c|}
\hline \multirow[b]{2}{*}{ Compound } & \multirow[b]{2}{*}{ Batch \# } & \multicolumn{2}{|c|}{ Matrix Spikes } & \multirow[b]{2}{*}{ RPD } & \multicolumn{2}{|c|}{ LCS } \\
\hline & & $\begin{array}{c}\text { \% Recovery } \\
\text { MS }\end{array}$ & $\begin{array}{c}\text { \% Recovery } \\
\text { MSD }\end{array}$ & & $\begin{array}{c}\text { \% Recovery } \\
\text { LCS }\end{array}$ & $\begin{array}{c}\text { \% Recovery } \\
\text { LCS-2 } \\
\end{array}$ \\
\hline & ACL98005S & & & & 98.8 & \\
\hline & ACL98007S & 44 & 46 & 4.4 & 110 & \\
\hline & ACL98012S & & & & 89 & \\
\hline & ACL98013S & & & & 92.3 & \\
\hline & ACL99001S & 75 & 58 & 25.6 & 96 & \\
\hline Average & & 56.4 & & 25.9 & 87.0 & \\
\hline Standard Deviation & & 12.9 & & 13.4 & 18.4 & \\
\hline Count (n) & & 20 & & 10 & 21 & \\
\hline \multirow[t]{2}{*}{ Hexachlorobenzene } & ACL98013S & & & & 92.8 & \\
\hline & ACL99001S & & & & 98 & \\
\hline Average & & & & & 95.4 & \\
\hline Standard Deviation & & & & & 3.7 & \\
\hline Count (n) & & & & & 2 & \\
\hline \multirow[t]{20}{*}{ Hexachloroethane } & ACL96002S & 41.3 & 40.3 & 2.5 & 99.5 & \\
\hline & ACL96004O & 52 & 52 & 0 & 99 & \\
\hline & ACL96005S & 51.3 & 29.2 & 54.9 & 93 & \\
\hline & ACL96007S & 47.9 & 62.4 & 26.3 & 94 & \\
\hline & ACL96008S & 56.5 & 42.4 & 28.5 & 96.3 & 102.5 \\
\hline & ACL97001S & 71.3 & 41.3 & 53.3 & 98 & \\
\hline & ACL97002S & & & & 93 & \\
\hline & ACL97003S & & & & 109.5 & \\
\hline & ACL97004S & 34.5 & 26.3 & 27.2 & 116 & \\
\hline & ACL97005S & & & & 105.8 & \\
\hline & ACL97006S & & & & 88.3 & \\
\hline & ACL97007S & & & & 95.8 & \\
\hline & ACL97008S & & & & 34 & \\
\hline & ACL97009S & 30 & 36.8 & 20.4 & 104.5 & \\
\hline & ACL97012S & & & & 92.3 & \\
\hline & ACL98005S & & & & 106.4 & \\
\hline & ACL98007S & 72 & 76 & 6.1 & 105.2 & \\
\hline & ACL98012S & & & & 98.5 & \\
\hline & ACL98013S & & & & 101.8 & \\
\hline & ACL99001S & 83.2 & 64.2 & 25.8 & 95 & \\
\hline Average & & 50.5 & & 24.5 & 96.6 & \\
\hline Standard Deviation & & 16.6 & & 18.9 & 15.8 & \\
\hline Count (n) & & 20 & & 10 & 21 & \\
\hline \multirow[t]{2}{*}{ m/p-Methylphenol } & ACL98013S & & & & 95 & \\
\hline & ACL99001S & & & & 90 & \\
\hline Average & & & & & 92.5 & \\
\hline Standard Deviation & & & & & 3.5 & \\
\hline Count (n) & & & & & 2 & \\
\hline
\end{tabular}


Table C-1. (continued).

\begin{tabular}{|c|c|c|c|c|c|c|}
\hline \multirow[b]{2}{*}{ Compound } & \multirow[b]{2}{*}{ Batch \# } & \multicolumn{2}{|c|}{ Matrix Spikes } & \multirow[b]{2}{*}{ RPD } & \multicolumn{2}{|c|}{ LCS } \\
\hline & & $\begin{array}{c}\text { \% Recovery } \\
\text { MS }\end{array}$ & $\begin{array}{c}\text { \% Recovery } \\
\text { MSD }\end{array}$ & & $\begin{array}{c}\text { \% Recovery } \\
\text { LCS }\end{array}$ & $\begin{array}{c}\text { \% Recovery } \\
\text { LCS-2 }\end{array}$ \\
\hline \multirow[t]{20}{*}{ Nitrobenzene } & ACL96002S & 35.5 & 34 & 4.3 & 75.8 & \\
\hline & ACL96004O & 56 & 53 & 6 & 88 & \\
\hline & ACL96005S & 53.8 & 33.3 & 46.9 & 81.8 & \\
\hline & ACL96007S & 51.9 & 67.7 & 26.4 & 83.3 & \\
\hline & ACL96008S & 56.5 & 40.2 & 33.8 & 79.8 & 101.8 \\
\hline & ACL97001S & 80 & 47 & 52 & 95.5 & \\
\hline & ACL97002S & & & & 98.8 & \\
\hline & ACL97003S & & & & 116 & \\
\hline & ACL97004S & 42 & 31.8 & 27.8 & 111.1 & \\
\hline & ACL97005S & & & & 108 & \\
\hline & ACL97006S & & & & 88.3 & \\
\hline & ACL97007S & & & & 93 & \\
\hline & ACL97008S & & & & 8.6 & \\
\hline & ACL97009S & 26.3 & 32.6 & 21.5 & 102 & \\
\hline & ACL97012S & & & & 75 & \\
\hline & ACL98005S & & & & 110.2 & \\
\hline & ACL98007S & 78 & 82 & 3.8 & 106.6 & \\
\hline & ACL98012S & & & & 97.5 & \\
\hline & ACL98013S & & & & 102.8 & 99.4 \\
\hline & ACL99001S & 65.8 & 43.5 & 40.8 & 101 & \\
\hline Average & & 50.5 & & 26.3 & 92.0 & \\
\hline Standard Deviation & & 17.0 & & 17.6 & 22.0 & \\
\hline Count (n) & & 20 & & 10 & 22 & \\
\hline \multirow[t]{2}{*}{ o-Methylphenol } & ACL98013S & & & & 102 & 105 \\
\hline & ACL99001S & & & & 89 & \\
\hline Average & & & & & 98.7 & \\
\hline Standard Deviation & & & & & 8.5 & \\
\hline Count (n) & & & & & 3 & \\
\hline \multirow[t]{2}{*}{ ortho-Dichlorobenzene } & ACL98013S & & & & 100 & 95.6 \\
\hline & ACL99001S & & & & 92 & \\
\hline Average & & & & & 95.9 & \\
\hline Standard Deviation & & & & & 4.0 & \\
\hline Count (n) & & & & & 3 & \\
\hline \multirow[t]{2}{*}{ Pentachlorophenol } & ACL98013S & & & & 110.3 & 69.6 \\
\hline & ACL99001S & & & & 120 & \\
\hline Average & & & & & 100.0 & \\
\hline Standard Deviation & & & & & 26.7 & \\
\hline Count (n) & & & & & 3 & \\
\hline
\end{tabular}


Table C-2. ACL SVOCs QC Average Percent Recovery of Surrogate Compounds by Batch.

Percent Recovery

\begin{tabular}{|c|c|c|c|c|c|c|}
\hline \multirow[b]{2}{*}{ Batch \# } & \multirow[b]{2}{*}{ Sample \# } & \\
\hline & & $\begin{array}{c}\% \text { R Surrogate } \\
\text { NBZ }\end{array}$ & $\begin{array}{c}\text { \%R Surrogate } \\
\text { FBP } \\
\end{array}$ & $\begin{array}{c}\text { \%R Surrogate } \\
\text { 2FP } \\
\end{array}$ & $\begin{array}{c}\text { \%R Surrogate } \\
\text { TBP } \\
\end{array}$ & $\begin{array}{c}\text { \%R Surrogate } \\
\text { PHN } \\
\end{array}$ \\
\hline \multirow[t]{3}{*}{ ACL96002S } & ID00421910CM1 & 50 & 56 & 57 & 41 & \\
\hline & ID00421920CM1 & 34 & 39 & 41 & 41 & \\
\hline & ID03267410CM1 & 60 & 77 & 5 & 23 & \\
\hline & 48.0 & 57.3 & 34.3 & 35.0 & \\
\hline \multicolumn{2}{|c|}{ Standard Deviation } & 13.1 & 19.0 & 26.6 & 10.4 & \\
\hline \multicolumn{2}{|c|}{ Count (n) } & 3 & 3 & 3 & 3 & 0 \\
\hline \multirow[t]{4}{*}{ ACL96004O } & ID01060410CM1 & 75 & 68 & 17 & 0 & 19 \\
\hline & ID01060420CM1 & 45 & 56 & 0 & 0 & 0 \\
\hline & ID01093110CM1 & 60 & 50 & 40 & 49 & 50 \\
\hline & ID01228710CM1 & 64 & 52 & 12 & 12 & 37 \\
\hline & 61.0 & 56.5 & 17.3 & 15.3 & 26.5 \\
\hline \multicolumn{2}{|c|}{ Standard Deviation } & 12.4 & 8.1 & 16.8 & 23.2 & 21.8 \\
\hline \multicolumn{2}{|c|}{ Count (n) } & 4 & 4 & 4 & 4 & 4 \\
\hline \multirow[t]{9}{*}{ ACL96005S } & ID01054910CM1 & 43 & 49.3 & 0 & $\overline{0}$ & \\
\hline & ID01054910CM1RE & 0 & 47.3 & 16.3 & 0 & \\
\hline & ID01078810CM1 & 33.5 & 28 & 0 & 0 & \\
\hline & ID01078820CM1 & 40.8 & 34.3 & 15.3 & 0 & \\
\hline & ID01570010CM1 & 48.5 & 49 & 0 & 0 & \\
\hline & ID01815210CM1 & 78.5 & 71.3 & 0 & 0 & \\
\hline & ID02250610CM1 & 37 & 42 & 9.3 & 2 & \\
\hline & ID02979310CM1 & 48 & 48.3 & 0 & 0 & \\
\hline & ID03034110CM1 & 42 & 48.8 & 0 & 0 & \\
\hline \multicolumn{2}{|c|}{ Average } & 41.3 & 46.5 & 4.5 & 0.2 & \\
\hline \multicolumn{2}{|c|}{ Standard Deviation } & 20.2 & 12.0 & 7.1 & 0.7 & \\
\hline \multicolumn{2}{|c|}{ Count (n) } & 9 & 9 & 9 & 9 & 0 \\
\hline \multirow[t]{10}{*}{ ACL96007S } & ID01053410CM1 & 46 & 47 & 4.3 & 7.3 & \\
\hline & ID01053420CM1 & 28.3 & 26.3 & 6.5 & 7.5 & \\
\hline & ID01085910CM1 & 44.8 & 45.3 & 6.5 & 14.5 & \\
\hline & ID01145010CM1 & 42.5 & 45.5 & 0 & 0 & \\
\hline & ID01275610CM1 & 41.8 & 45.8 & 0 & 0 & \\
\hline & ID01403110CM1 & 52.3 & 54 & 13 & 5 & \\
\hline & ID02356110CM1 & 49.8 & 51.3 & 0 & 0 & \\
\hline & ID03036210CM1 & 65.8 & 58.5 & 15 & 0 & \\
\hline & ID03114210CM1 & 0 & 54.8 & 17.3 & 15.8 & \\
\hline & ID03114220CM1 & 87.3 & 52 & 3.5 & 0 & \\
\hline \multicolumn{2}{|c|}{ Average } & 45.9 & 48.1 & 6.6 & 5.0 & \\
\hline \multicolumn{2}{|c|}{ Standard Deviation } & 22.6 & 8.9 & 6.4 & 6.2 & \\
\hline \multicolumn{2}{|c|}{ Count (n) } & 10 & 10 & 10 & 10 & 0 \\
\hline
\end{tabular}


Table C-2. (continued).

Percent Recovery

\begin{tabular}{|c|c|c|c|c|c|c|}
\hline Batch \# & Sample \# & $\begin{array}{c}\text { \%R Surrogate } \\
\text { NBZ }\end{array}$ & $\begin{array}{l}\text { \%R Surrogate } \\
\text { FBP }\end{array}$ & $\begin{array}{c}\% \text { R Surrogate } \\
\text { 2FP } \\
\end{array}$ & $\begin{array}{c}\text { \%R Surrogate } \\
\text { TBP } \\
\end{array}$ & $\begin{array}{c}\text { \%R Surrogate } \\
\text { PHN }\end{array}$ \\
\hline \multirow[t]{8}{*}{ ACL96008S } & ID00708510CM1 & 50 & 52 & 0 & 5 & \\
\hline & ID01141210CM1 & 34 & 32 & 0 & 0 & \\
\hline & ID01352210CM1 & 63 & 62 & 0 & 0 & \\
\hline & ID01361310CM1 & 49 & 45 & 0 & 0 & \\
\hline & ID01361320CM1 & 49 & 47 & 0 & 0 & \\
\hline & ID01606910CM1 & 56 & 56 & 0 & 0 & \\
\hline & ID01833310CM1 & 26 & 27 & 2 & 4 & \\
\hline & ID01833320CM1 & 28 & 31 & 2 & 3 & \\
\hline \multirow{2}{*}{\multicolumn{2}{|c|}{$\begin{array}{l}\text { Average } \\
\text { Standard Deviation }\end{array}$}} & 44.4 & 44.0 & 0.5 & 1.5 & \\
\hline & ation & 13.5 & 12.8 & 0.9 & 2.1 & \\
\hline \multicolumn{2}{|c|}{ Count (n) } & 8 & 8 & 8 & 8 & 0 \\
\hline \multirow[t]{5}{*}{ ACL97001S } & ID00108010CM1 & 36 & 22 & 0 & 0 & \\
\hline & ID00108020CM1 & 20 & 17 & 0 & 0 & \\
\hline & ID00322710CM1 & 54 & 50 & 7 & 0 & \\
\hline & ID00569510CM1 & 74 & 57 & 5 & 0 & \\
\hline & ID01342310CM1 & 36 & 33 & 0 & 0 & \\
\hline \multirow{2}{*}{\multicolumn{2}{|c|}{$\begin{array}{l}\text { Average } \\
\text { Standard Deviation }\end{array}$}} & 44.0 & 35.8 & 2.4 & 0.0 & \\
\hline & ation & 20.6 & 17.3 & 3.4 & 0.0 & \\
\hline \multicolumn{2}{|c|}{ Count (n) } & 5 & 5 & 5 & 5 & 0 \\
\hline \multirow[t]{2}{*}{ ACL97002S } & ID00088710CM1RE & 69 & 22 & 23 & 0 & \\
\hline & ID00847310CM1RE & 46 & 50 & 0 & 0 & \\
\hline \multirow{3}{*}{\multicolumn{2}{|c|}{$\begin{array}{l}\text { Average } \\
\text { Standard Deviation } \\
\text { Count (n) }\end{array}$}} & 57.5 & 36.0 & 11.5 & 0.0 & \\
\hline & & 16.3 & 19.8 & 16.3 & 0.0 & \\
\hline & & 2 & 2 & 2 & 2 & 0 \\
\hline \multirow[t]{8}{*}{ ACL97003S } & ID00393210CM1 & 76 & 69 & 0 & 0 & \\
\hline & ID00393220CM1 & 82 & 67 & 0 & 0 & \\
\hline & ID00422110CM1 & 97 & 64 & 0 & 0 & \\
\hline & ID00504910CM1 & 38 & 33 & 4 & 0 & \\
\hline & ID01287310CM1 & 77 & 64 & 0 & 0 & \\
\hline & ID01367210CM1 & 79 & 70 & 0 & 0 & \\
\hline & ID02003310CM1 & 56 & 48 & 0 & 0 & \\
\hline & ID02414810CM1 & 56 & 49 & 0 & 0 & \\
\hline \multirow{3}{*}{\multicolumn{2}{|c|}{$\begin{array}{l}\text { Average } \\
\text { Standard Deviation } \\
\text { Count (n) }\end{array}$}} & 70.1 & 58.0 & 0.5 & 0.0 & \\
\hline & & 18.7 & 13.2 & 1.4 & 0.0 & \\
\hline & & 8 & 8 & 8 & 8 & 0 \\
\hline \multirow[t]{8}{*}{ ACL97004S } & ID00835510CM1 & 39 & 0 & 23 & 5 & \\
\hline & ID01865710CM1DL1 & 0 & 60 & 0 & 0 & \\
\hline & ID02074910CM1 & 40 & 34 & 3 & 0 & \\
\hline & ID02074920CM1 & 38 & 35 & 2 & 0 & \\
\hline & ID02371710CM1 & 54 & 56 & 4 & 0 & \\
\hline & ID02382110CM1 & 71 & 80 & 0 & 8 & \\
\hline & ID02382120CM1 & 40 & 41 & 1 & 4 & \\
\hline & ID02449810CM1 & 66 & 70 & 20 & 16 & \\
\hline
\end{tabular}


Table C-2. (continued).

Percent Recovery

\begin{tabular}{|c|c|c|c|c|c|c|}
\hline \multirow[t]{3}{*}{ Batch \# } & Sample \# & $\begin{array}{c}\% \text { R Surrogate } \\
\text { NBZ } \\
\end{array}$ & $\begin{array}{c}\% \text { R Surrogate } \\
\text { FBP } \\
\end{array}$ & $\begin{array}{c}\% \text { R Surrogate } \\
\text { 2FP } \\
\end{array}$ & $\begin{array}{c}\% \text { R Surrogate } \\
\text { TBP } \\
\end{array}$ & $\begin{array}{c}\text { \%R Surrogate } \\
\text { PHN } \\
\end{array}$ \\
\hline & ID02467010CM1 & 77 & 83 & 12 & 12 & \\
\hline & ID02526510CM1 & 46 & 48 & 5 & 6 & \\
\hline \multicolumn{2}{|c|}{ Average } & 47.1 & 50.7 & 7.0 & 5.1 & \\
\hline \multicolumn{2}{|c|}{ Standard Deviation } & 22.0 & 24.9 & 8.4 & 5.6 & \\
\hline \multicolumn{2}{|c|}{ Count (n) } & 10 & 10 & 10 & 10 & 0 \\
\hline ACL97005S & ID00334410CM1 & 57 & 59 & 0 & 8 & \\
\hline Average & & 57.0 & 59.0 & 0.0 & 8.0 & \\
\hline \multicolumn{7}{|c|}{ Standard Deviation } \\
\hline \multicolumn{2}{|c|}{ Count (n) } & 1 & 1 & 1 & 1 & 0 \\
\hline \multirow[t]{3}{*}{ ACL97006S } & ID00672910CM1 & 30 & 17 & 14 & 0 & \\
\hline & ID01176110CM1 & 64 & 70 & 0 & 0 & \\
\hline & ID01787610CM1 & 62 & 64 & 0 & 0 & \\
\hline \multicolumn{2}{|c|}{ Average } & 52.0 & 50.3 & 4.7 & 0.0 & \\
\hline \multicolumn{2}{|c|}{ Standard Deviation } & 19.1 & 29.0 & 8.1 & 0.0 & \\
\hline \multicolumn{2}{|c|}{ Count (n) } & 3 & 3 & 3 & 3 & 0 \\
\hline \multirow[t]{7}{*}{ ACL97007S } & ID00326810CM1 & 85 & 69 & 0 & 0 & \\
\hline & ID00326820CM1 & 65 & 51 & 0 & 0 & \\
\hline & ID00683610CM1 & 74 & 56 & 0 & 0 & \\
\hline & ID00834410CM1 & 60 & 114 & 28 & 0 & \\
\hline & ID00837110CM1 & 56 & 50 & 10 & 0 & \\
\hline & ID00837120CM1 & 65 & 53 & 18 & 0 & \\
\hline & ID01791710CM1 & 80 & 65 & 2 & 0 & \\
\hline \multicolumn{2}{|l|}{ Average } & 69.3 & 65.4 & 8.3 & 0.0 & \\
\hline \multicolumn{2}{|c|}{ Standard Deviation } & 10.7 & 22.6 & 11.0 & 0.0 & \\
\hline \multicolumn{2}{|c|}{ Count (n) } & 7 & 7 & 7 & 7 & 0 \\
\hline \multirow[t]{5}{*}{ ACL97008S } & ID01314610CM1 & 42 & 45 & 0 & 0 & \\
\hline & ID01880610CM1 & 51 & 44 & 2 & 0 & \\
\hline & ID02075710CM1 & 73 & 0 & 0 & 0 & \\
\hline & ID02075710CM1RE & 52 & 22 & 0 & 0 & \\
\hline & ID02393810CM1RE & 34 & 28 & 0 & 0 & \\
\hline \multicolumn{2}{|c|}{ Average } & 50.4 & 27.8 & 0.4 & 0.0 & \\
\hline \multicolumn{2}{|c|}{ Standard Deviation } & 14.6 & 18.5 & 0.9 & 0.0 & \\
\hline \multicolumn{2}{|c|}{ Count (n) } & 5 & 5 & 5 & 5 & 0 \\
\hline ACL97009S & ID03123710CM1RE & 35 & 32 & 1 & 0 & \\
\hline \multicolumn{2}{|l|}{ Average } & 35.0 & 32.0 & 1.0 & 0.0 & \\
\hline \multicolumn{7}{|c|}{ Standard Deviation } \\
\hline \multicolumn{2}{|c|}{ Count (n) } & 1 & 1 & 1 & 1 & 0 \\
\hline
\end{tabular}


Table C-2. (continued).

Percent Recovery

\begin{tabular}{|c|c|c|c|c|c|c|}
\hline Batch \# & Sample \# & $\begin{array}{c}\% \text { R Surrogate } \\
\text { NBZ }\end{array}$ & $\begin{array}{c}\% \text { R Surrogate } \\
\text { FBP }\end{array}$ & $\begin{array}{c}\% \text { R Surrogate } \\
\text { 2FP }\end{array}$ & $\begin{array}{c}\% \text { R Surrogate } \\
\text { TBP }\end{array}$ & $\begin{array}{c}\text { \%R Surrogate } \\
\text { PHN }\end{array}$ \\
\hline \multirow[t]{5}{*}{ ACL97012S } & ID02734310CM1 & 56 & 58 & 0 & 0 & \\
\hline & ID02734320CM1 & 62 & 67 & 0 & 0 & \\
\hline & ID02745510CM1 & 50 & 50 & 0 & 0 & \\
\hline & ID02801810CM1 & 58 & 54 & 0 & 0 & \\
\hline & ID02863310CM1 & 70 & 54 & 0 & 0 & \\
\hline \multicolumn{2}{|c|}{ Average } & 59.2 & 56.6 & 0.0 & 0.0 & \\
\hline \multicolumn{2}{|c|}{ Standard Deviation } & 7.4 & 6.5 & 0.0 & 0.0 & \\
\hline \multicolumn{2}{|c|}{ Count (n) } & 5 & 5 & 5 & 5 & 0 \\
\hline \multirow[t]{3}{*}{ ACL98005S } & ID00158410CM1 & 95 & 78.8 & 31 & 11.8 & \\
\hline & ID02275410CM1RE & 85.2 & 81 & 54.8 & 60.5 & \\
\hline & ID02943010CM1 & 71 & 63.5 & 19 & 29 & \\
\hline \multicolumn{2}{|c|}{ Average } & 83.7 & 74.4 & 34.9 & 33.8 & \\
\hline \multicolumn{2}{|c|}{ Standard Deviation } & 12.1 & 9.5 & 18.2 & 24.7 & \\
\hline \multicolumn{2}{|c|}{ Count (n) } & 3 & 3 & 3 & 3 & 0 \\
\hline ACL98007S & ID00684710CM1DL5 & 90 & 78 & 22 & 14.5 & \\
\hline \multirow{2}{*}{\multicolumn{2}{|c|}{$\begin{array}{l}\text { Average } \\
\text { Standard Deviation }\end{array}$}} & 90.0 & 78.0 & 22.0 & 14.5 & \\
\hline & & & & & & \\
\hline \multicolumn{2}{|c|}{ Count (n) } & 1 & 1 & 1 & 1 & 0 \\
\hline \multirow[t]{2}{*}{ ACL98012S } & $\begin{array}{l}\text { ID01002910CM1RE } \\
(001)\end{array}$ & 94.8 & 76.8 & 24.5 & 36 & \\
\hline & ID02315310CM1 & 72.5 & 75.8 & 67.5 & 83.8 & \\
\hline \multicolumn{2}{|c|}{ Average } & 83.7 & 76.3 & 46.0 & 59.9 & \\
\hline \multicolumn{2}{|c|}{ Standard Deviation } & 15.8 & 0.7 & 30.4 & 33.8 & \\
\hline \multicolumn{2}{|c|}{ Count (n) } & 2 & 2 & 2 & 2 & 0 \\
\hline \multirow[t]{4}{*}{ ACL98013S } & ID01006010CM1 & 106.2 & 95.5 & 42.2 & 17.5 & \\
\hline & ID01196110CM1 & 71.2 & 66 & 36.5 & 22.2 & \\
\hline & ID01196120CM1 & 100.8 & 78 & 15 & 1.5 & \\
\hline & ID01196120CM1 & 74.8 & 67.5 & 43.5 & 45 & \\
\hline Average & & 88.3 & 76.8 & 34.3 & 21.6 & \\
\hline Standard De & ation & 17.8 & 13.6 & 13.2 & 18.0 & \\
\hline \multicolumn{2}{|c|}{ Count (n) } & 4 & 4 & 4 & 4 & 0 \\
\hline \multirow[t]{2}{*}{ ACL99001S } & ID01935810CM1 & 71.5 & 61.8 & 49.2 & 45.8 & \\
\hline & ID01935820CM1 & 93.5 & 83 & 11.8 & 16.8 & \\
\hline \multicolumn{2}{|c|}{ Average } & 82.5 & 72.4 & 30.5 & 31.3 & \\
\hline \multicolumn{2}{|c|}{ Standard Deviation } & 27.7 & 25.2 & 12.6 & 13.0 & \\
\hline \multicolumn{2}{|c|}{ Count (n) } & 2 & 2 & 2 & 2 & 0 \\
\hline
\end{tabular}

$\mathrm{NBZ}=$ Nitrobenzene-d5

$\mathrm{FBP}=2$-Fluorobiphenyl

2FP $=2$-Fluorophenol

TBP $=2,4,6$-Tribromophenol

$\mathrm{PHN}=$ Phenol-d6 


\section{Appendix D \\ VOC Back-up Data}


Table D-1. ACL VOC Quality Control MS and MSD Summary by Compound.

\begin{tabular}{|c|c|c|c|c|}
\hline \multirow[b]{2}{*}{ Compound } & \multirow[b]{2}{*}{ Batch \# } & \multicolumn{3}{|c|}{ Matrix Spikes } \\
\hline & & $\begin{array}{c}\text { MS } \\
\text { \% Recovery }\end{array}$ & $\begin{array}{c}\text { MSD } \\
\text { \% Recovery }\end{array}$ & RPD \\
\hline \multirow[t]{19}{*}{ 1,1-Dichloroethylene } & ACL96002V & 141 & 107.9 & 26.6 \\
\hline & ACL96004V & 80.9 & 97.3 & 18.5 \\
\hline & ACL96005V & 107 & 29 & 114.7 \\
\hline & ACL96007V & 8.4 & 43.5 & 135.2 \\
\hline & ACL96008V & 389 & 305 & 24.2 \\
\hline & ACL97001V & 86 & 90 & 4.2 \\
\hline & ACL97002V & 83 & 86 & \\
\hline & ACL97003V & 80 & 78 & 3.2 \\
\hline & ACL97004V & 77 & 85 & 10.2 \\
\hline & ACL97005V & & & \\
\hline & ACL97006V & & & \\
\hline & ACL97007V & 134 & 117 & 14 \\
\hline & ACL97008V & & & \\
\hline & ACL97009V & & & \\
\hline & ACL97012V & & & \\
\hline & ACL98005V & & & \\
\hline & ACL98012V & 87.8 & 92.4 & 5.06 \\
\hline & ACL98013V & 84.44 & 81.5 & 3.54 \\
\hline & ACL99001V & 75.05 & 74.05 & 1.34 \\
\hline Average & & 104.6 & & 30.1 \\
\hline Standard deviation & & 77.4 & & \\
\hline Count & & 26 & & 12 \\
\hline \multirow[t]{19}{*}{ Benzene } & ACL96002V & 87.1 & 82.4 & 5.6 \\
\hline & ACL96004V & 79.7 & 84.2 & 5.49 \\
\hline & ACL96005V & 85.9 & 86.8 & 1.1 \\
\hline & ACL96007V & 89.7 & 85.9 & 4.3 \\
\hline & ACL96008V & 88.8 & 83.4 & 6.25 \\
\hline & ACL97001V & 87 & 89 & 2.7 \\
\hline & ACL97002V & 84 & 85 & \\
\hline & ACL97003V & 84 & 78 & 6.5 \\
\hline & ACL97004V & 85 & 89 & 4.9 \\
\hline & ACL97005V & & & \\
\hline & ACL97006V & & & \\
\hline & ACL97007V & 94 & 90 & 4.4 \\
\hline & ACL97008V & & & \\
\hline & ACL97009V & & & \\
\hline & ACL97012V & & & \\
\hline & ACL98005V & & & \\
\hline & ACL98012V & 90.4 & 89.6 & 0.89 \\
\hline & ACL98013V & 84.13 & 83.4 & 0.87 \\
\hline & ACL99001V & 72.5 & 76.08 & 4.81 \\
\hline Average & & 85.2 & & 4.0 \\
\hline Standard deviation & & 4.8 & & \\
\hline Count & & 26 & & 12 \\
\hline
\end{tabular}


Table D-1. (continued).

\begin{tabular}{|c|c|c|c|c|}
\hline \multirow[b]{2}{*}{ Compound } & \multirow[b]{2}{*}{ Batch \# } & \multicolumn{3}{|c|}{ Matrix Spikes } \\
\hline & & $\begin{array}{c}\text { MS } \\
\text { \% Recovery }\end{array}$ & $\begin{array}{c}\text { MSD } \\
\text { \% Recovery }\end{array}$ & RPD \\
\hline \multirow{19}{*}{ Chlorobenzene } & ACL96002V & 89.6 & 97.2 & 8.2 \\
\hline & ACL96004V & 86.9 & 91.3 & 5 \\
\hline & ACL96005V & 91.5 & 97 & 5.8 \\
\hline & ACL96007V & 95.2 & 91.1 & 4.5 \\
\hline & ACL96008V & 96 & 95.2 & 7.38 \\
\hline & ACL97001V & 92 & 93 & 1.9 \\
\hline & ACL97002V & & & \\
\hline & ACL97003V & 89 & 84 & 5.4 \\
\hline & ACL97004V & 92 & 93 & 1.3 \\
\hline & ACL97005V & & & \\
\hline & ACL97006V & & & \\
\hline & ACL97007V & 94 & 92 & 1.6 \\
\hline & ACL97008V & & & \\
\hline & ACL97009V & & & \\
\hline & ACL97012V & & & \\
\hline & ACL98005V & & & \\
\hline & ACL98012V & 133 & 128.2 & 3.66 \\
\hline & ACL98013V & 102.4 & 105.28 & 2.77 \\
\hline & ACL99001V & 94.08 & 99.41 & 5.51 \\
\hline Average & & 96.8 & & 4.4 \\
\hline Standard deviation & & 11.4 & & \\
\hline Count & & 24 & & 12 \\
\hline \multirow[t]{19}{*}{ Toluene } & ACL96002V & 93 & 95.2 & 2.3 \\
\hline & ACL96004V & 83.3 & 90.4 & 8.21 \\
\hline & ACL96005V & 89.3 & 108.4 & 19.4 \\
\hline & ACL96007V & 94.7 & 104 & 9.3 \\
\hline & ACL96008V & 91.6 & 94.5 & 3.32 \\
\hline & ACL97001V & 95 & 97 & 2.8 \\
\hline & ACL97002V & & & \\
\hline & ACL97003V & 97 & 95 & 1.9 \\
\hline & ACL97004V & 105 & 101 & 3.5 \\
\hline & ACL97005V & & & \\
\hline & ACL97006V & & & \\
\hline & ACL97007V & 98 & 97 & 0.7 \\
\hline & ACL97008V & & & \\
\hline & ACL97009V & & & \\
\hline & ACL97012V & & & \\
\hline & ACL98005V & & & \\
\hline & ACL98012V & 111.1 & 110 & 0.98 \\
\hline & ACL98013V & 88.46 & 86.82 & 1.87 \\
\hline & ACL99001V & 77.26 & 82.57 & 6.64 \\
\hline Average & & 95.2 & & 5.1 \\
\hline Standard deviation & & 8.6 & & \\
\hline Count & & 24 & & 12 \\
\hline
\end{tabular}


Table D-1. (continued).

\begin{tabular}{|c|c|c|c|c|}
\hline \multirow[b]{2}{*}{ Compound } & \multirow[b]{2}{*}{ Batch \# } & \multicolumn{3}{|c|}{ Matrix Spikes } \\
\hline & & $\begin{array}{c}\text { MS } \\
\text { \% Recovery }\end{array}$ & $\begin{array}{c}\text { MSD } \\
\% \text { Recovery }\end{array}$ & RPD \\
\hline \multirow[t]{19}{*}{ Trichloroethylene } & ACL96002V & 92.1 & 91.8 & 0.4 \\
\hline & ACL96004V & 79.5 & 103.2 & 25.9 \\
\hline & ACL96005V & 95 & 65.9 & 36.1 \\
\hline & ACL96007V & 89.4 & 85.2 & 4.9 \\
\hline & ACL96008V & 87.9 & 85.7 & 2.47 \\
\hline & ACL97001V & 79 & 85 & 7.6 \\
\hline & ACL97002V & & & \\
\hline & ACL97003V & 77 & 79 & 2.2 \\
\hline & ACL97004V & 80 & 84 & 4.1 \\
\hline & ACL97005V & & & \\
\hline & ACL97006V & & & \\
\hline & ACL97007V & 93 & 90 & 3 \\
\hline & ACL97008V & & & \\
\hline & ACL97009V & & & \\
\hline & ACL97012V & & & \\
\hline & ACL98005V & & & \\
\hline & ACL98012V & 102.7 & 100.7 & 2 \\
\hline & ACL98013V & 92.02 & 92.54 & 0.56 \\
\hline & ACL99001V & 80.74 & 83.44 & 3.29 \\
\hline Average & & 87.3 & & 7.7 \\
\hline Standard deviation & & 8.8 & & \\
\hline Count & & 24 & & 12 \\
\hline
\end{tabular}

*Acceptance Criteria taken from WAP Table B3-4

**Detected: result must be greater than zero

***Nonconformances do not apply to matrix related exceedances.

MS \& MSD samples for the following batches were not IDC 001, 002 or 800 and were not included. 
Table D-2. ACL VOC Quality Control LCSs Summary by Compound.

\begin{tabular}{|c|c|c|c|c|}
\hline \multirow[b]{2}{*}{ Compound } & \multirow[b]{2}{*}{ Batch No. } & \multicolumn{3}{|c|}{ Laboratory Control Sample (LCS) } \\
\hline & & $\begin{array}{c}\text { LCS } \\
\text { \% Recovery }\end{array}$ & $\begin{aligned} \text { LCS-3 } \\
\text { \% Recovery }\end{aligned}$ & $\begin{aligned} \text { LCS-2 } \\
\% \text { Recovery }\end{aligned}$ \\
\hline \multirow[t]{20}{*}{ 1,1,1-Trichloroethane } & ACL96002V & 87.4 & & \\
\hline & ACL96004V & 97.9 & & \\
\hline & ACL96005V & 84 & & \\
\hline & ACL96007V & 80.5 & & \\
\hline & ACL96008V & 78 & & \\
\hline & ACL97001V & & & \\
\hline & ACL97002V & 86 & & \\
\hline & ACL97003V & 83 & & \\
\hline & ACL97004V & 79 & & \\
\hline & ACL97005V & 82 & & \\
\hline & ACL97006V & 94 & & \\
\hline & ACL97007V & 81 & & \\
\hline & ACL97008V & 108 & & \\
\hline & ACL97009V & 96 & & \\
\hline & ACL97012V & 91 & & \\
\hline & ACL98005V & 108.9 & 107.1 & \\
\hline & ACL98007V & 116.65 & & \\
\hline & ACL98012V & 82.8 & 85.2 & 87.28 \\
\hline & ACL98013V & 92.26 & & \\
\hline & ACL99001V & 94.4 & 93.84 & 103.56 \\
\hline Average & & 91.7 & & \\
\hline Standard deviation & & 10.7 & & \\
\hline Count & & 24 & & \\
\hline \multirow[t]{14}{*}{ 1,2-Dichloroethane } & ACL96002V & 114.6 & & \\
\hline & ACL96004V & 121.1 & & \\
\hline & ACL96005V & 120 & & \\
\hline & ACL96007V & 133.4 & & \\
\hline & ACL96008V & 120 & & \\
\hline & ACL97001V & & & \\
\hline & ACL97002V & 103 & & \\
\hline & ACL97003V & 90 & & \\
\hline & ACL97004V & 97 & & \\
\hline & ACL97005V & 90 & & \\
\hline & ACL97006V & 105 & & \\
\hline & ACL97007V & 98 & & \\
\hline & ACL97008V & 104 & & \\
\hline & ACL97009V & 108 & & \\
\hline
\end{tabular}


Table D-2. (continued).

\begin{tabular}{|c|c|c|c|c|}
\hline \multirow[b]{2}{*}{ Compound } & \multirow[b]{2}{*}{ Batch No. } & \multicolumn{3}{|c|}{ Laboratory Control Sample (LCS) } \\
\hline & & $\begin{array}{c}\text { LCS } \\
\% \text { Recovery }\end{array}$ & $\begin{array}{c}\text { LCS-3 } \\
\text { \% Recovery }\end{array}$ & $\begin{array}{c}\text { LCS-2 } \\
\% \text { Recovery }\end{array}$ \\
\hline & ACL97012V & 98 & & \\
\hline & ACL98005V & 105.5 & 104.3 & \\
\hline & ACL98007V & 112.25 & & \\
\hline & ACL98012V & 95.66 & 96.58 & 94.14 \\
\hline & ACL98013V & 96.66 & & \\
\hline & ACL99001V & 91.64 & 93.44 & 88.28 \\
\hline Average & & 103.4 & & \\
\hline Standard deviation & & 11.7 & & \\
\hline Count & & 24 & & \\
\hline \multirow[t]{20}{*}{ Carbon Tetrachloride } & ACL96002V & 84.1 & & \\
\hline & ACL96004V & 100.1 & & \\
\hline & ACL96005V & 83 & & \\
\hline & ACL96007V & 80.8 & & \\
\hline & ACL96008V & 77 & & \\
\hline & ACL97001V & & & \\
\hline & ACL97002V & 88 & & \\
\hline & ACL97003V & 74 & & \\
\hline & ACL97004V & 83 & & \\
\hline & ACL97005V & 88 & & \\
\hline & ACL97006V & 92 & & \\
\hline & ACL97007V & 93 & & \\
\hline & ACL97008V & 104 & & \\
\hline & ACL97009V & 105 & & \\
\hline & ACL97012V & 79 & & \\
\hline & ACL98005V & 35.7 & 97.4 & \\
\hline & ACL98007V & 147.05 & & \\
\hline & ACL98012V & 90.12 & 91.94 & 92.98 \\
\hline & ACL98013V & 90.86 & & \\
\hline & ACL99001V & 94.34 & 90.74 & 83.78 \\
\hline Average & & 89.4 & & \\
\hline Standard deviation & & 18.2 & & \\
\hline Count & & 24 & & \\
\hline
\end{tabular}


Table D-2. (continued).

\begin{tabular}{|c|c|c|c|c|}
\hline \multirow[b]{2}{*}{ Compound } & \multirow[b]{2}{*}{ Batch No. } & \multicolumn{3}{|c|}{ Laboratory Control Sample (LCS) } \\
\hline & & $\begin{array}{c}\text { LCS } \\
\text { \% Recovery }\end{array}$ & $\begin{aligned} & \text { LCS-3 } \\
& \text { \% Recovery }\end{aligned}$ & $\begin{array}{c}\text { LCS-2 } \\
\% \text { Recovery } \\
\end{array}$ \\
\hline \multirow[t]{20}{*}{ Chlorobenzene } & ACL96002V & 101.8 & & \\
\hline & ACL96004V & 95 & & \\
\hline & ACL96005V & 99 & & \\
\hline & ACL96007V & 113.2 & & \\
\hline & ACL96008V & 100 & & \\
\hline & ACL97001V & & & \\
\hline & ACL97002V & 99 & & \\
\hline & ACL97003V & 91 & & \\
\hline & ACL97004V & 94 & & \\
\hline & ACL97005V & 89 & & \\
\hline & ACL97006V & 102 & & \\
\hline & ACL97007V & 92 & & \\
\hline & ACL97008V & 99 & & \\
\hline & ACL97009V & 101 & & \\
\hline & ACL97012V & 86 & & \\
\hline & ACL98005V & & 106.7 & \\
\hline & ACL98007V & 107.6 & & \\
\hline & ACL98012V & 107.38 & 112 & 99.24 \\
\hline & ACL98013V & 97.3 & & \\
\hline & ACL99001V & 97.96 & 97.96 & 92.12 \\
\hline Average & & 99.1 & & \\
\hline Standard deviation & & 7.0 & & \\
\hline Count & & 23 & & \\
\hline \multirow[t]{14}{*}{ Chloroform } & ACL96002V & 93.7 & & \\
\hline & ACL96004V & 102.8 & & \\
\hline & ACL96005V & 92 & & \\
\hline & ACL96007V & 86.6 & & \\
\hline & ACL96008V & 83 & & \\
\hline & ACL97001V & & & \\
\hline & ACL97002V & 91 & & \\
\hline & ACL97003V & 86 & & \\
\hline & ACL97004V & 89 & & \\
\hline & ACL97005V & 90 & & \\
\hline & ACL97006V & 95 & & \\
\hline & ACL97007V & 83 & & \\
\hline & ACL97008V & 108 & & \\
\hline & ACL97009V & 95 & & \\
\hline
\end{tabular}


Table D-2. (continued).

\begin{tabular}{|c|c|c|c|c|}
\hline \multirow[b]{2}{*}{ Compound } & \multirow[b]{2}{*}{ Batch No. } & \multicolumn{3}{|c|}{ Laboratory Control Sample (LCS) } \\
\hline & & $\begin{array}{c}\text { LCS } \\
\% \text { Recovery }\end{array}$ & $\begin{array}{c}\text { LCS-3 } \\
\% \text { Recovery } \\
\end{array}$ & $\begin{array}{c}\text { LCS-2 } \\
\% \text { Recovery } \\
\end{array}$ \\
\hline & ACL97012V & 81 & & \\
\hline & ACL98005V & 105.6 & 100.2 & \\
\hline & ACL98007V & 98.5 & & \\
\hline & ACL98012V & 88.36 & 86.18 & 89.78 \\
\hline & ACL98013V & 95.46 & & \\
\hline & ACL99001V & 96.08 & 98.66 & 104.56 \\
\hline Average & & 93.3 & & \\
\hline Standard deviation & & 7.5 & & \\
\hline Count & & 24 & & \\
\hline \multirow[t]{20}{*}{ Ethylbenzene } & ACL96002V & 107.1 & & \\
\hline & ACL96004V & 102.9 & & \\
\hline & ACL96005V & 104 & & \\
\hline & ACL96007V & 116.7 & & \\
\hline & ACL96008V & 108 & & \\
\hline & ACL97001V & & & \\
\hline & ACL97002V & 104 & & \\
\hline & ACL97003V & 100 & & \\
\hline & ACL97004V & 101 & & \\
\hline & ACL97005V & 96 & & \\
\hline & ACL97006V & 106 & & \\
\hline & ACL97007V & 99 & & \\
\hline & ACL97008V & 108 & & \\
\hline & ACL97009V & 108 & & \\
\hline & ACL97012V & 92 & & \\
\hline & ACL98005V & 99.4 & 95.6 & \\
\hline & ACL98007V & 99.05 & & \\
\hline & ACL98012V & 100.34 & 102.74 & 91 \\
\hline & ACL98013V & 93.08 & & \\
\hline & ACL99001V & 96.32 & 93.46 & 88.78 \\
\hline Average & & 100.5 & & \\
\hline Standard deviation & & 6.6 & & \\
\hline Count & & 24 & & \\
\hline
\end{tabular}


Table D-2. (continued).

\begin{tabular}{|c|c|c|c|c|}
\hline \multirow[b]{2}{*}{ Compound } & \multirow[b]{2}{*}{ Batch No. } & \multicolumn{3}{|c|}{ Laboratory Control Sample (LCS) } \\
\hline & & $\begin{array}{c}\text { LCS } \\
\text { \% Recovery }\end{array}$ & $\begin{aligned} & \text { LCS-3 } \\
& \text { \% Recovery }\end{aligned}$ & $\begin{array}{c}\text { LCS-2 } \\
\% \text { Recovery } \\
\end{array}$ \\
\hline \multirow[t]{20}{*}{ m-Xylene and p-Xylene } & ACL96002V & 101 & & \\
\hline & ACL96004V & 91.4 & & \\
\hline & ACL96005V & 98 & & \\
\hline & ACL96007V & 110.3 & & \\
\hline & ACL96008V & 100 & & \\
\hline & ACL97001V & & & \\
\hline & ACL97002V & 98 & & \\
\hline & ACL97003V & 91 & & \\
\hline & ACL97004V & 92 & & \\
\hline & ACL97005V & 87 & & \\
\hline & ACL97006V & 100 & & \\
\hline & ACL97007V & 99 & & \\
\hline & ACL97008V & 101 & & \\
\hline & ACL97009V & 100 & & \\
\hline & ACL97012V & 86 & & \\
\hline & ACL98005V & 92 & 97.3 & \\
\hline & ACL98007V & 96.75 & & \\
\hline & ACL98012V & 102.03 & 99.79 & 91.7 \\
\hline & ACL98013V & 94.32 & & \\
\hline & ACL99001V & 98.38 & 93.92 & 94.85 \\
\hline Average & & 96.5 & & \\
\hline Standard deviation & & 5.4 & & \\
\hline Count & & 24 & & \\
\hline \multirow[t]{14}{*}{ o-Xylene } & ACL96002V & 101 & & \\
\hline & ACL96004V & 92.5 & & \\
\hline & ACL96005V & 97 & & \\
\hline & ACL96007V & 116.6 & & \\
\hline & ACL96008V & 101 & & \\
\hline & ACL97001V & & & \\
\hline & ACL97002V & 99 & & \\
\hline & ACL97003V & 90 & & \\
\hline & ACL97004V & 91 & & \\
\hline & ACL97005V & 86 & & \\
\hline & ACL97006V & 104 & & \\
\hline & ACL97007V & 99 & & \\
\hline & ACL97008V & 102 & & \\
\hline & ACL97009V & 100 & & \\
\hline
\end{tabular}


Table D-2. (continued).

\begin{tabular}{|c|c|c|c|c|}
\hline \multirow[b]{2}{*}{ Compound } & \multirow[b]{2}{*}{ Batch No. } & \multicolumn{3}{|c|}{ Laboratory Control Sample (LCS) } \\
\hline & & $\begin{array}{c}\text { LCS } \\
\% \text { Recovery }\end{array}$ & $\begin{array}{c}\text { LCS-3 } \\
\% \text { Recovery } \\
\end{array}$ & $\begin{array}{c}\text { LCS-2 } \\
\% \text { Recovery } \\
\end{array}$ \\
\hline & ACL97012V & 89 & & \\
\hline & ACL98005V & 97.2 & 97.5 & \\
\hline & ACL98007V & 100.7 & & \\
\hline & ACL98012V & 107.72 & 100.5 & 93.2 \\
\hline & ACL98013V & 90.02 & & \\
\hline & ACL99001V & 98.74 & 94.32 & 93.1 \\
\hline Average & & 97.5 & & \\
\hline Standard deviation & & 6.7 & & \\
\hline Count & & 24 & & \\
\hline \multirow[t]{20}{*}{ Tetrachloroethylene } & ACL96002V & 94.6 & & \\
\hline & ACL96004V & 83.8 & & \\
\hline & ACL96005V & 95 & & \\
\hline & ACL96007V & 80.6 & & \\
\hline & ACL96008V & 17.43 & & \\
\hline & ACL97001V & & & \\
\hline & ACL97002V & 88 & & \\
\hline & ACL97003V & 87 & & \\
\hline & ACL97004V & 91 & & \\
\hline & ACL97005V & 85 & & \\
\hline & ACL97006V & 91 & & \\
\hline & ACL97007V & 91 & & \\
\hline & ACL97008V & 87 & & \\
\hline & ACL97009V & 90 & & \\
\hline & ACL97012V & 78 & & \\
\hline & ACL98005V & 103.5 & 100.3 & \\
\hline & ACL98007V & 98.75 & & \\
\hline & ACL98012V & 106.38 & 104.82 & 95.6 \\
\hline & ACL98013V & 100.16 & & \\
\hline & ACL99001V & 92.44 & 88.8 & 95.72 \\
\hline Average & & 89.4 & & \\
\hline Standard deviation & & 17.0 & & \\
\hline Count & & 24 & & \\
\hline
\end{tabular}


Table D-2. (continued).

\begin{tabular}{|c|c|c|c|c|}
\hline \multirow[b]{2}{*}{ Compound } & \multirow[b]{2}{*}{ Batch No. } & \multicolumn{3}{|c|}{ Laboratory Control Sample (LCS) } \\
\hline & & $\begin{array}{c}\text { LCS } \\
\text { \% Recovery }\end{array}$ & $\begin{aligned} \text { LCS-3 } \\
\text { \% Recovery }\end{aligned}$ & $\begin{array}{c}\text { LCS-2 } \\
\% \text { Recovery }\end{array}$ \\
\hline \multirow[t]{20}{*}{ Toluene } & ACL96002V & 111.5 & & \\
\hline & ACL96004V & 99.8 & & \\
\hline & ACL96005V & 110 & & \\
\hline & ACL96007V & 94.6 & & \\
\hline & ACL96008V & 106 & & \\
\hline & ACL97001V & & & \\
\hline & ACL97002V & 108 & & \\
\hline & ACL97003V & 109 & & \\
\hline & ACL97004V & 112 & & \\
\hline & ACL97005V & 104 & & \\
\hline & ACL97006V & 110 & & \\
\hline & ACL97007V & 106 & & \\
\hline & ACL97008V & 112 & & \\
\hline & ACL97009V & 112 & & \\
\hline & ACL97012V & 92 & & \\
\hline & ACL98005V & 102.6 & 101 & \\
\hline & ACL98007V & 99.3 & & \\
\hline & ACL98012V & 102.78 & 104.44 & 91.58 \\
\hline & ACL98013V & 47.05 & & \\
\hline & ACL99001V & 93.1 & 87.58 & 94.06 \\
\hline Average & & 100.4 & & \\
\hline Standard deviation & & 13.6 & & \\
\hline Count & & 24 & & \\
\hline
\end{tabular}


Table D-3. ACL VOC QC Average Percent Recovery of Surrogate Compounds by Batch.

\begin{tabular}{|c|c|c|c|c|c|}
\hline \multirow[b]{2}{*}{ Batch \# } & \multirow[b]{2}{*}{ Sample \# } & \multicolumn{4}{|c|}{ Surrogate Organic Compounds } \\
\hline & & $\begin{array}{c}\text { BFM } \\
\text { \%Recovery }\end{array}$ & $\begin{array}{c}\text { TOL } \\
\text { \%Recovery }\end{array}$ & $\begin{array}{c}\text { BFB } \\
\text { \%Recovery }\end{array}$ & $\begin{array}{c}\text { DCA } \\
\text { \%Recovery } \\
\end{array}$ \\
\hline \multirow[t]{6}{*}{ ACL96002V } & ID004219101V1 & 108.8 & 84.4 & 74.2 & \\
\hline & ID004219102V1 & 92.7 & 88.8 & 94.5 & \\
\hline & ID004219201V1 & 137.5 & 96.3 & 96.4 & \\
\hline & ID004219202V1 & 124.2 & 89.5 & 83.5 & \\
\hline & ID032674101V1 & 36.0 & 101.2 & 94.1 & \\
\hline & ID032674102V1 & 51.2 & 103.7 & 99.5 & \\
\hline \multirow[t]{8}{*}{ ACL96004V } & ID010604101V1 & 80.7 & 93.8 & 98.0 & \\
\hline & ID010604102V1 & 76.5 & 98.5 & 95.1 & \\
\hline & ID010604201V1 & 64.6 & 98.5 & 90.7 & \\
\hline & ID010604202V1 & 50.6 & 94.4 & 91.5 & \\
\hline & ID010931101V1 & 6.1 & 96.9 & 79.4 & \\
\hline & ID010931102V1 & 9.9 & 90.7 & 88.0 & \\
\hline & ID012287101V1 & 84.3 & 98.6 & 94.7 & \\
\hline & ID012287102V1 & 107.7 & 92.8 & 90.8 & \\
\hline \multirow[t]{16}{*}{ ACL96005V } & ID010549101V1 & 98.2 & 101.0 & 101.0 & \\
\hline & ID010549102V1 & 105.0 & 103.1 & 94.9 & \\
\hline & ID010788101V1 & 119.9 & 106.3 & 100.8 & \\
\hline & ID010788102V1 & 105.4 & 102.1 & 98.0 & \\
\hline & ID010788201V1 & 119.9 & 104.2 & 98.8 & \\
\hline & ID010788202V1 & 120.1 & 99.5 & 93.4 & \\
\hline & ID015700101V1 & 112.1 & 104.9 & 99.5 & \\
\hline & ID015700102V1 & 111.6 & 111.1 & 103.8 & \\
\hline & ID018152101V1 & 274.1 & 107.9 & 101.9 & \\
\hline & ID018152102V1 & 301.9 & 105.4 & 102.7 & \\
\hline & ID022506101V1 & 94.4 & 104.1 & 97.5 & \\
\hline & ID022506102V1 & 106.8 & 104.7 & 90.0 & \\
\hline & ID029793101V1 & 274.8 & 108.3 & 100.7 & \\
\hline & ID029793102V1 & 266.5 & 106.5 & 97.7 & \\
\hline & ID030341101V1 & 244.6 & 104.5 & 96.7 & \\
\hline & ID030341102V1 & 235.5 & 102.8 & 117.1 & \\
\hline
\end{tabular}


Table D-3. (continued).

\begin{tabular}{|c|c|c|c|c|c|}
\hline \multirow[b]{2}{*}{ Batch \# } & \multirow[b]{2}{*}{ Sample \# } & \multicolumn{4}{|c|}{ Surrogate Organic Compounds } \\
\hline & & $\begin{array}{c}\text { BFM } \\
\text { \%Recovery } \\
\end{array}$ & $\begin{array}{c}\text { TOL } \\
\text { \%Recovery }\end{array}$ & $\begin{array}{c}\text { BFB } \\
\text { \%Recovery } \\
\end{array}$ & $\begin{array}{c}\text { DCA } \\
\text { \%Recovery } \\
\end{array}$ \\
\hline \multirow[t]{20}{*}{ ACL96007V } & ID031142101V1 & 235.6 & 111.6 & 100.3 & \\
\hline & ID031142102V1 & 295.0 & 103.8 & 98.1 & \\
\hline & ID030362101V1 & 293.5 & 110.4 & 101.4 & \\
\hline & ID030362102V1 & 338.1 & 109.1 & 101.1 & \\
\hline & ID031142201V1 & 111.9 & 102.9 & 97.7 & \\
\hline & ID031142202V1 & 176.9 & 100.2 & 100.5 & \\
\hline & ID023561101V1 & 100.1 & 111.8 & 101.6 & \\
\hline & ID023561102V1 & 78.7 & 111.9 & 101.3 & \\
\hline & ID014031101V1 & 93.4 & 118.8 & 109.2 & \\
\hline & ID014031102V1 & 99.8 & 117.7 & 108.7 & \\
\hline & ID010534201V1 & 91.6 & 104.7 & 97.7 & \\
\hline & ID010534101V1 & 98.3 & 107.1 & 99.7 & \\
\hline & ID010534102V1 & 93.9 & 106.4 & 96.7 & \\
\hline & ID010534202V1 & 107.0 & 98.7 & 91.7 & \\
\hline & ID011450101V1 & 100.7 & 101.3 & 97.3 & \\
\hline & ID012756101V2 & 112.8 & 110.2 & 99.2 & \\
\hline & ID011450102V2 & 96.9 & 104.7 & 99.4 & \\
\hline & ID012756102V1 & 121.7 & 110.9 & 92.3 & \\
\hline & ID010859101V1 & 102.2 & 104.2 & 102.6 & \\
\hline & ID010859102V1 & 98.6 & 102.6 & 96.4 & \\
\hline \multirow[t]{16}{*}{ ACL96008V } & ID016069101V1 & 75.9 & 98.5 & 139.0 & \\
\hline & ID016069102V1 & 97.5 & 102.0 & 99.6 & \\
\hline & ID013613101V1 & 70.2 & 84.3 & 190.0 & \\
\hline & ID013613102V1 & 108.0 & 103.0 & 100.0 & \\
\hline & ID013613202V1 & 100.0 & 104.0 & 102.0 & \\
\hline & ID007085101V1 & 99.7 & 101.0 & 96.0 & \\
\hline & ID013522101V1 & 237.0 & 102.0 & 100.0 & \\
\hline & ID007085102V1 & 213.0 & 102.0 & 98.8 & \\
\hline & ID013613201V1 & 122.0 & 103.0 & 101.0 & \\
\hline & ID013522102V1 & 201.0 & 96.2 & 93.1 & \\
\hline & ID018333201V1 & 310.0 & 96.6 & 163.0 & \\
\hline & ID018333202V1 & 293.0 & 108.0 & 97.7 & \\
\hline & ID018333101V1 & 202.0 & 101.0 & 108.0 & \\
\hline & ID018333102V1 & 130.0 & 103.0 & 96.4 & \\
\hline & ID011412101V1 & 290.0 & 104.0 & 96.9 & \\
\hline & ID011412102V1 & 291.0 & 106.0 & 98.6 & \\
\hline
\end{tabular}


Table D-3. (continued).

\begin{tabular}{|c|c|c|c|c|c|}
\hline \multirow[b]{2}{*}{ Batch \# } & \multirow[b]{2}{*}{ Sample \# } & \multicolumn{4}{|c|}{ Surrogate Organic Compounds } \\
\hline & & $\begin{array}{c}\text { BFM } \\
\text { \%Recovery }\end{array}$ & $\begin{array}{c}\text { TOL } \\
\text { \%Recovery }\end{array}$ & $\begin{array}{c}\text { BFB } \\
\text { \%Recovery }\end{array}$ & $\begin{array}{c}\text { DCA } \\
\text { \%Recovery } \\
\end{array}$ \\
\hline \multirow[t]{10}{*}{ ACL97001V } & ID001080101V1 & 9.6 & 88.0 & 86.0 & \\
\hline & ID001080102V1 & 9.8 & 89.0 & 88.0 & \\
\hline & ID001080201V1 & 3.5 & 90.0 & 86.0 & \\
\hline & ID001080202V1 & 1.2 & 85.0 & 86.0 & \\
\hline & ID003227101V1 & 21.0 & 93.0 & 94.0 & \\
\hline & ID003227102V1 & 21.0 & 90.0 & 72.0 & \\
\hline & ID005695101V1 & 41.0 & 96.0 & 97.0 & \\
\hline & ID005695102V1 & 66.0 & 142.0 & 137.0 & \\
\hline & ID013423101V1 & 8.9 & 99.0 & 92.0 & \\
\hline & ID013423102V1 & 33.0 & 88.0 & 90.0 & \\
\hline \multirow[t]{4}{*}{ ACL97002V } & ID000887101V1 & 62.0 & 83.0 & 83.0 & \\
\hline & ID000887102V1 & 4.2 & 86.0 & 88.0 & \\
\hline & ID008473101V1 & 63.0 & 100.0 & 94.0 & \\
\hline & ID008473102V1 & 44.0 & 91.0 & 84.0 & \\
\hline \multirow[t]{16}{*}{ ACL97003V } & ID003932101V1 & 68.0 & 95.0 & 91.0 & \\
\hline & ID003932102V1 & 52.0 & 92.0 & 92.0 & \\
\hline & ID003932201V1 & 28.0 & 87.0 & 82.0 & \\
\hline & ID003932202V1 & 50.0 & 90.0 & 88.0 & \\
\hline & ID004221101V1 & 21.0 & 87.0 & 85.0 & \\
\hline & ID004221102V1 & 0.7 & 93.0 & 92.0 & \\
\hline & ID005049101V1 & 39.0 & 95.0 & 90.0 & \\
\hline & ID005049102V1 & 22.0 & 92.0 & 91.0 & \\
\hline & ID012873101V1 & 72.0 & 85.0 & 81.0 & \\
\hline & ID012873102V1 & 77.0 & 91.0 & 89.0 & \\
\hline & ID013672101V1 & 63.0 & 87.0 & 83.0 & \\
\hline & ID013672102V1 & 64.0 & 90.0 & 86.0 & \\
\hline & ID020033101V1 & 30.0 & 89.0 & 85.0 & \\
\hline & ID020033102V1 & 45.0 & 89.0 & 85.0 & \\
\hline & ID024148101V1 & 51.0 & 88.0 & 85.0 & \\
\hline & ID024148102V1 & 4.6 & 86.0 & 87.0 & \\
\hline
\end{tabular}


Table D-3. (continued).

\begin{tabular}{|c|c|c|c|c|c|}
\hline \multirow[b]{2}{*}{ Batch \# } & \multirow[b]{2}{*}{ Sample \# } & \multicolumn{4}{|c|}{ Surrogate Organic Compounds } \\
\hline & & $\begin{array}{c}\text { BFM } \\
\text { \%Recovery } \\
\end{array}$ & $\begin{array}{c}\text { TOL } \\
\text { \%Recovery } \\
\end{array}$ & $\begin{array}{c}\text { BFB } \\
\text { \%Recovery } \\
\end{array}$ & $\begin{array}{c}\text { DCA } \\
\text { \%Recovery } \\
\end{array}$ \\
\hline \multirow[t]{22}{*}{ ACL97004V } & ID008355101V1 & 70.0 & 99.0 & 94.0 & \\
\hline & ID008355102V1 & 17.0 & 101.0 & 106.0 & \\
\hline & ID020749101V1 & 80.0 & 102.0 & 97.0 & \\
\hline & ID020749102V1 & 84.0 & 93.0 & 88.0 & \\
\hline & ID020749201V1 & 82.0 & 99.0 & 96.0 & \\
\hline & ID020749202V1 & 78.0 & 95.0 & 96.0 & \\
\hline & ID023717101V1 & 61.0 & 81.0 & 79.0 & \\
\hline & ID023717102V1 & 54.0 & 86.0 & 84.0 & \\
\hline & ID023821101V1 & 73.0 & 91.0 & 86.0 & \\
\hline & ID023821102V1 & 66.0 & 78.0 & 120.0 & \\
\hline & ID023821201V1 & 72.0 & 85.0 & 80.0 & \\
\hline & ID023821202V1 & 77.0 & 91.0 & 84.0 & \\
\hline & ID024498101V1 & 80.0 & 93.0 & 87.0 & \\
\hline & ID024498102V1 & 75.0 & 92.0 & 85.0 & \\
\hline & ID024670101V1 & 76.0 & 87.0 & 83.0 & \\
\hline & ID024670102V1 & 54.0 & 89.0 & 83.0 & \\
\hline & ID025265101V1 & 76.0 & 92.0 & 90.0 & \\
\hline & ID025265102V1 & 67.0 & 95.0 & 87.0 & \\
\hline & ID028657101V1DL & $\mathrm{D}$ & $\mathrm{D}$ & $\mathrm{D}$ & \\
\hline & ID028657102V1DL & $\mathrm{D}$ & $\mathrm{D}$ & $\mathrm{D}$ & \\
\hline & ID028657101V1 & 0.0 & 93.0 & 90.0 & \\
\hline & ID028657102V1 & 34.0 & 94.0 & 82.0 & \\
\hline \multirow[t]{2}{*}{ ACL97005V } & ID003344101V1 & 106.0 & 95.0 & 94.0 & \\
\hline & ID003344102V1 & 102.0 & 88.0 & 91.0 & \\
\hline \multirow[t]{8}{*}{ ACL97006V } & ID006729101V1DL & 126.0 & 100.0 & 100.0 & \\
\hline & ID006729101V1DL2 & 104.0 & 94.0 & 102.0 & \\
\hline & ID006729102V1DL & 96.0 & 91.0 & 95.0 & \\
\hline & ID006729102V1DL2 & 74.0 & 93.0 & 96.0 & \\
\hline & ID011761101V1 & 51.0 & 88.0 & 95.0 & \\
\hline & ID011761102V1 & 53.0 & 87.0 & 86.0 & \\
\hline & ID017876101V1 & 88.0 & 94.0 & 101.0 & \\
\hline & ID017876102V1 & 96.0 & 94.0 & 102.0 & \\
\hline
\end{tabular}


Table D-3. (continued).

\begin{tabular}{|c|c|c|c|c|c|}
\hline \multirow[b]{2}{*}{ Batch \# } & \multirow[b]{2}{*}{ Sample \# } & \multicolumn{4}{|c|}{ Surrogate Organic Compounds } \\
\hline & & $\begin{array}{c}\text { BFM } \\
\text { \%Recovery } \\
\end{array}$ & $\begin{array}{c}\text { TOL } \\
\text { \%Recovery } \\
\end{array}$ & $\begin{array}{c}\text { BFB } \\
\text { \%Recovery } \\
\end{array}$ & $\begin{array}{c}\text { DCA } \\
\text { \%Recovery } \\
\end{array}$ \\
\hline \multirow[t]{14}{*}{ ACL97007V } & ID017917101V1 & 90.0 & 99.0 & 81.0 & \\
\hline & ID017917102V1 & 107.0 & 97.0 & 102.0 & \\
\hline & ID006836101V1 & 104.0 & 93.0 & 91.0 & \\
\hline & ID006836102V1 & 102.0 & 93.0 & 94.0 & \\
\hline & ID008371101V1 & 94.0 & 91.0 & 101.0 & \\
\hline & ID008371102V1 & 80.0 & 97.0 & 94.0 & \\
\hline & ID008371201V1 & 122.0 & 97.0 & 97.0 & \\
\hline & ID008371202V1 & 76.0 & 94.0 & 93.0 & \\
\hline & ID008344101V1 & 82.0 & 98.0 & 101.0 & \\
\hline & ID008344102V1 & 106.0 & 95.0 & 100.0 & \\
\hline & ID003268101V1 & 115.0 & 96.0 & 102.0 & \\
\hline & ID003268102V1 & 86.0 & 96.0 & 102.0 & \\
\hline & ID003268201V1 & 122.0 & 102.0 & 102.0 & \\
\hline & ID003268202V1 & 68.0 & 96.0 & 99.0 & \\
\hline \multirow[t]{8}{*}{ ACL97008V } & ID013146101V1 & 129.0 & 104.0 & 109.0 & \\
\hline & ID013146102V1 & 86.0 & 86.0 & 98.0 & \\
\hline & ID018806101V1 & 123.0 & 100.0 & 104.0 & \\
\hline & ID018806102V1 & 66.0 & 99.0 & 103.0 & \\
\hline & ID020757101V1 & 100.0 & 97.0 & 96.0 & \\
\hline & ID020757102V1 & 81.0 & 90.0 & 149.0 & \\
\hline & ID023938101V1 & 76.0 & 91.0 & 95.0 & \\
\hline & ID023938102V1 & 106.0 & 91.0 & 95.0 & \\
\hline \multirow[t]{2}{*}{ ACL97009V } & ID031237101V1 & 114.0 & 88.0 & 88.0 & \\
\hline & ID031237102V1 & 92.0 & 90.0 & 97.0 & \\
\hline \multirow[t]{10}{*}{ ACL97012V } & ID028633101V1 & 0.0 & 86.8 & 114.0 & \\
\hline & ID028633102V1 & 2.5 & 86.6 & 111.0 & \\
\hline & ID028018101V1 & 0.0 & 94.4 & 116.0 & \\
\hline & ID028018102V1 & 0.0 & 86.7 & 78.6 & \\
\hline & ID027455101V1 & 17.9 & 86.5 & 82.9 & \\
\hline & ID027455102V1 & 29.6 & 88.6 & 84.6 & \\
\hline & ID027343101V1 & 0.0 & 84.1 & 91.8 & \\
\hline & ID027343102V1 & 0.0 & 90.7 & 83.8 & \\
\hline & ID027343201V1 & 0.0 & 86.4 & 87.4 & \\
\hline & ID027343202V1 & $\mathbf{0 . 0}$ & 86.5 & 82.9 & \\
\hline
\end{tabular}


Table D-3. (continued).

\begin{tabular}{|c|c|c|c|c|c|}
\hline \multirow[b]{2}{*}{ Batch \# } & \multirow[b]{2}{*}{ Sample \# } & \multicolumn{4}{|c|}{ Surrogate Organic Compounds } \\
\hline & & $\begin{array}{c}\text { BFM } \\
\text { \%Recovery } \\
\end{array}$ & $\begin{array}{c}\text { TOL } \\
\text { \%Recovery } \\
\end{array}$ & $\begin{array}{c}\text { BFB } \\
\text { \%Recovery } \\
\end{array}$ & $\begin{array}{c}\text { DCA } \\
\text { \%Recovery } \\
\end{array}$ \\
\hline \multirow[t]{6}{*}{ ACL98005V } & ID022754101V1 & & 118.0 & 124.0 & 113 \\
\hline & ID022754102V1 & & 119.0 & 125.0 & 114 \\
\hline & ID001584101V1 & & 120.0 & 126.0 & 115 \\
\hline & ID001584102V1 & & 90.0 & 84.4 & 90.2 \\
\hline & ID029430102V1 & & 87.3 & 82.8 & 86.7 \\
\hline & ID017148102V1 & & 90.0 & 91.1 & 91.8 \\
\hline \multirow[t]{2}{*}{ ACL98007V } & ID006847101V1 & & 81.4 & 83.1 & 80.96 \\
\hline & ID006847102V1 & & 84.8 & 86.7 & 84.3 \\
\hline ACL98010V & Data Deleted & & & & \\
\hline \multirow[t]{4}{*}{ ACL98012V } & ID023153101V1 & & 100.7 & 95.4 & 88.6 \\
\hline & ID023153102V1 & & 96.8 & 90.2 & 85.82 \\
\hline & ID010029102V1 & & 94.4 & 86.4 & 83.18 \\
\hline & ID010029101V1 & & 102.1 & 90.1 & 89.46 \\
\hline \multirow[t]{2}{*}{ ACL98013V } & ID010060101V1 & & 91.1 & 90.3 & 83.16 \\
\hline & ID010060102V1 & & 86.5 & 93.1 & 89.2 \\
\hline \multirow[t]{4}{*}{ ACL99001V } & ID019358101V1 & & 80.8 & 83.2 & 86.28 \\
\hline & ID019358102V1 & & 80.8 & 84.0 & 77.27 \\
\hline & ID019358202V1 & & 80.8 & 89.9 & 78.05 \\
\hline & ID019358201V1 & & 76.0 & 80.3 & 72.3 \\
\hline \multicolumn{6}{|c|}{$\mathrm{BFM}=$ Dibromofluoromethane } \\
\hline \multicolumn{6}{|c|}{$\mathrm{TOL}=$ Toluene-d 8} \\
\hline \multicolumn{6}{|c|}{$\mathrm{BFB}=4$-Bromofluorobenzene } \\
\hline \multicolumn{6}{|c|}{$\mathrm{DCA}=1,2$-Dichloroethane } \\
\hline
\end{tabular}




\section{Appendix E}

NH VOC Back-up Data 
Table E-1. ACL NH Organic Compounds Quality Control MS and LCS Summary by Compound.

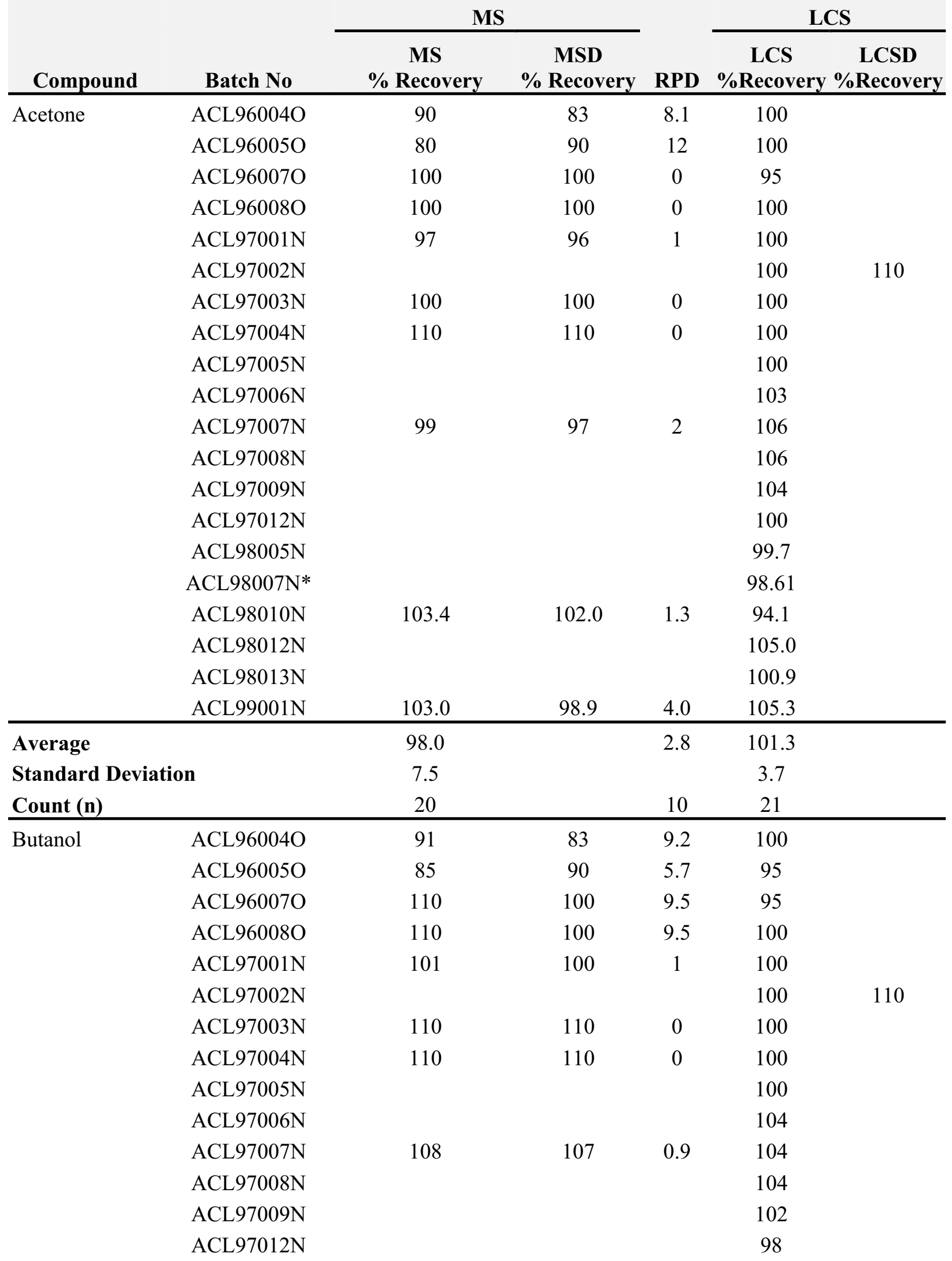


Table E-1. (continued).

\begin{tabular}{|c|c|c|c|c|c|c|}
\hline \multirow[b]{2}{*}{ Compound } & \multirow[b]{2}{*}{ Batch No } & \multicolumn{2}{|c|}{ MS } & \multirow[b]{2}{*}{ RPD } & \multicolumn{2}{|c|}{ LCS } \\
\hline & & \multirow[t]{2}{*}{$\begin{array}{c}\text { MS } \\
\% \text { Recovery } \\
\end{array}$} & $\begin{array}{c}\text { MSD } \\
\% \text { Recovery } \\
\end{array}$ & & $\begin{array}{c}\text { LCS } \\
\text { \%Recovery } \\
\end{array}$ & $\begin{array}{c}\text { LCSD } \\
\% \text { Recovery } \\
\end{array}$ \\
\hline & ACL98005N & & & & 101.0 & \\
\hline & ACL98007N* & & & & 102.44 & \\
\hline & ACL98010N & 103.9 & 102.9 & 1.0 & 95.1 & \\
\hline & ACL98012N & & & & 103.3 & \\
\hline & ACL98013N & & & & 100.4 & \\
\hline & ACL99001N & 103.3 & 99.6 & 3.7 & 105.6 & \\
\hline \multirow{3}{*}{\multicolumn{2}{|c|}{$\begin{array}{l}\text { Average } \\
\text { Standard Deviation } \\
\text { Count (n) } \\
\end{array}$}} & 101.7 & & 4.0 & 100.9 & \\
\hline & & 8.5 & & & 3.6 & \\
\hline & & 20 & & 10 & 21 & \\
\hline \multirow[t]{20}{*}{ Ethyl ether } & ACL96004O & 78 & 69 & 12 & 95 & \\
\hline & ACL96005O & 47 & 52 & 10 & 100 & \\
\hline & ACL96007O & 87 & 80 & 8.4 & 90 & \\
\hline & ACL960080 & 88 & 92 & 7.2 & 100 & \\
\hline & ACL97001N & 84 & 84 & 0 & 100 & \\
\hline & ACL97002N & & & & 100 & 100 \\
\hline & ACL97003N & 88 & 89 & 1.1 & 100 & \\
\hline & ACL97004N & 75 & 74 & 1.3 & 100 & \\
\hline & ACL97005N & & & & 95 & \\
\hline & ACL97006N & & & & 92 & \\
\hline & ACL97007N & 21 & 21 & 0 & 96 & \\
\hline & ACL97008N & & & & 106 & \\
\hline & ACL97009N & & & & 108 & \\
\hline & ACL97012N & & & & 98 & \\
\hline & ACL98005N & & & & 96.4 & \\
\hline & ACL98007N* & & & & 93.7 & \\
\hline & ACL98010N & 98.7 & 94.8 & 4.1 & 90.5 & \\
\hline & ACL98012N & & & & 109.6 & \\
\hline & ACL98013N & & & & 108.2 & \\
\hline & ACL99001N & 95.1 & 89.2 & 6.4 & 98.0 & \\
\hline \multicolumn{2}{|c|}{ Average } & 75.3 & & 5.1 & 98.9 & \\
\hline \multicolumn{2}{|c|}{ Standard Deviation } & 22.8 & & & 5.5 & \\
\hline \multicolumn{2}{|c|}{ Count (n) } & 20 & & 10 & 21 & \\
\hline
\end{tabular}


Table E-1. (continued).

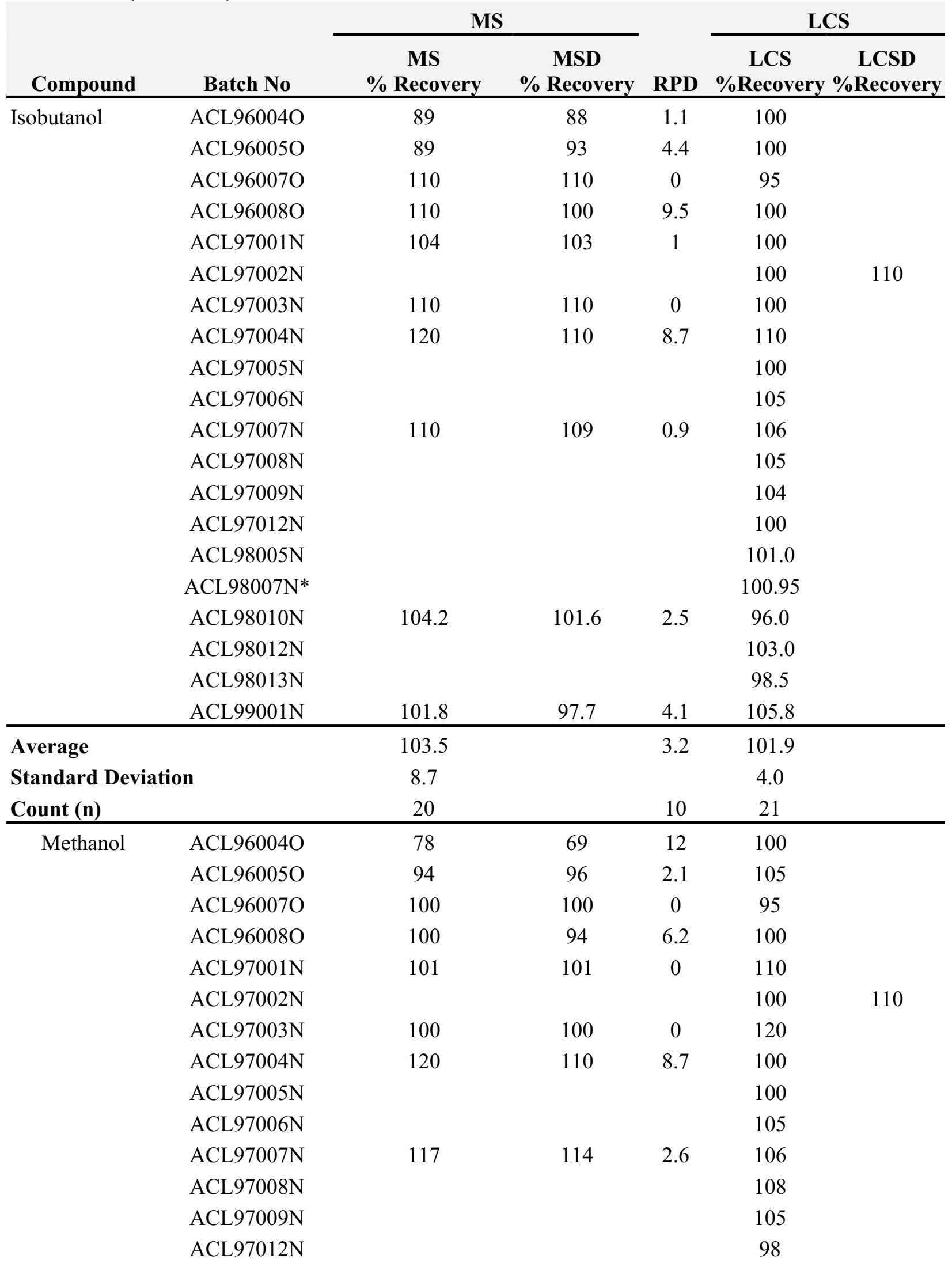


Table E-1. (continued).

\begin{tabular}{|c|c|c|c|c|c|c|}
\hline \multirow[b]{2}{*}{ Compound } & \multirow[b]{2}{*}{ Batch No } & \multicolumn{2}{|c|}{ MS } & \multirow[b]{2}{*}{ RPD } & \multicolumn{2}{|c|}{ LCS } \\
\hline & & $\begin{array}{c}\text { MS } \\
\text { \% Recovery }\end{array}$ & $\begin{array}{c}\text { MSD } \\
\text { \% Recovery }\end{array}$ & & $\begin{array}{c}\text { LCS } \\
\text { \%Recovery }\end{array}$ & $\begin{array}{c}\text { LCSD } \\
\% \text { Recovery }\end{array}$ \\
\hline & ACL98005N & & & & 100.0 & \\
\hline & ACL98007N* & & & & 99.72 & \\
\hline & ACL98010N & 104.1 & 102.4 & 1.6 & 96.7 & \\
\hline & ACL98012N & & & & 102.7 & \\
\hline & ACL98013N & & & & 98.9 & \\
\hline & ACL99001N & 102.8 & 98.1 & 4.6 & 105.7 & \\
\hline \multirow{3}{*}{\multicolumn{2}{|c|}{$\begin{array}{l}\text { Average } \\
\text { Standard Deviation } \\
\text { Count (n) } \\
\end{array}$}} & 100.1 & & 3.8 & 103.1 & \\
\hline & & 11.6 & & & 5.7 & \\
\hline & & 20 & & 10 & 21 & \\
\hline \multirow{20}{*}{$\begin{array}{l}\text { Methyl ethyl } \\
\text { ketone }\end{array}$} & ACL96004O & 89 & 81 & 9.4 & 100 & \\
\hline & ACL96005O & 83 & 85 & 2.4 & 95 & \\
\hline & ACL96007O & 100 & 100 & 0 & 95 & \\
\hline & ACL96008O & 100 & 100 & 0 & 100 & \\
\hline & ACL97001N & 102 & 101 & 1 & 100 & \\
\hline & ACL97002N & & & & 100 & 110 \\
\hline & ACL97003N & 100 & 100 & 0 & 100 & \\
\hline & ACL97004N & 120 & 110 & 8.7 & 110 & \\
\hline & ACL97005N & & & & 100 & \\
\hline & ACL97006N & & & & 106 & \\
\hline & ACL97007N & 97 & 96 & 1 & 106 & \\
\hline & ACL97008N & & & & 105 & \\
\hline & ACL97009N & & & & 104 & \\
\hline & ACL97012N & & & & 98 & \\
\hline & ACL98005N & & & & 99.5 & \\
\hline & ACL98007N* & & & & 100.21 & \\
\hline & ACL98010N & 102.1 & 101.1 & 0.9 & 94.5 & \\
\hline & ACL98012N & & & & 102.8 & \\
\hline & ACL98013N & & & & 99.2 & \\
\hline & ACL99001N & 101.5 & 98.3 & 3.3 & 103.4 & \\
\hline \multicolumn{2}{|c|}{ Average } & 98.4 & & 2.7 & 101.4 & \\
\hline \multicolumn{2}{|c|}{ Standard Deviation } & 8.8 & & & 4.3 & \\
\hline \multicolumn{2}{|c|}{ Count (n) } & 20 & & 10 & 21 & \\
\hline
\end{tabular}


Table E-1. (continued).

\begin{tabular}{|c|c|c|c|c|c|c|}
\hline \multirow[b]{2}{*}{ Compound } & \multirow[b]{2}{*}{ Batch No } & \multicolumn{2}{|c|}{ MS } & \multirow[b]{2}{*}{ RPD } & \multicolumn{2}{|c|}{ LCS } \\
\hline & & $\begin{array}{c}\text { MS } \\
\% \text { Recovery } \\
\end{array}$ & $\begin{array}{c}\text { MSD } \\
\% \text { Recovery } \\
\end{array}$ & & $\begin{array}{c}\text { LCS } \\
\text { \%Recovery } \\
\end{array}$ & $\begin{array}{c}\text { LCSD } \\
\text { \%Recovery } \\
\end{array}$ \\
\hline \multirow[t]{20}{*}{ Pyridine } & ACL96004O & 110 & 88 & 22 & 105 & \multirow{20}{*}{100} \\
\hline & ACL96005O & 89 & 96 & 7.6 & 100 & \\
\hline & ACL96007O & 93 & 93 & 0 & 95 & \\
\hline & ACL96008O & 94 & 94 & 0 & 100 & \\
\hline & ACL97001N & 93 & 92 & 1.1 & 100 & \\
\hline & ACL97002N & & & & 100 & \\
\hline & ACL97003N & 95 & 95 & 0 & 100 & \\
\hline & ACL97004N & 110 & 100 & 9.5 & 100 & \\
\hline & ACL97005N & & & & 100 & \\
\hline & ACL97006N & & & & 97 & \\
\hline & ACL97007N & 100 & 98 & 2 & 98 & \\
\hline & ACL97008N & & & & 99.5 & \\
\hline & ACL97009N & & & & 100 & \\
\hline & ACL97012N & & & & 91 & \\
\hline & ACL98005N & & & & 89.8 & \\
\hline & ACL98007N* & & & & 90.42 & \\
\hline & ACL98010N & 103.1 & 102.8 & 0.3 & 97.0 & \\
\hline & ACL98012N & & & & 102.9 & \\
\hline & ACL98013N & & & & 98.5 & \\
\hline & ACL99001N & 99.9 & 96.8 & 3.2 & 106.0 & \\
\hline Average & & 97.1 & & 4.6 & 98.6 & \\
\hline \multicolumn{2}{|c|}{ Standard Deviation } & 6.0 & & & 4.2 & \\
\hline \multicolumn{2}{|c|}{ Count (n) } & 20 & & 10 & 21 & \\
\hline
\end{tabular}

Batch ACL96002O: QC data was not included in the data package.

*Batch ACL98007N MS \& MSD were not prepared nor analyzed by the lab. Sample too small. 